\author{
Universidade de São Paulo \\ Instituto de Física
}

\title{
Aplicações de métodos para validação de materiais radiologicamente equivalentes ao tecido humano e à água
}

\section{Ana Carolina Albernaz Sirico}

Orientador: Prof. Dr. Paulo Roberto Costa

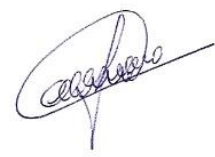

Dissertação de mestrado apresentada ao Instituto de Física como requisito parcial para a obtenção do título de Mestre em Ciências.

Banca Examinadora:

Prof. Dr. Paulo Roberto Costa (IF - USP)

Prof. Dr. Martin Eduardo Poletti (FFCLRP - USP)

Profa. Dra. Ana Figueiredo Maia (UFS) 


\title{
University of São Paulo \\ Physics Institute
}

\section{Applications of methods for validation of materials radiologically equivalent to human tissues and water}

\author{
Ana Carolina Albernaz Sirico
}

Supervisor: Prof. Dr. Paulo Roberto Costa

Examining Committee:

Prof. Dr. Paulo Roberto Costa (IF - USP)

Prof. Dr. Martin Eduardo Poletti (FFCLRP - USP)

Profa. Dra. Ana Figueiredo Maia (UFS)

Dissertation submitted to the Physics Institute of the University of São Paulo in partial fulfillment of the requirements for the degree of Master of Science. 


\section{FICHA CATALOGRÁFICA \\ Preparada pelo Serviço de Biblioteca e Informação do Instituto de Física da Universidade de São Paulo}

Sirico, Ana Carolina Albernaz

Aplicações de métodos para validação de materiais radiologicamente equivalentes ao tecido humano e à água. São Paulo, 2021.

Dissertação (Mestrado) - Universidade de São Paulo. Instituto de Física. Depto. de Física Nuclear.

Orientador: Prof. Dr. Paulo Roberto Costa

Área de Concentração: Física Médica

Unitermos: 1. Objetos simuladores; 2. Número atômico efetivo; 3. Tomografia computadorizada; 4. Tomografia computadorizada de dupla energia; 5. Espectrometria por raios $\mathrm{X}$ 
Dedicado em memória de Tinê, Tia Zeny e Nic. 


\section{Agradecimentos}

Gostaria de agradecer primeiramente ao meu orientador Prof. Dr. Paulo Roberto Costa pela oportunidade de trabalho, incentivo e apoio pleno.

À Comissão Nacional de Energia Nuclear (CNEN) pela concessão da bolsa de pósgraduação (processo 01341.000947/2018) e à Comissão de Pós-Graduação (CPG) do IFUSP pelo auxílio financeiro.

À FAPESP (processos 2017/24999-8 e 2018/05982-0) e ao CNPq (processo 315096/2018-7).

Aos funcionários da CPG e da secretaria do Departamento de Física Nuclear (DFN) sempre muito prestativos.

Ao InRaD por possibilitar o uso de um de seus equipamentos de tomografia computadorizada para este estudo.

À Denise Nersissian por ter me ajudado nos experimentos realizados no InRad.

Ao Prof. Rick Franich do Instituto Real de Tecnologia de Melbourne por ceder o software Auto- $Z_{\text {eff }}$ para este trabalho.

Ao Marcos e funcionários da Oficina Central do IFUSP pelo auxílio no corte das placas e fabricação de peças para este trabalho.

Ao Prof. Ricardo pelos ensinamentos principalmente sobre o funcionamento do detector de CdTe.

Ao Prof. Carlos pelos ensinamentos em eletrônica e por ter me ajudado com os equipamentos do laboratório de dosimetria e meu computador.

À Audrew Frimaio por ter produzido os materiais estudados neste trabalho, pelo suporte e amizade.

À Camila Amorim por ter me ajudado com as medições de densidade.

À minha colega de sala Vivian pela convivência e amizade.

Aos professores, técnicos e membros do Grupo de Dosimetria das Radiações e Física Médica em especial Profa. Beth, Profa. Emico, Nancy e Chico por me acolherem e pelos bons momentos que passamos.

Às minhas amigas Jacy, Marcela e Luciana pela amizade e descontração mesmo à distância.

Aos meus pais Airton e Suely, meu irmão Hugo e B pela afeição e companheirismo.

E, ao meu irmão Luis, companheiro de quarentena, que me deu apoio incondicional nesses dias tão difíceis. 


\section{Resumo}

Materiais radiologicamente equivalentes ao tecido humano são projetados para replicar os efeitos da radiação eletromagnética dentro de diferentes tecidos humanos, como ossos, pulmões, tecidos moles, músculos e outros. O presente trabalho, teve como objetivo principal estudar métodos para validação de materiais radiologicamente equivalentes ao tecido humano e à água a partir da determinação da densidade mássica e do número atômico efetivo, análise do coeficiente de atenuação mássico a partir de imagens tomográficas convencionais e de dupla energia e análise do coeficiente de atenuação linear a partir da espectrometria por raios X. Ao total, dezessete amostras com base de polipropileno e resina epóxi foram estudadas. Dentre elas estão amostras radiologicamente equivalentes à água, tecido mole e materiais comerciais CIRS BR12 e CIRS 70/30. As amostras estudadas apresentaram diferenças entre 9 e $15 \%$ em relação a densidade do material de referência, com exceção das amostras MA8 e MA9 radiologicamente equivalentes ao CIRS BR12 com 1.6\% e - 6.9\% de diferença, respectivamente. Estes são os únicos materiais produzidos com base de polipropileno e esse resultado pode apontar que o polipropileno é mais indicado para ser utilizado como material-base, além de ser um material reciclável, diferentemente da resina epóxi. Os valores de número atômico efetivo foram determinados a partir do método de Manohara e validados pelo software Auto- $Z_{\text {eff. }}$ No intervalo de 60-150 keV os resultados de ambos os métodos são compatíveis com diferenças relativas menores que $12 \%$. Entre $10-150 \mathrm{keV}$, os materiais radiologicamente equivalentes à água e os materiais TM1, TM3, MA1 e MA8 apresentaram diferenças relativas menores que $23 \%$ em relação aos seus materiais de referência. As discrepâncias observadas entre os valores de número atômico efetivo dos materiais produzidos e materiais de referência são sempre positivas. Este resultado estimula correções na metodologia de produção, por exemplo, incluindo-se o cálculo de $Z_{e f}(E)$ como um limitante na escolha dos componentes das amostras. A análise computacional do $Z_{e f}(E)$ é fácil e rápida, permitindo avaliar a compatibilidade entre as formulações de materiais radiologicamente equivalentes com diferentes tecidos do corpo humano em diferentes intervalos de energia. Como exemplo, os materiais AG3 e MA7 foram compatíveis com: ovário, cristalino, tecido pulmonar, músculo esquelético e testículo com menos de $6 \%$ de diferença relativa no intervalo de 1-150 keV. A análise do coeficiente de atenuação mássico dos materiais a partir de imagens de tomografia computadorizada convencional mostra que as amostras AG1, AG2, AG3 e AG5 são compatíveis aos coeficientes de atenuação mássicos previstos pela metodologia de Mariano \& Costa. Em relação aos coeficientes mássicos da água obtidos pelo XCOM, estas amostras apresentaram diferenças relativas de 4 a 7\%. A análise do coeficiente mássico a partir de imagens de tomografia computadorizada de dupla energia mostram que os materiais AG1, AG2, AG3 e AG5 possuem diferença relativa média menor que $7 \%$ em relação ao coeficiente mássico da água. A determinação do coeficiente de atenuação linear a partir da espectrometria é um dos métodos mais confiáveis, porém exige acuidade na geometria do arranjo experimental. Nesta análise, os valores de coeficiente de atenuação linear da amostra AG2 é compatível com a água no intervalo de 40-100 keV com $\pm 5 \%$ de diferença como determinado pelo ICRU Report 44. Para a amostra AG6 o intervalo de compatibilidade é entre $40-80 \mathrm{keV}$ e para a amostra MA8 entre $31-40 \mathrm{keV}$. Para energias menores que $30 \mathrm{keV}$ e maiores que $100 \mathrm{keV}$ será necessário refinar a metodologia experimental para obter estimativas de coeficiente de atenuação com menor incerteza nesses intervalos. A comparação entre os resultados de coeficiente de atenuação linear a partir da análise por tomografia computadorizada e espectrometria mostram que os valores de coeficiente de atenuação lineares obtidos para os dois métodos são concordantes.

Palavras-chave: Objetos simuladores. Número atômico efetivo. Tomografia computadorizada. Tomografia computadorizada de dupla energia. Espectrometria por raios $\mathrm{X}$ 


\begin{abstract}
Materials radiologically equivalent to human tissue are designed to replicate the effects of electromagnetic radiation within different human tissues, such as bones, lungs, soft tissues, muscles, and others. The present work aimed to study methods for the validation of radiologically equivalent materials to human tissue and water by the determination of mass density and effective atomic number, analysis of the mass attenuation coefficient by conventional and dual energy computed tomography images and analysis of the linear attenuation coefficient by spectrometry. In total, seventeen polypropylene- and epoxy resinbased samples were studied. Among them are samples radiologically equivalent to water, soft tissue and commercial materials CIRS BR12 and CIRS 70/30. The studied samples showed differences between 9 and $15 \%$ in relation to the density of the reference material, with the exception of samples MA8 and MA9 radiologically equivalent to CIRS BR12 with $1.6 \%$ and $6.9 \%$ difference, respectively. These are the only materials produced with polypropylene as base and this result may indicate that polypropylene is more suitable for use as a base material, in addition to being a recyclable material unlike epoxy resin. Effective atomic number values were determined using the direct method of Manohara and validated by the Auto- $Z_{\text {eff }}$ software. In the range of $60-150 \mathrm{keV}$ the results of both methods are compatible with percentage differences of less than $12 \%$. In the range of $10-150 \mathrm{keV}$, materials radiologically equivalent to water and materials TM1, TM3, MA1 and MA8 showed relative differences of less than 23\% in relation to their reference materials. The discrepancies observed between the effective atomic number values of the produced materials and reference materials are always positive. This result encourages corrections in the production methodology, for example, to include the calculation of $Z_{e f}(E)$ as a constraint factor. The computation analysis of the $Z_{e f}(E)$ is easy and fast, allowing the evaluation of the compatibility between the formulations of radiologically equivalent materials with different tissues of the human body at different ranges of energy. For example, samples AG3 and MA7 were compatible with: ovary, eye lens, lung tissue, skeletal muscle and testis with less than $6 \%$ of relative percentage difference in the range of $1-150 \mathrm{keV}$. The analysis of the mass attenuation coefficient of the materials using conventional computed tomography images show that the samples AG1, AG2, AG3 and AG5 are compatible with the mass coefficients obtained by the methodology of Mariano \& Costa. Regarding the water mass attenuation coefficients obtained by XCOM, the materials AG1, AG2, AG3 and AG5 showed relative percentage differences of 4 to $7 \%$. The analysis of the mass coefficient using dual energy computed tomography images shows that the materials AG1, AG2, AG3 and AG5 have an average relative difference of less than $7 \%$ in relation to the water mass coefficient. The determination of the linear attenuation coefficient from spectrometry is one of the most reliable methods. However, this method requires accuracy in the geometry of the experimental arrangement. In this analysis, the values of the linear attenuation coefficient of the sample AG2 are compatible with water in the $40-100 \mathrm{keV}$ range with $\pm 5 \%$ difference as determined by ICRU Report 44. For sample AG6 the compatibility range is between $40-80 \mathrm{keV}$ and for sample MA8 is between 31-40 keV. For energies lower than $30 \mathrm{keV}$ and greater than $100 \mathrm{keV}$ it will be necessary to refine the experimental methodology to obtain estimates of the attenuation coefficient with less uncertainty in these intervals. The comparison between the linear attenuation coefficient results from computed tomography and spectrometry analysis show that the linear attenuation coefficient values obtained for the two methods are in agreement.
\end{abstract}

Keywords: Phantoms. Effective atomic number. Computed Tomography. Dual energy computed tomography. X-ray spectrometry 


\section{Lista de figuras}

Figura 1 - À esquerda, objeto simulador para tomografia computadorizada modelo CT ACR 464. À direita, imagens tomográficas dos quatro módulos para avaliação da qualidade de imagem. Fonte: (Samei et al., 2019).

Figura 2 - À esquerda, objeto simulador antropomórfico Lungman da empresa Kyoto Kagaku com rede vascular pulmonar detalhada e à direta a imagem tomográfica do phantom. Fonte: (Samei et al., 2019).

Figura 3 - Coeficiente de atenuação mássico e as contribuições de diferentes interações de fótons com a matéria para a água líquida no intervalo de energia de 1-150 keV obtidos pelo banco de dados XCOM (Berger et al., 2010).

Figura 4 - Distribuição da seção de choque de Klein Nishina por ângulo de espalhamento para as energias de 20,60, 80, 120, 200, 511 e $2000 \mathrm{keV}$. O fóton de raios X viaja da esquerda para a direita, enquanto o elétron livre está posicionado na origem das coordenadas polares. Fonte: (Russo, 2017).

Figura 5 - Eficiência em função da energia e pontos experimentais para um detector CdTe. As curvas foram obtidas a partir de funções resposta do detector simuladas pelo método de Monte Carlo. Fonte: (Tomal et al., 2015).

Figura 6 - Perfil de transmissão em um equipamento de TC convencional e geometria. Fonte:

(Russo, 2017). 35

Figura 7 - Valores usuais de número CT para água, ar e alguns tecidos e órgãos do corpo humano. Fonte: Kalender (2011)

Figura 8 - Esquema do processo de reconstrução de imagem no Discovery CT 750 HD.

Fonte: (Chandra and Langan, 2011).

Figura 9 - Diagrama do processo de análise dos materiais radiologicamente equivalentes... 41

Figura 10 - Processo de produção em laboratório das amostras de materiais radiologicamente equivalentes ao tecido humano e à água. Experimento realizado no Laboratório do GDRFM do IFUSP. Fonte: a Autora, 2019.

Figura 11 - Amostras AG2* e TM2 produzidos com base de resina epóxi e aditivos por reação de cura pela ação de um endurecedor. Fonte: (Frimaio, 2019).

Figura 12 - Desenho esquemático de um equipamento de moldagem por injeção. Fonte:

Callister (2000) 46

Figura 13 - Amostras MA8 e MA9 produzidas com base de polipropileno e aditivos pelo processo industrial de moldagem por injeção. Fonte: (Frimaio, 2019). 
Figura 14 - Desenho do arranjo experimental utilizado para a determinação da massa aparente das amostras de materiais radiologicamente equivalentes ao tecido humano e à água.

Figura 15 - Diagrama do procedimento para determinação do número atômico efetivo em função da energia dos materiais radiologicamente equivalentes ao tecido humano e à água estudados.

Figura 16 - Interface da rotina criada para o cálculo do número atômico efetivo. .50

Figura 17 - Interface da rotina criada para cálculo da diferença relativa entre os valores de número atômico efetivo dos materiais produzidos em relação aos materiais de referência.

Figura 18 - Posicionamento das amostras no suporte de paciente do GE Discovery CT 750 HD do Instituto de Radiologia do HCFMUSP. Na imagem estão, também, apresentados outros materiais que não fizerem parte do presente estudo. Fonte:

Denise Yanikian Nersisian, 2018.

Figura 19 - Imagem de TC realizada para as amostras de materiais radiologicamente equivalentes à água estudados analisada no software ImageJ. Esta imagem representa a amostra AG3 e foi obtida utilizando a tensão de $100 \mathrm{kV}$

Figura 20 - Disposição das amostras estudadas em um equipamento de tomografia computadorizada de dupla energia GE Discovery CT 750 HD Gemstone Spectral Imaging (GSI) (General Electric, USA) do Instituto de Radiologia do HCFMUSP. Fonte: Denise Yanikian Nersissian, 2018

Figura 21 - Arranjo experimental utilizado na aquisição de espectros. Adaptado de (Gonzales et al., 2016).

Figura 22 - Radiografia lateral do detector de CdTe realizada no Laboratório do GDRFM do IFUSP. Fonte: a Autora, 2019.

Figura 23 - Arranjo experimental para alinhamento do detector no Laboratório do GDRFM do IFUSP. Fonte: a Autora, 2019

Figura 24 - Imagem radiográfica do dispositivo utilizado para alinhamento realizada no Laboratório do GDRFM do IFUSP. Fonte: a Autora, 2019. 58

Figura 25 - Imagens do posicionamento das amostras e suporte utilizado no Laboratório do GDRFM do IFUSP. Fonte: a Autora, 2019

Figura 26 - Diagrama do programa de correção de espectros. Fonte: (Mariano, 2017). 60 
Figura 27 - Densidades mássicas de órgãos e tecidos do corpo humano obtidos pelo ICRU Report 44 e densidades mássicas dos materiais radiologicamente equivalentes ao tecido humano e à água estudados.

Figura 28 - Números atômicos efetivos para água líquida, tecido mole, CIRS BR12 e

CIRS 70/30 a partir do método de Manohara e de software Auto- $Z_{\text {eff. }}$

Figura 29 - Diferença relativa do número atômico efetivo dos materiais AG1, AG2, AG3,

AG5 e AG6 em relação à água líquida utilizando o método de Manohara.

Figura 30 - Diferença relativa do número atômico efetivo dos materiais TM1, TM2, TM3 e

TM6 em relação ao tecido mole utilizando o método de Manohara.

Figura 31 - Diferença relativa do número atômico efetivo dos materiais MA1 e MA7 em relação ao CIRS 70/30 e dos materiais MA8 e MA9 em relação ao CIRS BR12 utilizando o método de Manohara.

Figura 32 - Valores de número atômico efetivo dos materiais AG3 e MA7 em relação a outros tecidos. As composição química elementar dos tecidos foi obtida a partir do ICRU Report 44 (White et al., 1989).

Figura 33 - Gráfico comparativo dos coeficientes mássicos determinados para cada amostra de material radiologicamente equivalente e para os coeficiente mássicos previstos na metodologia (Mariano, 2017).

Figura 34 - Gráfico comparativo dos coeficientes de atenuação mássicos determinados das amostras de materiais radiologicamente equivalentes à água calculados a partir de imagens de TCDE em relação aos valores de coeficiente mássico da água nas mesmas energias.

Figura 35 - Gráfico comparativo do coeficiente mássico da amostra MA7 obtido em relação aos valores de coeficiente mássico do CIRS 70/30 nas mesmas energias.

Figura 36 - Gráfico comparativo do coeficiente mássico das amostras MA8 e MA9 obtidos em relação aos valores de coeficiente mássico do CIRS BR12 nas mesmas energias.

Figura 37 - Curva de calibração em energia do detector de CdTe. As incertezas dos pontos experimentais são menores que $2 \%$ do valor da energia, as incertezas no número do canal foram incorporadas nestes valores.

Figura 38 - Ajuste de uma distribuição bi-gaussiana para picos em energia de uma fonte radioativa de ${ }^{241} \mathrm{Am}$. No ajuste, o ruído foi modelado como uma reta.

Figura 39 - Resolução em energia do detector de CdTe utilizado. 
Figura 40 - (a), (c) e (e) valores de coeficiente de atenuação linear das amostras AG2, AG6 e AG4 respectivamente. (b), (d) e (f) diferença entes valores e os valores de coeficiente de atenuação linear da água. As retas pontilhadas demarcam uma diferença de $\pm 5 \%$.

Figura 41 - Valores de coeficiente de atenuação linear das amostras AG2 e AG6 em relação aos valores da água obtidos utilizando o banco de dados XCOM (Berger et al., 2010). 82

Figura 42 - (a) valores de coeficiente de atenuação linear da amostra TM2 e (b) diferença entre estes valores e os valores de coeficiente de atenuação linear do tecido mole. As retas pontilhadas demarcam uma diferença de $\pm 5 \%$.

Figura 43 - Valores de coeficiente de atenuação linear da amostra TM2 em relação aos valores do tecido mole obtidos utilizando o banco de dados XCOM (Berger et al., 2010).

Figura 44 - (a) valores de coeficiente de atenuação linear da amostra MA8 e (b) diferença entre estes valores e os valores de coeficiente de atenuação linear do material comercial CIRS BR12. As retas pontilhadas demarcam uma diferença de $\pm 5 \% . .85$

Figura 45 - Valores de coeficiente de atenuação linear da amostra MA8 em relação aos valores do material comercial CIRS BR12 obtidos a partir do banco de dados XCOM (Berger et al., 2010). .86

Figura 46 - (a) valores de coeficiente de atenuação linear da amostra MA8 e (b) diferença entre estes valores e os valores de coeficiente de atenuação linear do material comercial CIRS BR12. As retas pontilhadas demarcam uma diferença de $\pm 5 \%$.. 87

Figura 47 - Valores de coeficiente de atenuação linear da amostra MA8 em relação aos valores do tecido mamário obtidos a partir do banco de dados XCOM (Berger et al., 2010). 


\section{Lista de tabelas}

Tabela 1 - Composição química elementar dos materiais utilizados como referência neste trabalho.

Tabela 2 - Materiais utilizados como base na produção das amostras de materiais radiologicamente equivalentes ao tecido humano e água. Fonte: (Frimaio, 2019) 43

Tabela 3 - Formulação em massa das amostras de materiais radiologicamente equivalentes ao tecido humano e a água estudadas.

Tabela 4 - Parâmetros utilizados na aquisição das imagens de tomografia computadorizada a partir de um equipamento de tomografia de dupla energia.

Tabela 5 - Parâmetros utilizados na aquisição das imagens monoenergéticas a partir de um equipamento de tomografia de dupla energia.

Tabela 6 - Parâmetros utilizados no tubo de raios X para produção do feixe de raios X........56

Tabela 7 - Parâmetros utilizados no detector de CdTe para aquisição dos espectros. 57

Tabela 8 - Valores de densidade dos materiais de referência utilizados neste trabalho. 63

Tabela 9 - Densidades experimentais das amostras de materiais radiologicamente equivalentes à água e sua diferença em relação ao material de referência

Tabela 10 - Densidades experimentais das amostras de materiais radiologicamente equivalentes ao tecido mole e sua diferença em relação ao material de referência.

Tabela 11 - Densidades experimentais dos materiais radiologicamente equivalentes aos materiais comerciais CIRS BR12 e CIRS 70/30.

Tabela 12 - Densidades esperadas das amostras a partir do Método Mariano \& Costa e diferenças percentuais entre as densidades esperadas e os resultados experimentais das amostras de materiais radiologicamente equivalentes à água, tecido mole e materiais comerciais CIRS BR12 e CIRS 70/30.

Tabela 13 - Diferenças percentuais relativas entre os números atômicos efetivos obtidos e calculados pelo software Auto- $Z_{\text {eff }}$ para os materiais de referência em diferentes energias

Tabela 14 - Valores de coeficiente linear $\left(\mathrm{a}_{0}\right)$, coeficiente angular $\left(\mathrm{a}_{1}\right)$ e coeficiente de determinação $\left(\mathrm{R}^{2}\right)$ obtidos a partir de um ajuste linear dos valores de coeficiente mássico determinados a partir do número CT médio na imagem de TC em relação aos valores de coeficiente mássico da água obtido utilizando o XCOM(Berger et al., 2010). 
Tabela 15 - Valores de coeficiente linear $\left(\mathrm{a}_{0}\right)$, coeficiente angular $\left(\mathrm{a}_{1}\right)$ e coeficiente de determinação $\left(\mathrm{R}^{2}\right)$ obtidos a partir de um ajuste linear dos valores de coeficientes de atenuação linear das amostras obtidos por meio de imagens de TCDE em relação aos valores de coeficiente de atenuação linear da água obtido utilizando o XCOM (Berger et al., 2010).

Tabela 16 - Valores de coeficiente linear $\left(\mathrm{a}_{0}\right)$, coeficiente angular $\left(\mathrm{a}_{1}\right)$ e coeficiente de determinação $\left(\mathrm{R}^{2}\right)$ obtidos a partir de um ajuste linear dos valores de coeficientes de atenuação linear das amostras obtidos por meio de imagens de TCDE em relação aos valores de coeficiente de atenuação linear dos materiais comerciais CIRS BR12 e CIRS 70/30 obtidos utilizando o XCOM (Berger et al., 2010)

Tabela 17 - Valores de $\chi^{2}$ calculados a partir da diferença para as amostras produzidas em relação à água.

Tabela 18 - Valores de coeficiente linear $\left(\mathrm{a}_{0}\right)$, coeficiente angular $\left(\mathrm{a}_{1}\right)$ e coeficiente de determinação $\left(\mathrm{R}^{2}\right)$ obtidos a partir de um ajuste linear dos valores de coeficientes de atenuação linear das amostras em relação aos valores de coeficiente de atenuação linear da água obtido utilizando o XCOM (Berger et al., 2010).

Tabela 19 - Valores de $\chi^{2}$ calculados a partir da diferença para as amostras TM1, TM2, TM3 e TM6 em relação ao tecido mole.

Tabela 20 - Valores de coeficiente linear ( $\left.\mathrm{a}_{0}\right)$, coeficiente angular $\left(\mathrm{a}_{1}\right)$ e coeficiente de determinação $\left(\mathrm{R}^{2}\right)$ obtidos a partir de um ajuste linear dos valores de coeficientes de atenuação linear das amostras em relação aos valores de coeficiente de atenuação linear do tecido mole obtido utilizando o XCOM (Berger et al., 2010).

Tabela 21 - Valores de $\chi^{2}$ calculados a partir da diferença para as amostras MA1 e MA7 em relação ao material comercial CIRS 70/30 e para as amostras MA8 e MA9 em relação ao material comercial CIRS BR12.

Tabela 22 - Valores de coeficiente linear ( $\left.\mathrm{a}_{0}\right)$, coeficiente angular $\left(\mathrm{a}_{1}\right)$ e coeficiente de determinação $\left(\mathrm{R}^{2}\right)$ obtidos a partir de um ajuste linear dos valores de coeficientes de atenuação linear das amostras em relação aos valores de coeficiente de atenuação linear dos materiais comerciais CIRS BR12 e CIRS 70/30 obtidos utilizando o XCOM (Berger et al., 2010).

Tabela 23 - Valores de $\chi^{2}$ calculados a partir da diferença para as amostras MA1, MA7, MA8 e MA9 em relação ao tecido mamário definido no ICRU Report 44. 
Tabela 24 - Valores de coeficiente linear $\left(\mathrm{a}_{0}\right)$, coeficiente angular $\left(\mathrm{a}_{1}\right)$ e coeficiente de determinação $\left(\mathrm{R}^{2}\right)$ obtidos a partir de um ajuste linear dos valores de coeficientes de atenuação linear das amostras em relação aos valores de coeficiente de atenuação linear do tecido mamário obtidos utilizando o XCOM (Berger et al., 2010).

Tabela 25 - Diferenças percentuais entre os valores de coeficientes de atenuação linear, $\mu(E)$, obtidos para a análise de TC convencional em relação aos coeficientes de atenuação linear obtidos pela análise de espectrometria para as amostras AG1, AG2, AG3 e AG5.

Tabela 26 - Diferenças percentuais entre os valores de coeficientes de atenuação linear, $\mu(E)$, obtidos para a análise de TC de dupla energia em relação aos coeficientes de atenuação linear obtidos pela análise de espectrometria para as amostras AG1, AG2, AG3 e AG5. 


\section{Lista de abreviações}

AAPM American Association of Physicists in Medicine

ACR American College of Radiology

ANVISA Agência Nacional de Vigilância Sanitária

COVID-19 Doença por SARS-CoV-2

CT Computed Tomography

DICOM Digital Imaging and Communications in Medicine

GDRFM Grupo de Dosimetria das Radiações e Física Médica

HCFMUSP Hospital das Clínicas da Faculdade de Medicina da USP

HU Hounsfield units

IAEA International Atomic Energy Agency

ICRU International Commission on Radiation Units and Measurements

InRad Instituto de Radiologia do HCFMUSP

MMQ Método dos mínimos quadrados

NIST National Institute of Standards and Technology

SARS-CoV-2 Severe acute respiratory syndrome coronavirus 2

TC Tomografia computadorizada

TCDE Tomografia computadorizada de dupla energia 


\section{Sumário}

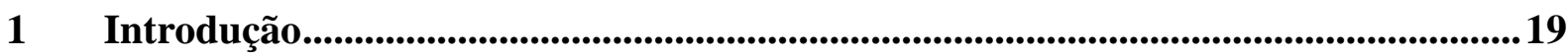

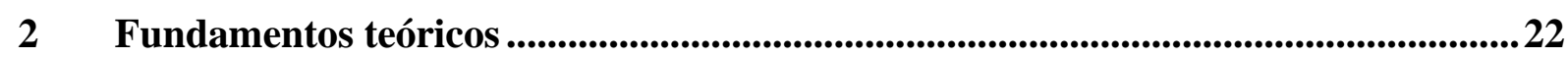

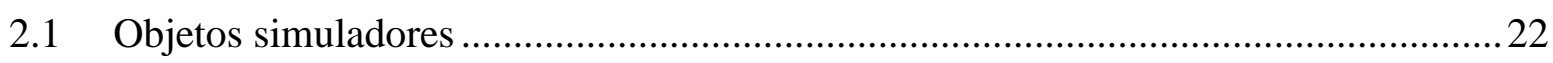

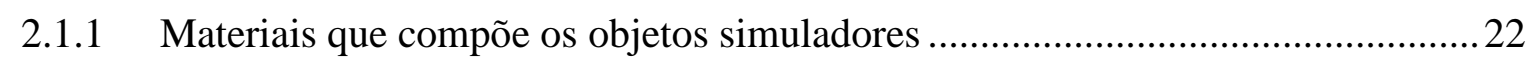

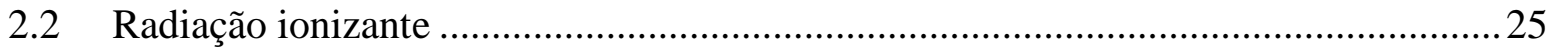

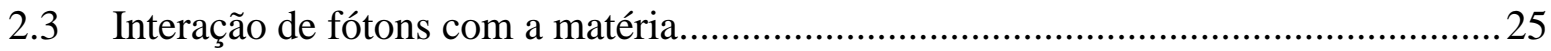

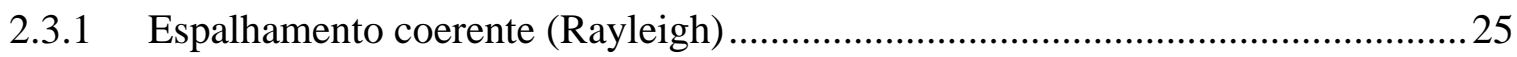

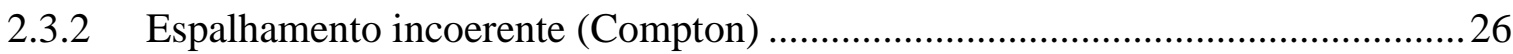

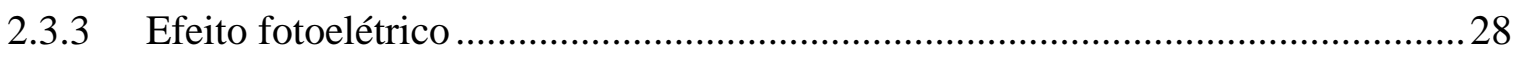

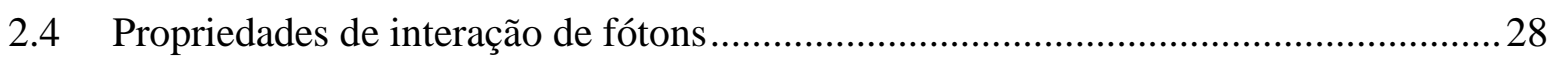

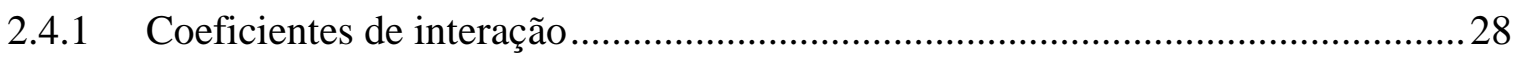

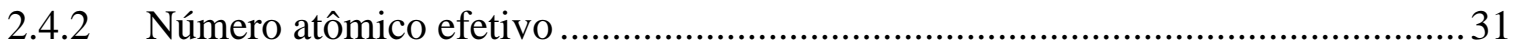

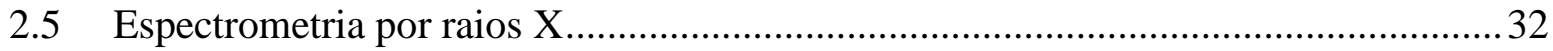

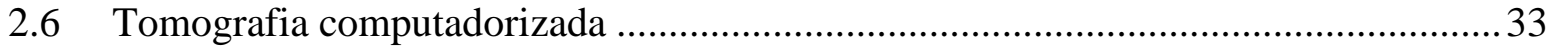

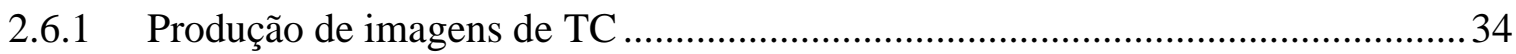

2.6.2 Tomografia computadorizada de dupla energia ............................................... 36

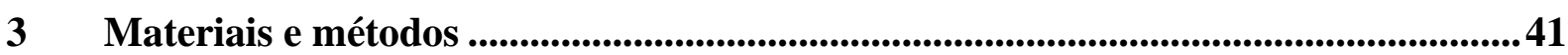

3.1 Materiais radiologicamente equivalentes ao tecido humano e água ......................... 42

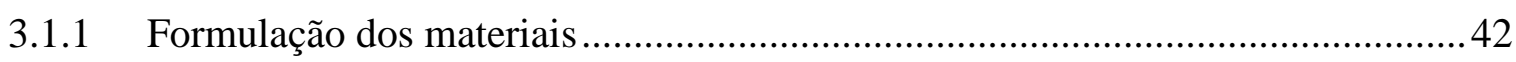

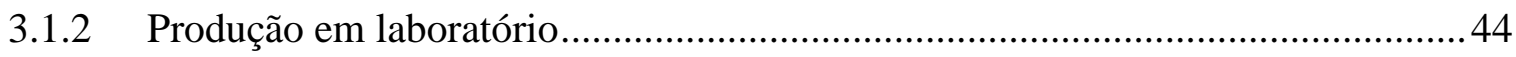

3.1.3 Produção industrial de moldagem por injeção ................................................... 45

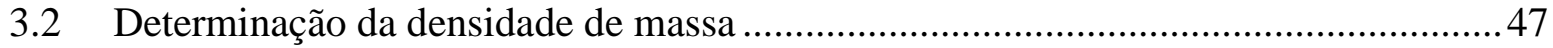

3.3 Algoritmo para determinação do número atômico efetivo............................................ 48

3.4 Estimativa do coeficiente de atenuação mássico utilizando imagens tomográficas ...51

3.4.1 Metodologia utilizando números TC de imagens de tomografia computadorizada 51

3.4.2 Metodologia utilizando tomografia computadorizada de dupla energia 53

3.5 Estimativa do coeficiente de atenuação linear utilizando espectroscopia por raios X 55

3.5.1 Arranjo experimental para aquisição dos espectros ............................................55

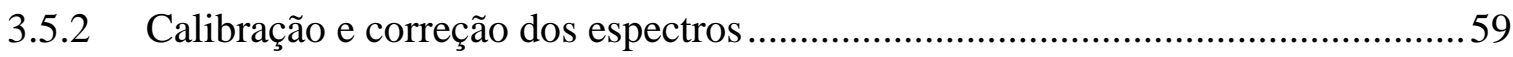

3.5.3 Determinação do coeficiente de atenuação linear .............................................. 60 
3.5.4 Análise comparativa entre os coeficientes de atenuação linear das amostras de materiais radiologicamente equivalentes ao tecido humano e à água e os materiais de referência

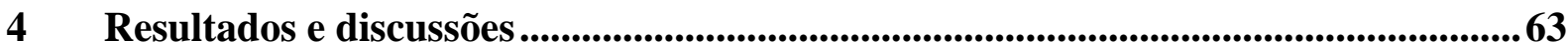

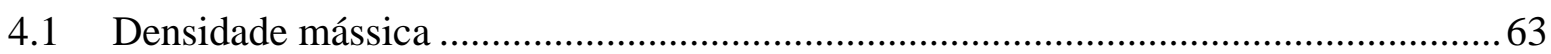

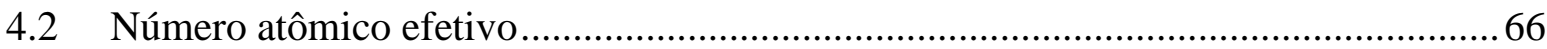

4.2.1 Validação do método de Manohara para cálculo do número atômico efetivo .....66

4.2.2 Número atômico efetivo dos materiais radiologicamente equivalentes à água....69

4.2.3 Número atômico efetivo dos materiais radiologicamente equivalentes ao tecido mole 70

4.2.4 Número atômico efetivo dos materiais radiologicamente equivalentes ao CIRS

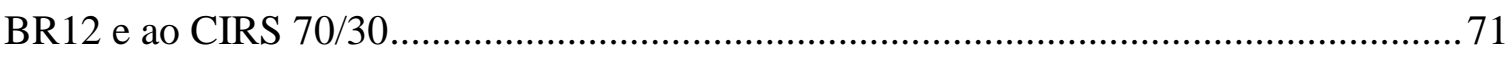

4.2.5 Comparações com outros tecidos .................................................................... 71

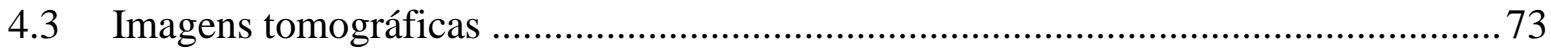

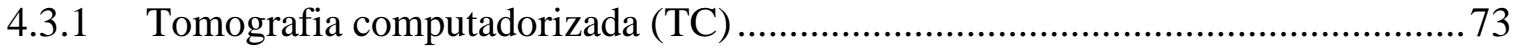

4.3.2 Tomografia computadorizada de dupla energia (TCDE) ................................. 75

4.4 Estimativa do coeficiente de atenuação linear utilizando espectroscopia por raios X 77

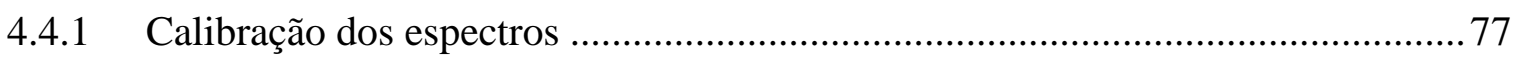

4.4.2 Resolução em energia do detector de CdTe ..................................................... 78

4.4.3 Estimativa dos coeficientes de atenuação linear de materiais radiologicamente equivalentes à água 80

4.4.4 Estimativa dos coeficientes de atenuação linear de materiais radiologicamente equivalentes ao tecido mole.

4.4.5 Estimativa dos coeficientes de atenuação linear de materiais equivalentes aos materiais comerciais CIRS BR12 e CIRS 70/30 
Apêndice A - Estimativa do coeficiente de atenuação linear de materiais radiologicamente equivalentes à água 93

Apêndice B - Estimativa do coeficiente de atenuação linear de materiais radiologicamente equivalentes ao tecido mole. 99

Apêndice C - Estimativa do coeficiente de atenuação linear de materiais radiologicamente equivalentes aos materiais comerciais CIRS BR12 e CIRS 70/30 .....102

Referências bibliográficas .105 


\section{Introdução}

A radiologia é um dos ramos da medicina que utiliza imagens médicas para o diagnóstico e tratamento de problemas de saúde. Após a descoberta dos raios X por Röntgen em 1895, uma série de modalidades para o diagnóstico por imagens foram desenvolvidas. Hoje, as principais modalidades de imagens médicas são: radiografia, mamografia, tomografia computadorizada, fluoroscopia, imagens por ressonância magnética, imagens por ultrassom e imagens em medicina nuclear (tomografia por emissão de pósitrons e tomografia por emissão de fóton único). Durante o desenvolvimento e aprimoramento destas tecnologias objetos simuladores e materiais que mimetizam o tecido humano são importantes para avaliação do desempenho do sistema de imagem.

Objetos simuladores ou phantoms são dispositivos que representam o corpo humano tanto na forma quanto na composição (DeWerd and Kissick, 2014). Os materiais que compõem os objetos simuladores são projetados para replicar os efeitos da radiação eletromagnética dentro de diferentes tecidos humanos, como ossos, pulmões, tecidos moles, músculos e outros. A água por exemplo é um material amplamente utilizado, pois compreende uma fração significativa do corpo humano. Em 1906, Kienbock sugeriu a utilização de água como um material que mimetiza o tecido muscular.

Atualmente, existe uma grande variedade de modelos de objetos simuladores disponíveis com aplicações na radiologia. No âmbito clínico, objetos simuladores são utilizados em rotinas de controle de qualidade do sistema de imagem e dosimetria da radiação para garantir qualidade de imagem e segurança na prática médica. A Figura 1 apresenta um objeto simulador para equipamentos tomografia computadorizada CT ACR 464 (McCollough et al., 2004) da empresa Gammex. Este objeto possui quatro módulos distintos para testes de qualidade de imagem, todos os módulos estão envoltos em material radiologicamente equivalente à água.

Nos últimos anos, o desenvolvimento de objetos simuladores se concentra na produção por impressoras 3D, por exemplo para objetos simuladores da mama (Malliori et al., 2020, Schopphoven et al., 2019, Badal et al., 2018), objeto simulador da glândula tiroide (Alssabbagh et al., 2017) e objeto simulador de um recém-nascido prematuro (Irnstorfer et al., 2019). O estudo de materiais para fabricação de objetos simuladores também é de grande interesse, por exemplo, a produção de materiais à base de gelatina (Dahal et al., 2018) e desenvolvimento de código computacional para otimização de formulações para objetos simuladores (Homolka et al., 2002). 

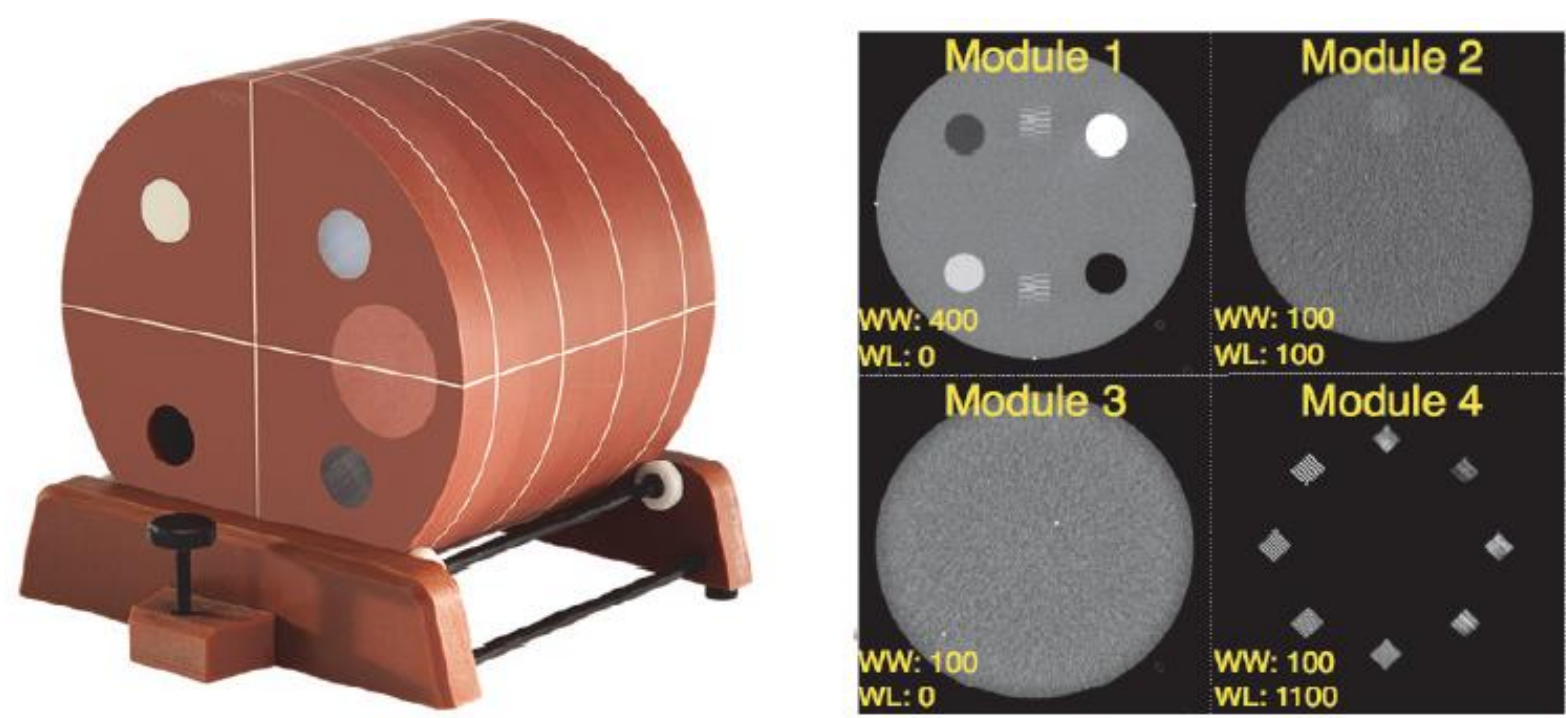

Figura 1 - À esquerda, objeto simulador para tomografia computadorizada modelo CT ACR 464. À direita, imagens tomográficas dos quatro módulos para avaliação da qualidade de imagem. Fonte: (Samei et al., 2019).

No Brasil, a produção de objetos simuladores para radiologia ainda é pequena. Destacase o desenvolvimento de um objeto simulador antropomórfico de tórax (Cerqueira et al., 2010), objeto simulador dosimétrico para mamografia (Almeida et al., 2012) e objeto simulador de pâncreas para uso em medicina nuclear (Silva et al., 2015).

Quanto ao desenvolvimento de materiais radiologicamente equivalentes, destaca-se o trabalho de Mariano \& Costa (Mariano and Costa, 2017, Mariano, 2017) que estabelece uma metodologia matemática para determinação de formulações químicas para materiais radiologicamente equivalentes por meio do método dos mínimos quadrados (MMQ) e Frimaio (Frimaio, 2019) que desenvolveu uma metodologia para produção destes materiais a partir das formulações químicas obtidas. Em continuidade, o presente trabalho propõe estudar métodos experimentais para a validação de materiais radiologicamente equivalentes ao tecido humano e à água produzidos por Frimaio (Frimaio, 2019).

Para representar os tecidos humanos, estes materiais devem mimetizar tanto as propriedades físicas quanto as radiológicas dos materiais de referência. A composição de um material radiologicamente equivalente a tecido baseia-se na composição do tecido real e suas características de absorção e espalhamento da radiação.

A densidade de massa $\rho$ e o número atômico efetivo $Z_{e f}$ podem descrever as grandezas físicas, já a caracterização radiológica requer o conhecimento de suas propriedades de atenuação. O coeficiente de atenuação linear é uma boa representação das propriedades de atenuação, pois é o parâmetro que representa o comportamento da atenuação em relação à composição do meio e com a energia do fóton incidente. Em publicações recentes, medidas dos 
coeficientes de atenuação linear foram feitas para caracterização de tecidos mamários (Soares et al., 2020) e substitutos de tecido ósseo (Joshi et al., 2020).

Este trabalho tem como objetivo principal estudar métodos experimentais para validação de materiais radiologicamente equivalentes ao tecido humano e à água quanto suas características físicas e radiológicas. O trabalho tem como objetivos específicos:

- Aplicação de técnicas de espectrometria por raios X para estimativa do coeficiente de atenuação linear dos materiais estudados no intervalo de energia utilizados em radiodiagnóstico;

- Aplicação de técnicas de tomografia computadorizada convencional e de dupla energia para estimativa do coeficiente de atenuação mássico dos materiais estudados no intervalo de energias utilizadas em radiodiagnóstico;

- Desenvolvimento de programa computacional para cálculo do número atômico efetivo dos materiais estudados;

- Determinação da densidade mássica dos materiais estudados

Os resultados destas análises podem ser utilizados para justificar a utilização futura destes materiais tanto no âmbito da prática clínica como no âmbito da pesquisa. 


\section{Fundamentos teóricos}

\subsection{Objetos simuladores}

Segundo o Relatório 44 da International Commission on Radiation Units and Measurements - ICRU Report 44 (White et al., 1989), quando um volume de material simulador de tecido é usado para simular as interações da radiação, esse volume é denominado objeto simulador. Os objetos simuladores, também podem mimetizar os tecidos humanos tanto com base na anatomia do corpo, quanto sua forma, tamanho e densidade mássica. O design e a composição dos objetos simuladores são determinados pelo propósito a que servirão.

Após a descoberta dos raios $\mathrm{X}$ e da radioatividade foram identificadas aplicações potenciais bem como efeitos nocivos das radiações ionizantes. No início do século XX, reconheceu-se que, para quantificar a dose administrada em um tecido de interesse, medições devem ser feitas no próprio tecido. Sendo assim, surgiu a necessidade de criar objetos simuladores de tecidos humanos.

Os primeiros objetos simuladores utilizados eram compostos por água ou cera. Possuíam geometrias simples como tanques de água e blocos de cera e eram utilizados em medições de fontes radioativas ou feixes de raios X (Baumeister and Rocky, 1923). Ao longo dos anos, novos materiais simuladores de tecido humano (como as resinas epóxi e poliuretanos) foram identificados, permitindo a produção de objetos simuladores de melhor qualidade, reprodutibilidade e precisão quanto à simulação de tecidos humanos em ampla gama de energias.

\subsubsection{Materiais que compõe os objetos simuladores}

Os objetos simuladores desenvolvidos com materiais radiologicamente equivalentes ao tecido humano são usados em áreas como a medicina, proteção radiológica e radiobiologia. Eles podem representar uma grande variedade de tecidos e/ou órgãos do corpo humano, e também a água. Podem ser tão simples como placas de material radiologicamente equivalente ao tecido humano quanto tão complexos como os objetos simuladores antropomórficos, com representação detalhadas do corpo humano e/ou de seus tecidos e órgãos. A Figura 2 apresenta o objeto simulador para tomografia computadorizada Lungman da empresa Kyoto Kagaku (Kyoto Kagaku Co., Ltd., Kyoto, Japão) que apresenta, de forma detalhada, a anatomia torácica e pulmonar. 

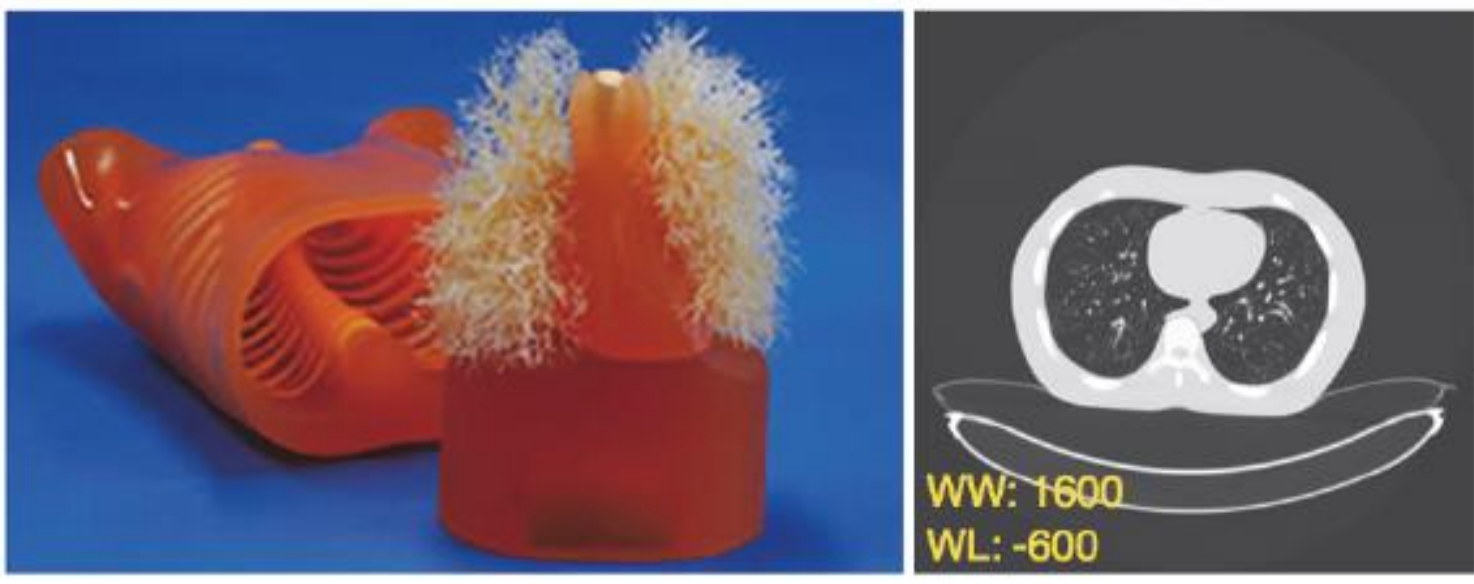

Figura 2 - À esquerda, objeto simulador antropomórfico Lungman da empresa Kyoto Kagaku com rede vascular pulmonar detalhada e à direta a imagem tomográfica do phantom. Fonte: (Samei et al., 2019).

O objetivo principal de um objeto simulador é mimetizar as alterações do campo de radiação causada pela absorção e espalhamento nos tecidos ou órgãos de interesse. Sendo assim, a geometria e composição dos objetos simuladores devem se aproximar da geometria e composição dos tecidos ou órgãos reais com alta precisão. Segundo o ICRU Report 44 (White et al., 1989), os materiais simuladores de tecido são desenvolvidos, frequentemente, a partir de misturas formuladas de modo que suas propriedades de interação com a radiação coincidam com as do tecido biológico com diferenças inferiores a 5\%.

Diversos fatores devem ser considerados durante a produção de um material radiologicamente equivalente ao tecido humano. O primeiro aspecto a ser considerado é o intervalo de energia que o material deve abranger. $\mathrm{O}$ espectro de raios $\mathrm{X}$ utilizado nas modalidades de diagnóstico médico por imagens abrange desde alguns kilo-elétron-volts (keV) até $150 \mathrm{keV}$. O espectro de raios $\mathrm{X}$ de uma imagem de mamografia compreende energias desde 5 a $35 \mathrm{keV}$, já o espectro de uma tomografia computadorizada de abdómen compreende energias de 20 a $150 \mathrm{keV}$ (Russo, 2017). Sendo assim, um material radiologicamente equivalente desenvolvido para representar um tecido ou órgão em um intervalo de baixas energias não necessariamente será apropriado para representar o mesmo tecido ou órgão em um intervalo de altas energias.

Outro fator importante a ser considerado são as características físicas que podem interferir na obtenção das imagens de radiodiagnóstico. Por exemplo, imagens de tomografia computadorizada são representadas em unidades Hounsfield (HU) a partir do coeficiente de atenuação linear, $\mu$, do tecido de interesse em relação ao coeficiente de atenuação linear da 
água. Assim, é importante que o coeficiente de atenuação linear do material radiologicamente equivalente a ser utilizado neste tipo de aplicação corresponda ao tecido de interesse.

A Figura 3 apresenta o coeficiente de atenuação mássico $\mu / \rho\left(\mathrm{em} \mathrm{cm}^{2} / \mathrm{g}\right)$ em que $\mu$ é o coeficiente de atenuação linear em $\mathrm{cm}^{-1}$ e $\rho$ é a densidade mássica em $\mathrm{g} / \mathrm{cm}^{3}$. Os valores de coeficiente de atenuação mássico para a água líquida e as contribuições das diferentes interações de fótons com a matéria para o intervalo de energia de 1-150 keV foram obtidos utilizando o banco de dados XCOM (Berger et al., 2010). É importante perceber a variação na dependência da energia com o coeficiente de atenuação mássico e com as contribuições das diferentes interações de fótons com a matéria. Essas diferenças devem ser consideradas na identificação de materiais que sejam radiologicamente equivalentes ao tecido humano e mostram como esta identificação pode ser complexa.

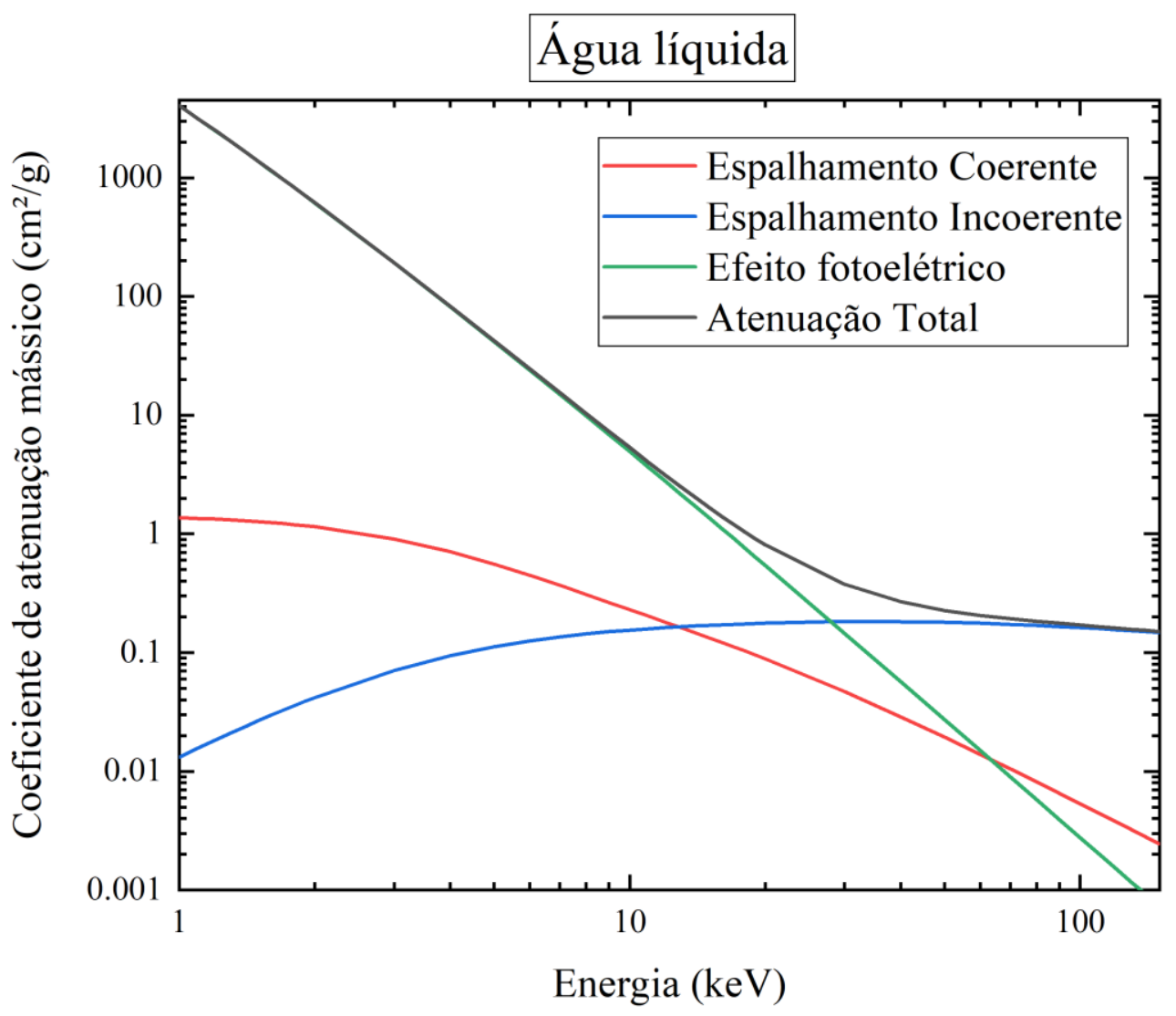

Figura 3 - Coeficiente de atenuação mássico e as contribuições de diferentes interações de fótons com a matéria para a água líquida no intervalo de energia de 1-150 keV obtidos pelo banco de dados XCOM (Berger et al., 2010). 


\subsection{Radiação ionizante}

De acordo com o ICRU Report 85 (ICRU, 2011), o termo radiação ionizante refere-se às partículas com carga (como elétrons ou prótons) e partículas que não possuem carga (como fótons ou nêutrons) que podem produzir ionizações em um meio ou iniciar transformações nucleares ou de partículas elementares que resultam em ionização ou produção de radiação ionizante. Os processos de interação da radiação com a matéria dependem da energia e do número atômico do material absorvedor. Na interação, a partícula incidente pode ser absorvida ou ter sua energia e/ou direção alterados. Após a interação pode haver a emissão de uma ou mais partículas secundárias.

\subsection{Interação de fótons com a matéria}

Os principais processos de interação de fótons com a matéria dentro do intervalo de energia utilizada em radiodiagnóstico $(h v<150 \mathrm{keV})$ são os espalhamentos coerente (Rayleigh) e incoerente (Compton) e o efeito fotoelétrico. Estes serão os processos abordados nesta seção. Informações sobre os demais processos de interação como produção de pares, espalhamento Thomson e absorção fotonuclear podem ser encontrados em livros sobre física das radiações (Podgoršak, 2016).

\subsubsection{Espalhamento coerente (Rayleigh)}

O espalhamento coerente ou Rayleigh ocorre quando um fóton interage com o átomo como um todo. $\mathrm{O}$ fóton incidente é espalhado em uma nova direção de propagação com ângulo usualmente pequeno e praticamente sem perda de energia. Apenas uma parcela muito pequena de energia é transferida, necessária para o recuo do átomo. Após a interação, os elétrons ligados ao átomo retornam para suas configurações originais.

No espalhamento Rayleigh, mais de $75 \%$ dos fótons são espalhados com ângulo menor que $2 \sin ^{-1}\left(0,026 \mathrm{Z}^{1 / 3} E_{0} / h v\right)$ (Moon, 1950) em que $E_{0}$ representa a energia de repouso do elétron $(0,511 \mathrm{MeV})$ e $\mathrm{Z}$ o número atômico do átomo com o qual o fóton interage e $h v$ a energia do fóton incidente. Este resultado mostra que o espalhamento Rayleigh é relevante para energias mais baixas dos fótons incidentes, uma vez que os ângulos de espalhamento são maiores. 
A probabilidade de ocorrência do espalhamento Rayleigh pode ser descrita por sua seção de choque atômica, ${ }_{a} \sigma_{R}$, que é assume a proporcionalidade (Podgoršak, 2016):

$$
{ }_{a} \sigma_{R} \propto \frac{Z^{2}}{(h v)^{2}}
$$

\subsubsection{Espalhamento incoerente (Compton)}

O espalhamento Compton, também denominado espalhamento incoerente, acontece quando um fóton incidente de energia $h v_{0}$ interage com um elétron livre (ou fracamente ligado) que se encontra em repouso no material. O processo dá origem a um fóton secundário de energia $h v_{s}$, espalhado em um ângulo $\vartheta$ em relação à sua direção original, e a um elétron com energia $E_{e}=h v_{0}-h v_{s}$. A energia do fóton secundário é determinada por (Podgoršak, 2016):

$$
h v_{s}=\frac{h v_{0}}{1+\alpha(1-\cos \vartheta)}
$$

em que $\alpha=h v_{0} / m_{e} c^{2}$, sendo $m_{e} c^{2}$ a energia de repouso do elétron.

Para a interação de um fóton com um elétron livre, a seção de choque diferencial de Klein-Nishina é definida como (Podgoršak, 2016):

$$
\frac{d \sigma_{K N}}{d \Omega}=\frac{r_{e}^{2}}{2}\left(\frac{1}{(1+\alpha(1-\cos \vartheta))^{2}}\left(1+\cos ^{2} \vartheta+\frac{\alpha^{2}(1-\cos \vartheta)^{2}}{1+\alpha(1-\cos \vartheta)}\right)\right) c m^{2} s r^{-1} e^{-1}
$$

em que $r_{e}=2,818 \times 10^{-13} \mathrm{~cm}$ (Attix, 2008) é o "raio clássico do elétron". A distribuição da seção de choque de Klein-Nishina por ângulo de espalhamento para diversas energias pode ser visualizada na Figura 4. Para um dado ângulo de espalhamento, quando a energia do fóton incidente aumenta, a fração de energia transferida para o fóton espalhado diminui, e consequentemente, a energia transferida para o elétron aumenta. Este efeito é mais perceptível para o intervalo de energia utilizada em radiologia, de 20 a $150 \mathrm{keV}$ (Russo, 2017). 


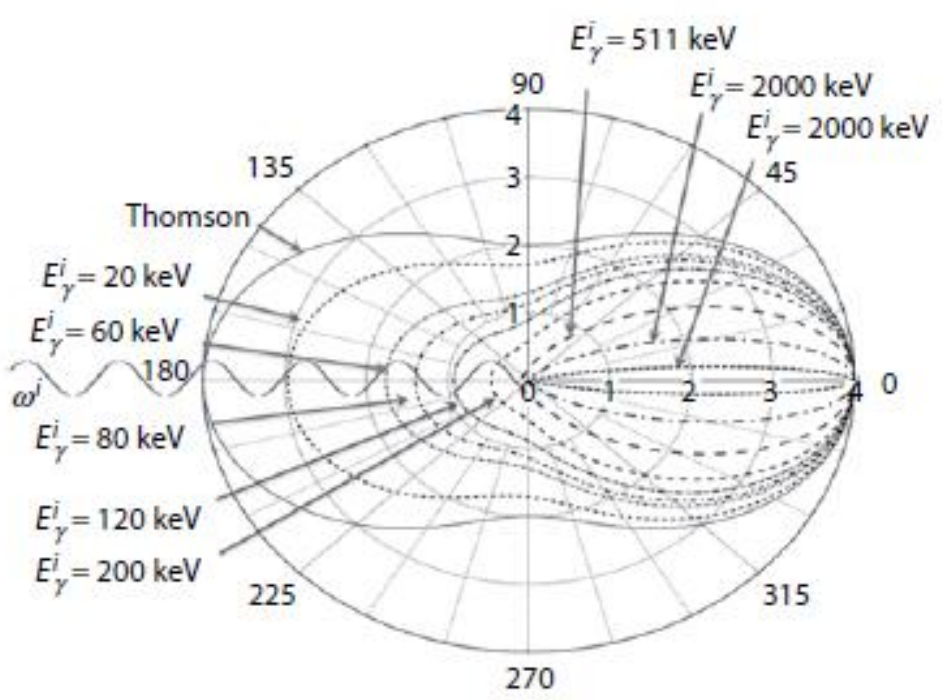

Figura 4 - Distribuição da seção de choque de Klein Nishina por ângulo de espalhamento para as energias de $20,60,80,120,200,511$ e $2000 \mathrm{keV}$. O fóton de raios X viaja da esquerda para a direita, enquanto o elétron livre está posicionado na origem das coordenadas polares. Fonte: (Russo, 2017).

Quando o elétron está ligado ao material, introduz-se um fator de correção denominado função de espalhamento incoerente $S(q, Z)$ que depende da transferência de momento do fóton incidente para o elétron, $q$, e do número atômico, $Z$, do material. Assim, a seção de choque diferencial do espalhamento Compton, corrigida para todos os elétrons atômicos, pode ser escrita como:

$$
\left(\frac{d \sigma}{d \Omega}\right)_{\text {Compton }}=\left(\frac{d \sigma}{d \Omega}\right)_{K N} S(q, Z)
$$

$S(q, Z)$ é aproximadamente proporcional à $Z$ quando os valores de energia do fóton incidente são suficientemente altos. Como a seção de choque do espalhamento Compton, segundo a equação de Klein-Nishina, é aproximadamente constante em relação ao número atômico $Z$, pode-se definir que para um material puro, a seção de choque atômica total do espalhamento Compton ${ }_{a} \sigma$ é aproximadamente proporcional ao número atômico $Z$ (Russo, 2017). 


\subsubsection{Efeito fotoelétrico}

No efeito fotoelétrico, um fóton interage com um elétron orbital do átomo do material absorvedor. O fóton incidente de energia $h v$ é totalmente absorvido pelo átomo e o elétron orbital é ejetado do átomo com energia cinética definida como $T=h v-E_{b}$, onde $E_{b}$ é a energia de ligação do elétron no átomo. Este resultado considera que a energia cinética de recuo do átomo é muito pequena e pode ser desprezada.

Diferentemente do espalhamento Compton, em que o fóton incidente interage com um elétron livre (ou fracamente ligado) do átomo, no efeito fotoelétrico a interação acontece com um elétron orbital (fortemente ligado) do átomo. A diferenciação entre elétrons fracamente e fortemente ligados vem da relação entre as magnitudes de $h v$ e $E_{b}$ e não de seus valores absolutos. Assim, quando $E_{b} \ll h v$ o elétron é fracamente ligado e quando $E_{b} \lesssim h v$ o elétron é fortemente ligado.

Cerca de $80 \%$ das absorções fotoelétricas ocorrem com elétrons da camada $\mathrm{K}$ (Podgoršak, 2016). Após a emissão do elétron, a vacância da carga negativa gerada é preenchida por um elétron de uma camada eletrônica superior, com a emissão de raios X característicos ou um elétron Auger.

A seção de choque do efeito fotoelétrico, $a \tau$, representa a probabilidade de ocorrência deste efeito e varia aproximadamente com energia e número atômico $\mathrm{Z}$ do material de acordo com a relação (Attix, 2008):

$$
{ }_{a} \tau \propto \frac{Z^{n}}{(h v)^{m}}
$$

em que $n \cong 4$ para $h v \leq 100 \mathrm{keV}$, aumentando gradualmente para que $n \cong 4,6$ em $3 \mathrm{MeV}$ e $\mathrm{m} \cong 3$ para $h v \leq 100 \mathrm{keV}$, diminuindo gradualmente para $n \cong 1 \mathrm{em} 5 \mathrm{MeV}$.

\subsection{Propriedades de interação de fótons}

\subsubsection{Coeficientes de interação}

Como visto na Seção 2.3, em uma interação, o fóton pode ser absorvido ou ter sua energia e/ou direção incidente modificada. Esta interação pode resultar na emissão de uma ou mais partículas secundárias. A caracterização de tecidos do corpo humano e de materiais radiologicamente equivalentes ao tecido humano em relação às interações da radiação com a 
matéria é realizada através de coeficientes de interação. Estes coeficientes representam a probabilidade de uma interação ocorrer levando em conta o transporte de radiação primário e secundário no intervalo de energia de interesse.

\subsubsection{Coeficiente de atenuação linear}

A seção de choque total do átomo, ${ }_{a} \sigma^{\text {tot }}$, representa a probabilidade de uma interação qualquer ocorrer. No intervalo de energia para radiodiagnóstico, ${ }_{a} \sigma^{\text {tot }}$ é definida como a soma das contribuições independentes das diversas interações:

$$
{ }_{a} \sigma^{t o t}={ }_{a} \sigma_{R}+{ }_{a} \sigma+{ }_{a} \tau
$$

em que ${ }_{a} \sigma_{R}$ e ${ }_{a} \sigma$ são as seções de choque atômicas dos espalhamentos Rayleigh e Compton, respectivamente. ${ }_{a} \tau$ é a seção de choque do efeito fotoelétrico. Na equação (6), as interações são consideradas independentes entre si.

O coeficiente de atenuação linear, $\mu$, caracteriza o comportamento da atenuação em relação ao material do meio e com a energia do fóton incidente (Okuno and Yoshimura, 2016). Estabelecendo $n_{V}$ como o número de átomos por unidade de volume, pode-se definir o coeficiente de atenuação linear como a soma das contribuições das interações que podem ocorrer para cada energia e cada meio como:

$$
\mu=\left({ }_{a} \sigma_{R}+{ }_{a} \sigma+{ }_{a} \tau\right) \cdot n_{V}
$$

\subsubsection{Coeficiente de atenuação mássico}

O coeficiente de atenuação mássico de um elemento químico está diretamente relacionado com a seção de choque total do átomo pela relação:

$$
\frac{\mu}{\rho}=\left(\frac{N_{A}}{A}\right){ }_{a} \sigma^{t o t}
$$

em que $N_{A}$ é o número de Avogadro e $A$ é o peso atômico. As seções de choque parciais de interação são proporcionais a $Z^{x}$, onde o exponente $x$ depende do processo de interação. 
Para uma mistura, o coeficiente de atenuação mássico pode ser obtido por:

$$
\frac{\mu}{\rho}=\sum_{i} w_{i}\left(\frac{\mu}{\rho}\right)_{i}
$$

considerando que a mistura seja composta por átomos independentes, sem levar em conta as relações moleculares. $w_{i}$ corresponde à fração mássica do i-ésimo elemento da mistura.

$$
w_{i}=\frac{n_{i} A}{\sum_{i} n_{i} A_{i}}
$$

em que $n_{i}$ é o número de átomos do i-ésimo elemento da mistura.

\subsubsection{Coeficiente mássico de transferência de energia}

No intervalo de energias para radiodiagnóstico, a transferência de energia do fóton para o meio é feita pela aquisição de energia cinética por partículas carregadas no espalhamento Compton e efeito fotoelétrico.

O coeficiente mássico de transferência de energia é o produto entre o coeficiente de atenuação mássico e a fração da energia média que é transferida (Okuno and Yoshimura, 2016):

$$
\frac{\mu_{t r}}{\rho}=\frac{\mu}{\rho} \overline{\frac{E_{t r}}{E}}
$$

em que $\overline{E_{t r}}$ é a energia média do fóton incidente $E$ transferida ao meio.

\subsubsection{Coeficiente mássico de absorção}

O coeficiente mássico de absorção é definido como (Okuno and Yoshimura, 2016):

$$
\frac{\mu_{a b}}{\rho}=(1-g) \frac{\mu_{t r}}{\rho}
$$

em que $g$ representa a fração de energia transferida dos fótons para elétrons e pósitrons que é irradiada, e não convertida em ionização do meio. 


\subsubsection{Número atômico efetivo}

Ao lidar com um composto ou mistura de moléculas é conveniente descrever um material pelo seu número atômico efetivo, $Z_{e f}$. Inicialmente, o número atômico efetivo foi calculado a partir de leis de potência. Bragg \& Pierce (1914) descreveram a dependência da absorção de raios $X$, em relação ao número atômico $Z$ e energia $E$ (ou comprimento de onda $\lambda$ como descrito originalmente) seguindo a lei de potência $Z^{m} E^{-n}$.

Para interações fotoelétricas, Mayneord (1937) considerou um composto ou mistura como um elemento de número atômico efetivo descrito pela lei de potências:

$$
Z_{e f}^{m-1}=\sum_{i} \alpha_{i} Z_{i}^{m-1}
$$

em que

$$
\alpha_{i}=\frac{\left(w_{i} Z_{i} / A_{i}\right)}{\sum_{i}\left(w_{i} Z_{i} / A_{i}\right)}
$$

e $\sum_{i} \alpha_{i}=1$. Na literatura, valores de $m$ foram propostos para as interações fotoelétricas como: 3,47 (Mayneord, 1937) e 4,5 (Johns and Cunningham, 1983).

Com o desenvolvimento de bancos de dados de seções de choque de interação (Hubbell and Seltzer, 1996) mais detalhados foi possível desenvolver novas metodologias (Manohara et al., 2008, Taylor et al., 2012) para o cálculo de número atômico efetivo com melhor exatidão para um intervalo amplo de energias.

Manohara et al. (Manohara et al., 2008) estabeleceram uma relação geral para o cálculo do número atômico efetivo de compostos e misturas a partir da seção de choque de interação dos elementos constituintes. Neste método, o número atômico efetivo é determinado pela equação (14) a partir do coeficiente de atenuação mássico $(\mu / \rho)$, fração molar $f$, número atômico $Z$ e massa atômica $A$ de cada elemento constituinte $i$.

$$
Z_{e f}(E)=\frac{\sum_{i} f_{i} A_{i}\left(\frac{\mu}{\rho}\right)_{i}(E)}{\sum f_{i}\left(A_{i} / Z_{i}\right)\left(\frac{\mu}{\rho}\right)_{i}(E)}
$$

Taylor et al. (2012) desenvolveram o software Auto- $Z_{\text {eff }}$ para o cálculo de número atômico efetivo em função da energia, número atômico efetivo médio e número atômico ponderado por espectro, explorando a correlação entre a seção de choque atômica e número atômico.

Outras definições do número atômico efetivo também foram propostas a partir da razão dos espalhamentos Rayleigh e Compton, por exemplo utilizando espectros medidos (Antoniassi 
et al., 2011, Del Lama et al., 2015) e tomografia computadorizada de dupla energia (Bonnin et al., 2014).

\subsection{Espectrometria por raios $\mathrm{X}$}

A determinação experimental de espectros de raios $\mathrm{X}$ com o uso de detectores semicondutores é amplamente utilizada, pois estes detectores possuem as melhores resoluções em energia (Knoll, 2010).

Kurkova e Judas (2016) apontam duas dificuldades na medição de espectros de raios X. São elas: a alta taxa de fluência de fótons que influência o tempo morto do detector e as distorções espectrais causadas por empilhamento de pulsos, efeitos de escape, coleta incompleta de carga pelo efeito Compton no detector. Deve-se considerar, também, a dependência energética da eficiência de detecção.

Para reduzir a taxa de fluência de fótons é recomendado o uso de colimadores, assim como aumentar a distância entre o tubo de raios X e o detector. Neste segundo caso, é necessário levar em conta a influência da atenuação do ar na contagem final de fótons de raios X.

As demais distorções espectrais dependem do tipo de detector utilizado e necessitam da aplicação de um procedimento matemático para correção que leva em conta a resposta do detector. Procedimentos, tais como o método de stripping (Seelentag and Panzer, 1979), são amplamente usados em espectroscopia por raios X. Métodos de correção usando a matriz de resposta do detector a partir de modelos algébricos também foram reportados na literatura (Kurkova and Judas, 2016, Santos et al., 2017, Moralles et al., 2007).

Neste trabalho, foi utilizado um detector de telureto de cádmio $(\mathrm{CdTe})$ para aquisição espectral. Detetores de CdTe são amplamente utilizados em espectroscopia por raios X (Miyajima et al., 2002, Poletti et al., 2002) e gama por este material possuir coeficiente de atenuação linear alto, permitindo alta eficiência de detecção em volumes pequenos. A portabilidade destes equipamentos permite o uso em estudos clínicos de mamografia (Miyajima and Imagawa, 2002, Santos et al., 2017). Estes detectores também apresentam baixa fuga de corrente, permitindo baixo ruído eletrônico sem necessitar de resfriamento criogênico.

Tomal et al. (2015) obteve as funções resposta para um detector de CdTe através de simulações Monte Carlo (MC) para o intervalo de energia de 5-150 keV. A Figura 5 apresenta a curva de eficiência obtida por estes autores a partir das funções resposta simuladas. Os pontos experimentais foram obtidos através espectros de fontes radioativas. 


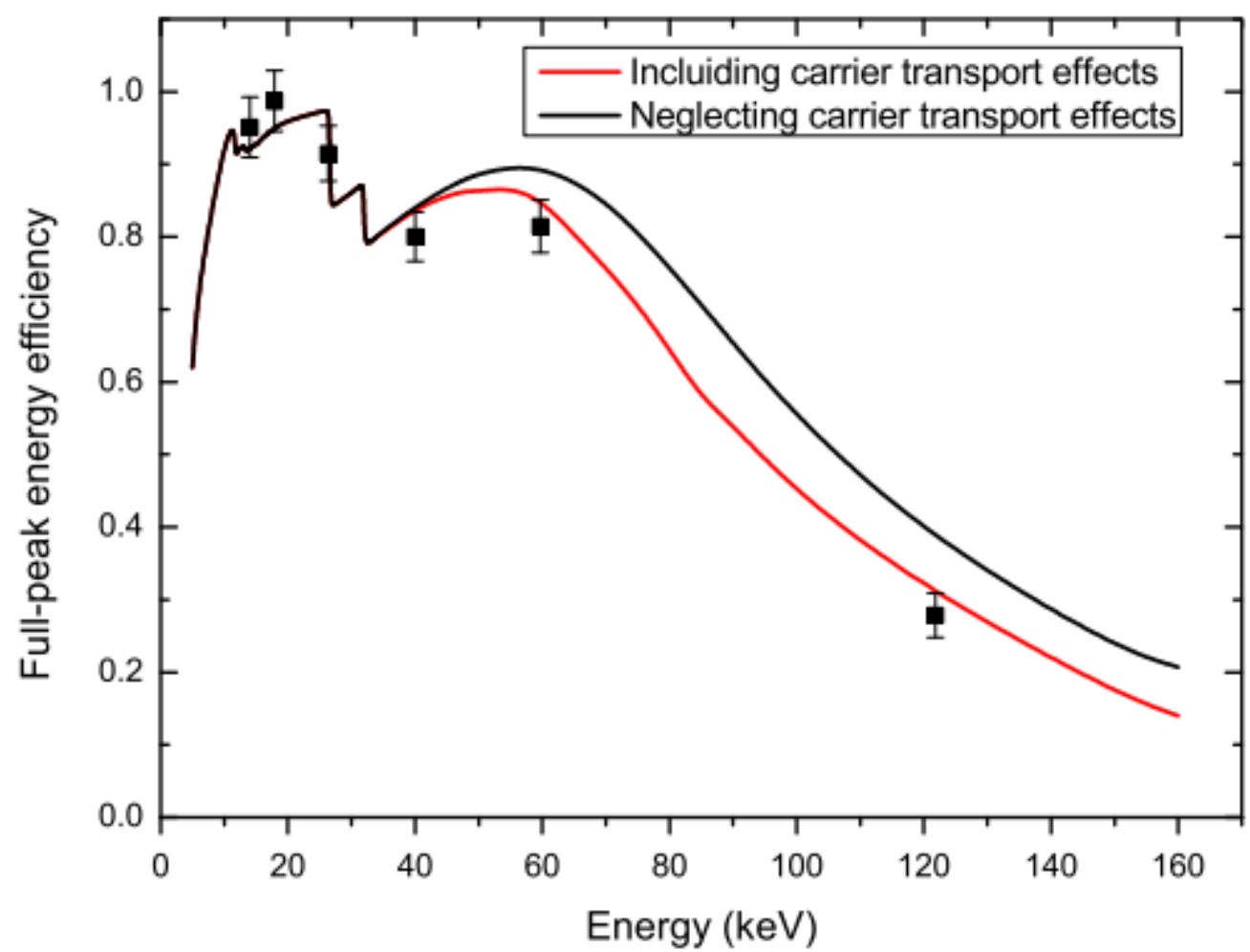

Figura 5 - Eficiência em função da energia e pontos experimentais para um detector CdTe. As curvas foram obtidas a partir de funções resposta do detector simuladas pelo método de Monte Carlo. Fonte: (Tomal et al., 2015).

\subsection{Tomografia computadorizada}

A tomografia computadorizada (TC) é um dos métodos de aquisição de imagens utilizado em radiologia diagnóstica mais populares. O método se baseia na atenuação do feixe de raios $\mathrm{X}$ que penetram o corpo do paciente.

O coeficiente mais importante usado para caracterizar a absorção de fótons (de raios X ou raios gama) em um material é o coeficiente de atenuação linear $\mu$. Este coeficiente depende da energia $E$ do fóton incidente e do número atômico $Z$ do absorvedor e pode ser descrito como a probabilidade por unidade de comprimento de caminho que um fóton terá interação com o absorvedor. Devido às diferenças nas propriedades de atenuação dos raios $\mathrm{X}$ dos diferentes tecidos que compõe o corpo humano, a imagem de TC é formada com contraste adequado para permitir a visualização das estruturas internas do paciente.

As tecnologias utilizadas em TC evoluíram substancialmente desde a criação dos primeiros tomógrafos no início dos anos 1970. Esta evolução considera desde sua capacidade para aplicações clínicas como a velocidade de aquisição de dados e formação de imagens (Russo, 2017). 
Dentre os principais avanços tecnológicos destaca-se: a TC helicoidal (Kalender et al., 1989) permitindo a rotação contínua do tubo de raios $X$ em conjunto com o detector e o TC multidetectores, aparelhos com múltiplos canais de detectores. O primeiro equipamento oferecido com esta arquitetura foi da empresa Elscint (modelo Elscint TWIN) em 1992 com cois canais. Anos depois, detectores de 64 canais (Flohr et al., 2005) e até 320 canais (Rybicki et al., 2008) foram desenvolvidos. O desenvolvimento deste tipo de equipamento foi de grande interesse nos anos 1990 pelo desejo de produzir imagens do coração e órgãos do corpo humano sem movimento do suporte de paciente (Russo, 2017).

Os sete principais componentes de um tomógrafo computadoriza multidetectores são (Russo, 2017): (i) um tubo de raios X que gera o feixe de raios X que irradia o paciente, (ii) um filtro de raios $\mathrm{X}$ que elimina fótons de baixa energia para reduzir a dose de radiação absorvida pelo paciente e ruído na imagem, (iii) um colimador após o paciente para eliminar os fótons espalhados que reduzem o contraste da imagem, (iv) uma matriz de detectores de radiação, (v) um sistema de aquisição de dados, (vi) um sistema para reconstrução de imagem e (vii) um computador para visualização dos dados.

\subsubsection{Produção de imagens de TC}

A imagem 2D gerada por um sistema de TC representa uma fatia do corpo humano com espessura equivalente à largura do corte tomográfico definido pela colimação do equipamento. Cada pixel desta imagem corresponde a um pequeno volume (ou vóxel) do corpo. O número CT é o valor de intensidade de pixel na imagem tomográfica, e está relacionado ao coeficiente de atenuação linear do material no volume representado pelo vóxel correspondente.

Neste equipamento, os raios $\mathrm{X}$ emitidos pelo tubo passam pelo paciente e o detector mede o perfil de intensidade transmitido. $\mathrm{O}$ tubo de raios $\mathrm{X}$ e o detector giram em torno do objeto a ser avaliado. Assim os perfis de atenuação são adquiridos em diferentes direções. Os coeficientes de atenuação para cada vóxel são determinados a partir destes perfis de transmissão.

Assumindo um feixe de TC monocromático com fótons de energia $E$, intensidade inicial $I_{0}$ e intensidade transmitida $I$, ao longo da reta $(r, \theta)$, representada na Figura 6 , a projeção pode ser descrita como (Russo, 2017):

$$
P=\ln \left(\frac{I_{0}}{I}\right)=\int_{-\infty}^{+\infty} \mu_{E}(x, y) d s
$$

em que 


$$
\left(\begin{array}{l}
x \\
y
\end{array}\right)=\left(\begin{array}{cc}
\cos \theta & -\sin \theta \\
\sin \theta & \cos \theta
\end{array}\right)\left(\begin{array}{l}
r \\
s
\end{array}\right)
$$

e $\mu_{E}(x, y)$ é o coeficiente de atenuação linear do tecido contido no vóxel de posição $(x, y)$.

Para os feixes de raios $\mathrm{X}$ policromáticos de equipamentos de TC, a projeção pode ser definida como (Russo, 2017):

$$
I=\int_{0}^{E_{M A ́ X}} I_{0}(E) e^{\int_{-\infty}^{+\infty} \mu_{E}(x, y) d s} d E
$$

em que $E_{M A ́ X}=e \cdot k V$, sendo $k V$ a tensão aplicada ao tubo, selecionada no protocolo de aquisição do TC. Considerando $E_{e f}$ como a energia efetiva do feixe de TC incidente, pode-se definir:

$$
\ln \left(\frac{I_{0}}{I}\right)=\int_{-\infty}^{+\infty} \mu_{E_{e f}}(x, y) d s
$$

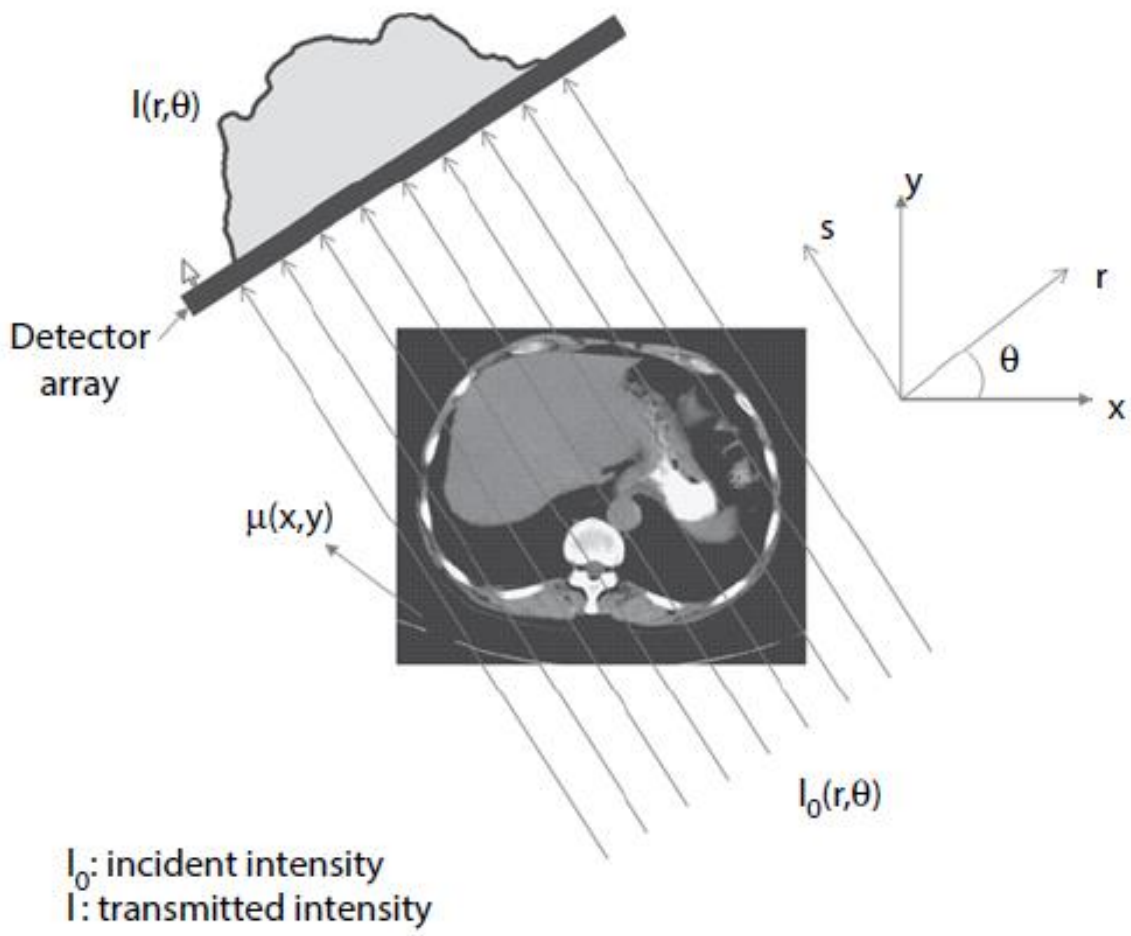

Figura 6 - Perfil de transmissão em um equipamento de TC convencional e geometria. Fonte: (Russo, 2017).

As integrais de linha $\int_{-\infty}^{+\infty} \mu_{E_{e f}}(x, y) d s$ são utilizadas para derivar os valores de $\mu_{E_{e f}}(x, y)$ a partir de métodos de reconstrução por retroprojeção ou iterativos. 
A partir dos valores estimados de $\mu_{E_{e f}}(x, y)$, pode-se derivar o valor de número CT em relação ao coeficiente de atenuação linear para água na energia efetiva do feixe de TC incidente

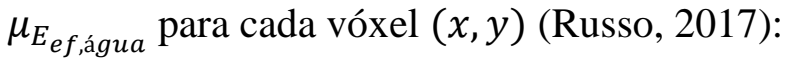

$$
H U(x, y)=1000 \times \frac{\mu_{e f}(x, y)-\mu_{e f, \text { água }}}{\mu_{e f, \text { água }}}
$$

O número CT é medido em unidades $H U$ (do inglês Hounsfield units) e, em geral, possui valores entre -1000 e 3000 . A Figura 7 apresenta valores usuais de número CT para alguns tecidos do corpo humano.

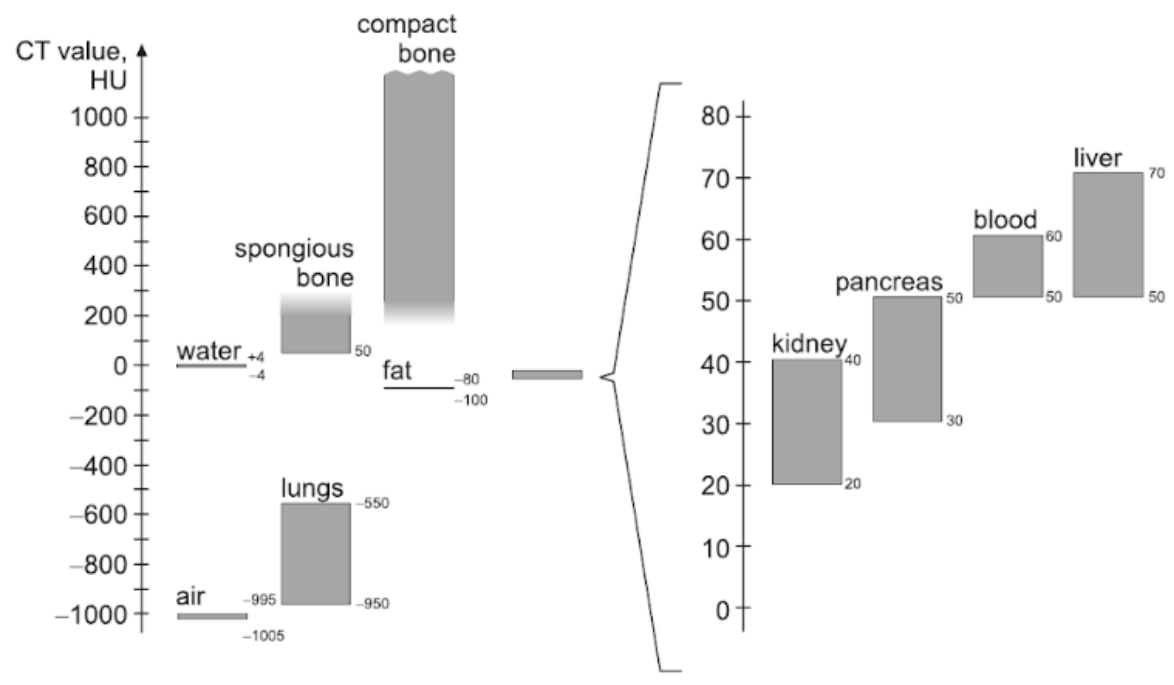

Figura 7 - Valores usuais de número CT para água, ar e alguns tecidos e órgãos do corpo humano. Fonte: Kalender (2011).

\subsubsection{Tomografia computadorizada de dupla energia}

A tomografia computadorizada de dupla energia é uma modalidade que começou a ser utilizada no final dos anos 70 (Millner et al., 1979, Genant and Boyd, 1977, Alvarez and Macovski, 1976). As imagens de TC de dupla energia são adquiridas a partir de dois espectros de raios $\mathrm{X}$ com energias diferentes com a finalidade de realçar a diferenciação entre materiais.

Como apresentado por Johnson et al. (2011) há outros dois requisitos são importantes na técnica de dupla energia. São eles o detector, que deve ser capaz de diferenciar fótons de energias diferentes, e os materiais a serem estudados. É importante que os materiais analisados possuam diferenças consideráveis nas propriedades de atenuação nos intervalos de energias 
utilizados. Como apresentado anteriormente, o coeficiente de atenuação linear de um material é a soma das contribuições dos diversos efeitos de interação da radiação com a matéria, sendo os principais: o efeito Compton, o espalhamento Rayleigh e o efeito fotoelétrico no intervalo de energias utilizada em diagnóstico por imagem. O efeito fotoelétrico depende fortemente do número atômico, $Z$. Sendo assim, essa técnica é mais eficaz para materiais com $Z$ consideravelmente diferentes.

\subsubsection{Decomposição de materiais em TC de dupla energia}

Dentro do intervalo de energia utilizado em radiodiagnóstico, o coeficiente de atenuação mássico total de um material $(\mu / \rho)_{\text {total }}$ pode ser considerado como a combinação linear dos dois componentes principais: o efeito fotoelétrico e o espalhamento Compton. As duas interações podem ser definidas fisicamente em função da energia $E$ dos fótons de raios X. Sendo assim, pode-se definir os coeficientes de atenuação mássico do efeito fotoelétrico e espalhamento Compton, em função de $f_{F}(E)$ e $f_{C}(E)$, respectivamente. Logo, o coeficiente de atenuação mássico total pode ser descrito como (McCollough et al., 2020):

$$
\left(\frac{\mu}{\rho}\right)(E)=\alpha_{F} f_{F}(E)+\alpha_{C} f_{C}(E)
$$

em que $\alpha_{F}$ e $\alpha_{C}$ representam a contribuição independente da energia dos coeficientes de atenuação mássicos do efeito fotoelétrico e do espalhamento Compton. Para determinar $\alpha_{F} \mathrm{e}$ $\alpha_{C}$ são necessárias duas medições, uma de energia baixa $E_{b}$ e uma de energia alta $E_{a}$. A partir de $E_{b}$ e $E_{a}$ podemos definir um sistema de duas equações com duas incógnitas:

$$
\left(\frac{\mu}{\rho}\right)\left(E_{b}\right)=\alpha_{F} f_{F}\left(E_{b}\right)+\alpha_{C} f_{C}\left(E_{b}\right)
$$

$\mathrm{e}$

$$
\left(\frac{\mu}{\rho}\right)\left(E_{a}\right)=\alpha_{F} f_{F}\left(E_{a}\right)+\alpha_{C} f_{C}\left(E_{a}\right)
$$

Cada material de interesse, agora pode ser representado pelo conjunto $\left(\alpha_{F}, \alpha_{C}\right)$. O efeito devido a borda $\mathrm{K}$ do material deve ser considerado nas equações caso suas contribuições sejam significativas nas medidas. Além disso, o modelo de ajuste paramétrico tem precisão limitada ao descrever materiais, pois as interações moleculares não são consideradas (Williamson et al., 2006). 
Como o objetivo principal do TC de dupla energia é facilitar a identificação de diferentes materiais, é conveniente utilizar funções de atenuação de materiais conhecidos (como água e iodo) como base para definir outros materiais de interesse. Para isso é necessário substituir as funções $f_{F}(E)$ e $f_{C}(E)$, pelas funções de atenuação mássica dos materiais base $B_{1}$ e $B_{2}$. A partir da equação (19), pode-se definir:

$$
\left(\frac{\mu}{\rho}\right)_{B_{1}}(E)=\alpha_{B_{1}, F} f_{F}(E)+\alpha_{B_{1}, C} f_{C}(E)
$$

$\mathrm{e}$

$$
\left(\frac{\mu}{\rho}\right)_{B_{2}}(E)=\alpha_{B_{2}, F} f_{F}(E)+\alpha_{B_{2}, C} f_{C}(E)
$$

em que $\alpha_{B_{1}, F}, \alpha_{B_{1}, C}, \quad \alpha_{B_{2}, F}$ e $\alpha_{B_{2}, C}$ representam as contribuições do efeito fotoelétrico e espalhamento Compton para os materiais base $B_{1}$ e $B_{2}$, respectivamente.

Resolvendo o sistema de equações para $f_{F}(E)$ e $f_{C}(E)$, é possível definir (McCollough et al., 2020):

$$
\begin{gathered}
\left(\frac{\mu}{\rho}\right)(E)=\frac{\alpha_{F} \alpha_{B_{2}, C}-\alpha_{C} \alpha_{B_{2}, F}}{\alpha_{B_{1}, F} \alpha_{B_{2}, C}-\alpha_{B_{2}, F} \alpha_{B_{1}, C}}\left(\frac{\mu}{\rho}\right)_{B_{1}}(E)+\frac{\alpha_{C} \alpha_{B_{1}, F}-\alpha_{F} \alpha_{B_{1}, C}}{\alpha_{B_{1}, F} \alpha_{B_{2}, C}-\alpha_{B_{2}, F} \alpha_{B_{1}, C}}\left(\frac{\mu}{\rho}\right)_{B_{2}}(E)= \\
\beta_{B_{1}}\left(\frac{\mu}{\rho}\right)_{B_{1}}(E)+\beta_{B_{2}}\left(\frac{\mu}{\rho}\right)_{B_{2}}(E) .
\end{gathered}
$$

\subsubsection{Imagens virtuais monoenergéticas}

Multiplicando os dois lados da equação (22) pela densidade mássica $\rho$, pode-se escrever:

$$
\begin{gathered}
\mu\left(E_{j}\right)=\beta_{B_{1}}\left(\frac{\mu}{\rho}\right)_{B_{1}}\left(E_{j}\right) \rho+\beta_{B_{2}}\left(\frac{\mu}{\rho}\right)_{B_{2}}\left(E_{j}\right) \rho, j=b, a \\
\mu\left(E_{j}\right)=\left(\frac{\mu}{\rho}\right)_{B_{1}}\left(E_{j}\right) \rho_{B_{1}}+\left(\frac{\mu}{\rho}\right)_{B_{2}}\left(E_{j}\right) \rho_{B_{2}} \rho, j=b, a
\end{gathered}
$$

em que $E_{b}$ e $E_{a}$ representam duas medidas de espectros diferentes utilizando baixa e alta energia respectivamente. As densidades dos materiais base $B_{1}$ e $B_{2}$ são obtidos resolvendo a equação (23) pixel a pixel. 
A partir das densidades dos materiais base $B_{1}$ e $B_{2}$, a imagem virtual monoenergética de energia base $E_{m}$ pode ser gerada a partir da equação:

$$
\mu\left(E_{m}\right)=\left(\frac{\mu}{\rho}\right)_{B_{1}}\left(E_{m}\right) \rho_{B_{1}}+\left(\frac{\mu}{\rho}\right)_{B_{2}}\left(E_{m}\right) \rho_{B_{2}}
$$

\subsubsection{TC de dupla energia via troca rápida de tensão}

Existem cinco técnicas diferentes para aquisição de dados implementadas em equipamentos de TC disponíveis atualmente no mercado. São eles: aquisição consecutiva, dupla tubo de raios $\mathrm{X}$, troca rápida de tensão, detector de dupla camada e dupla filtração do feixe.

O equipamento utilizado neste estudo foi o GE Discovery CT 750 HD GSI (GE Healthcare, Milwakee, WI) do Instituto de Radiologia do Hospital das Clínicas da Faculdade de Medicina da USP ${ }^{1}(\mathrm{InRaD})$. Este equipamento funciona com troca rápida de tensão no tubo, que é intercalada entre baixa e alta enquanto os perfis de intensidade são medidos.

As tensões utilizadas neste equipamento são de 80 e $140 \mathrm{kV}$. As energias efetivas desses espectros são, aproximadamente, 48 e $62 \mathrm{keV}$, respectivamente (Puerto, 2018). Ao longo do arco de rotação de $360^{\circ}$, os dados de projeção são adquiridos duas vezes (uma para baixa e outra para alta tensão) na mesma posição, aproximadamente, da fonte de raios X. O cintilador de oxissulfeto de gadolíneo utilizado nos equipamentos da GE permite que a aquisição dos dados de projeção seja quase simultânea (com intervalo de troca menor que 0,5 milissegundos) (Russo, 2017).

O esquema de decomposição de materiais GSI (Gemstone Spectral Imaging) utilizado no sistema GE Discovery CT 750 HD é apresentado na Figura 8. Na imagem, o sinograma intercalado com as projeções de baixa e alta voltagem é dividido nas projeções correspondentes. A partir dessas projeções, imagens padrões de tomografia computadorizada podem ser reconstruídas. Também podem ser obtidas imagens de densidade em pares de materiais base como iodo e água. Estas imagens podem ser combinadas para criação de imagens

\footnotetext{
${ }^{1}$ Projeto 099/2017 aprovado pelo Departamento de Radiologia e Oncologia da Faculdade de Medicina da USP em 18/10/2017.
} 
monoenergéticas em qualquer nível de energia possível (de $40 \mathrm{keV}$ a $140 \mathrm{keV}$ para o Discovery CT 750).

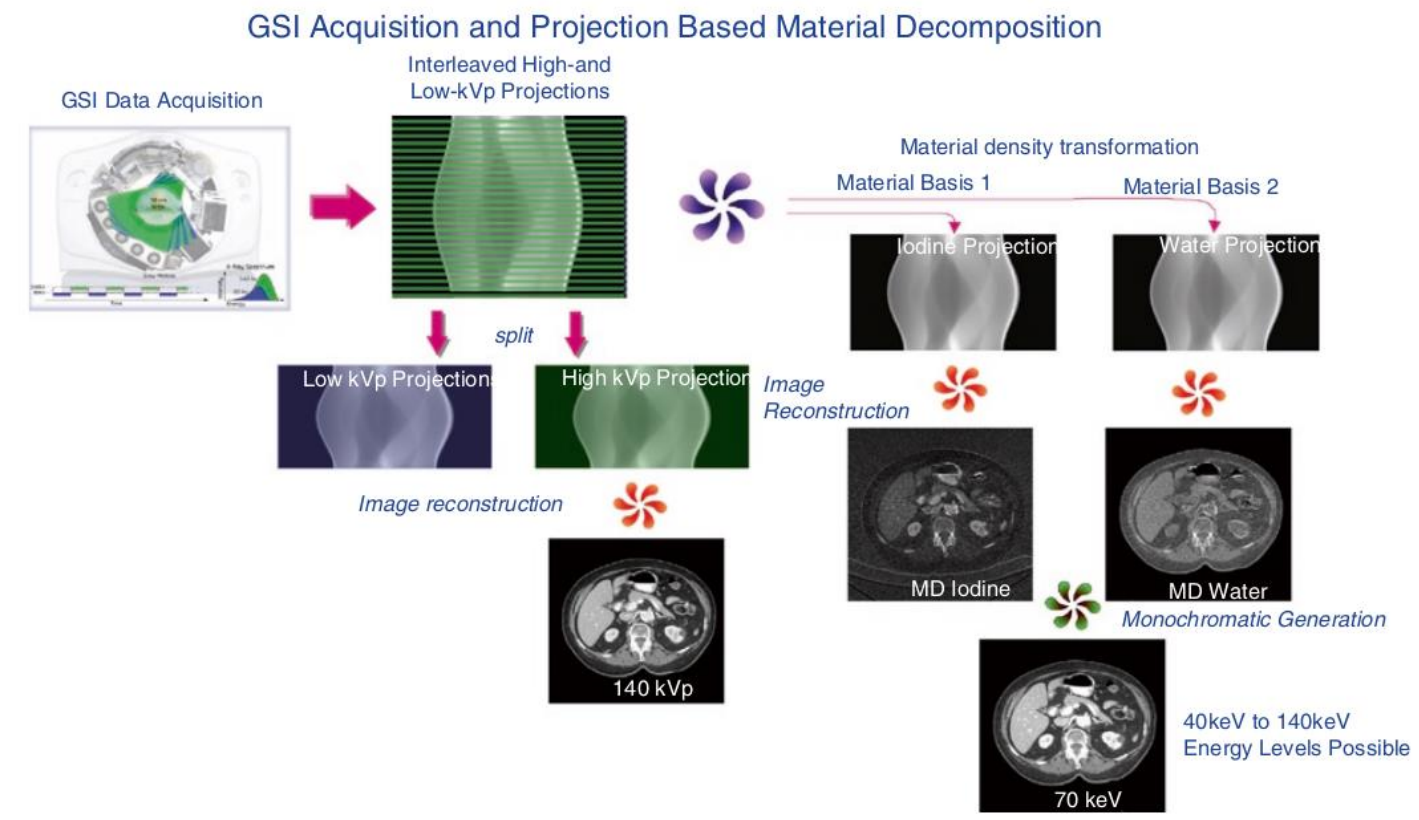

Figura 8 - Esquema do processo de reconstrução de imagem no Discovery CT 750 HD. Fonte: (Chandra and Langan, 2011). 


\section{Materiais e métodos}

Este capítulo foi organizado em cinco seções que explicitam os materiais e métodos utilizados neste trabalho. A Figura 9 ilustra as etapas executadas no processo de análise dos materiais radiologicamente equivalentes. Foram estudadas dezessete amostras produzidas a partir de quatorze formulações de materiais radiologicamente equivalentes ao tecido humano e à água. Como apresentado no capítulo 1, o principal objetivo deste trabalho foi o estudar métodos experimentais para validar materiais radiologicamente equivalentes à água e a tecidos humanos. O método principal utilizado foi a espectrometria por raios X. Porém mais quatro estudos foram realizados para caracterização dos materiais produzidos: a determinação da densidade mássica, a determinação do número atômico efetivo, análise de imagens de tomografia computadorizada e análise de imagens de tomografia de dupla energia.

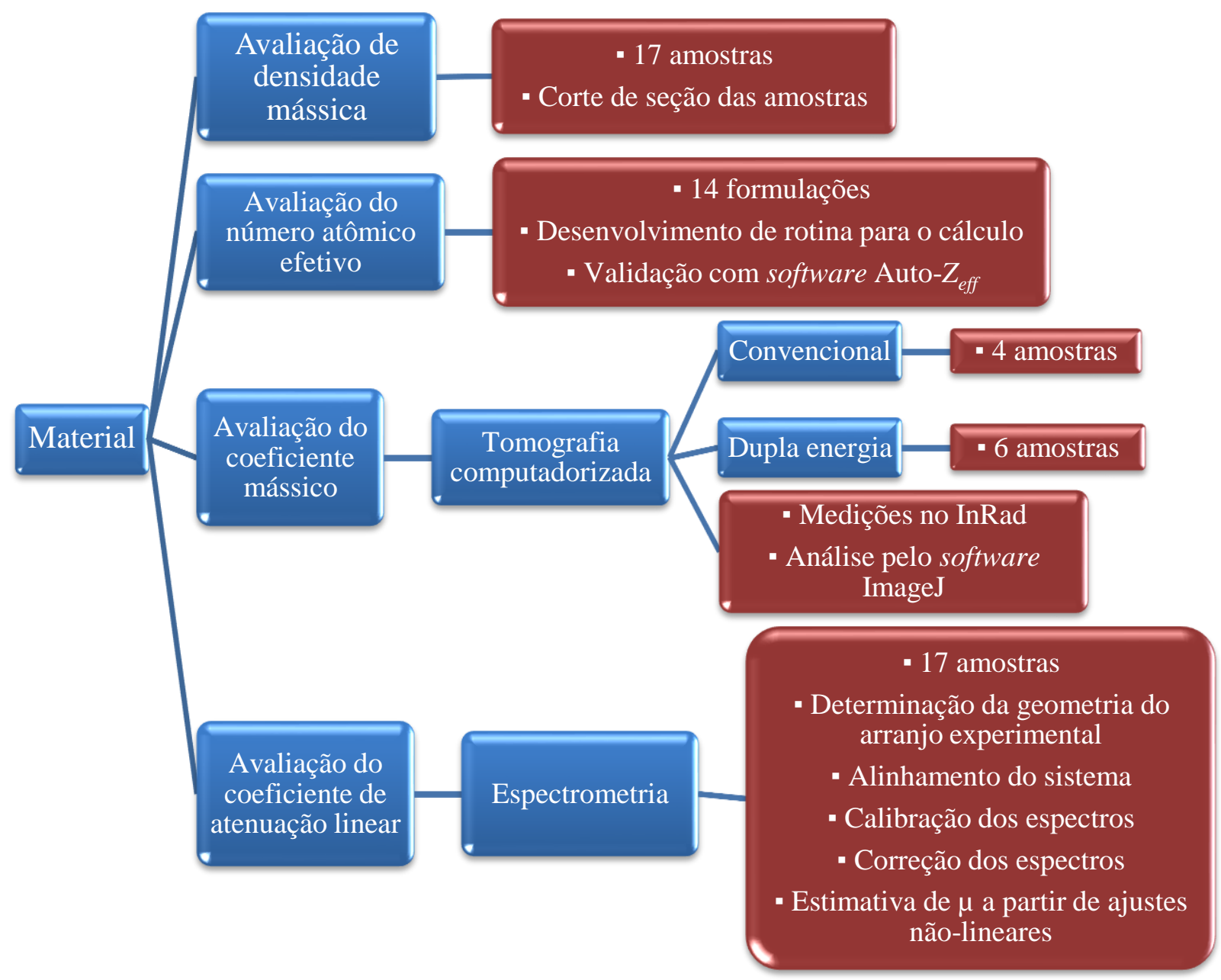

Figura 9 - Diagrama do processo de análise dos materiais radiologicamente equivalentes. 
3.1 Materiais radiologicamente equivalentes ao tecido humano e água

Neste trabalho foram estudadas dezessete amostras, sendo nove amostras de materiais radiologicamente equivalentes à água, quatro amostras de materiais radiologicamente equivalentes ao tecido mole (White et al., 1987) e quatro amostras de materiais radiologicamente equivalentes a simuladores comerciais de tecido mamário: CIRS BR12 e CIRS 70/30 (CIRS, inc, Norfolk, VA, EUA). O CIRS BR12 foi desenvolvido para simular a composição do tecido mamário com $47 \%$ de tecido glandular e $53 \%$ de tecido adiposo (White et al., 1987). O CIRS 70/30 foi desenvolvido para simular 70\% de tecido glandular e $30 \%$ de tecido adiposo.

A composição química elementar dos materiais utilizados como referência neste trabalho é apresentada na Tabela 1. Para o tecido mole, os valores de percentual em massa dos elementos químicos representam a média da composição elementar de tecidos moles do corpo humano com 60 a $80 \%$ de conteúdo de água em sua massa como definido por White et al. (White et al., 1987).

Tabela 1 - Composição química elementar dos materiais utilizados como referência neste trabalho.

\begin{tabular}{|c|c|c|c|c|c|}
\hline \multirow[b]{2}{*}{ Materiais } & \multicolumn{5}{|c|}{ Composição química elementar (\% em massa) } \\
\hline & $\mathrm{H}$ & $\mathrm{C}$ & $\mathrm{N}$ & $\mathrm{O}$ & Elementos com $Z>8$ \\
\hline Água líquida ${ }^{1}$ & 11,1898 & - & - & 88,8102 & - \\
\hline CIRS BR $12^{2}$ & 8,68 & 69,95 & 2,37 & 17,91 & $0,14 \mathrm{Cl} ; 0,95 \mathrm{Ca}$ \\
\hline CIRS $70 / 30^{3}$ & $11,72(6)$ & $73,78(7)$ & $1,30(4)$ & $12,44(25)$ & $0,76(8) \mathrm{Ca}$ \\
\hline Tecido mole ${ }^{4}$ & 10,2 & 14,3 & 3,4 & 70,8 & $\begin{array}{r}0,2 \mathrm{Na} ; 0,3 \mathrm{P} ; 0,3 \mathrm{~S} ; \\
0,2 \mathrm{Cl} ; 0,3 \mathrm{~K}\end{array}$ \\
\hline $\begin{array}{l}{ }^{1} \text { (Hubbell and } \\
2 \text { (White et al., } \\
3 \text { (Poletti et al., } \\
4 \text { (White et al., }\end{array}$ & $\begin{array}{l}\text { zer, 1996) } \\
\text { 7) } \\
\text { 2) } \\
\text { 7) }\end{array}$ & & & & \\
\hline
\end{tabular}

\subsubsection{Formulação dos materiais}

As formulações de materiais radiologicamente equivalentes estudadas foram obtidas a partir do método Mariano \& Costa (Mariano and Costa, 2017, Mariano, 2017). Neste método, o coeficiente de atenuação linear do material a ser desenvolvido é ajustado para o material de referência, utilizando o método dos mínimos quadrados. 
O método de Mariano \& Costa é baseado no método de Hermann e colaboradores (Hermann et al., 1986, Hermann et al., 1985) e encontra as proporções em volume de uma mistura (de um material-base e um ou mais aditivos) para obter um material resultante com valores de coeficiente de atenuação linear similares ao do material de referência em um determinado intervalo de energias. As matérias-primas utilizadas como base para produção das amostras estudadas neste trabalho são poliméricas e estão descritas na Tabela 2.

Tabela 2 - Materiais utilizados como base na produção das amostras de materiais radiologicamente equivalentes ao tecido humano e água. Fonte: (Frimaio, 2019)

\begin{tabular}{llll}
\hline Nome & Sigla & Fórmula química & $\begin{array}{l}\text { Densidade } \\
\left(\mathrm{g} / \mathrm{cm}^{3}\right)\end{array}$ \\
\hline Resina Epóxi & $\mathrm{RE}$ & $\mathrm{C}_{2} \mathrm{H}_{3} \mathrm{O}$ & 1,11 \\
Polipropileno & $\mathrm{PP}$ & $\mathrm{C}_{3} \mathrm{H}_{6}$ & 0,89 \\
\hline
\end{tabular}

Os polímeros podem ser classificados em termofixos e termoplásticos. Esta classificação está relacionada ao comportamento do material quando sujeito à elevação da temperatura e está associado à estrutura molecular dominante do polímero (Callister, 2000). Doze amostras de materiais e mais três amostras replicatas foram produzidos em laboratório com base de resina epóxi (polímero termofixo) e duas amostras de materiais foram produzidos com base de polipropileno (polímero termoplástico) pelo processo industrial de moldagem por injeção.

As formulações (em percentual mássico) utilizadas para produção das amostras de materiais radiologicamente equivalentes ao tecido humano e à água estudadas são apresentadas na Tabela 3 juntamente com as siglas utilizadas para sua identificação. As formulações estudadas são compostas por um material-base (resina epóxi ou polipropileno) e um aditivo (óxido de magnésio, óxido de titânio, carbonato de cálcio, entre outros).

A escolha das formulações para produção das amostras foi baseada nos melhores valores de qui-quadrado reduzido do ajuste dos mínimos quadrados feito pelo método de Mariano \& Costa e no número atômico efetivo calculado (Johns and Cunningham, 1983) a partir da formulação obtida. Os valores de qui-quadrado reduzido e número atômico efetivo, bem como detalhes de como a seleção das formulações produzidas foram publicados por Frimaio (Frimaio, 2019). 
Tabela 3 - Formulação em massa das amostras de materiais radiologicamente equivalentes ao tecido humano e a água estudadas.

\begin{tabular}{|c|c|c|}
\hline Nome & Material de referência & $\begin{array}{l}\text { Formulação } \\
\text { (em percentual mássico) }\end{array}$ \\
\hline AG1 & Água líquida ${ }^{1}$ & $98 \% \mathrm{RE}+2 \% \mathrm{MgO}$ \\
\hline $\mathrm{AG} 1 *$ & Água líquida ${ }^{1}$ & $98 \% \mathrm{RE}+2 \% \mathrm{MgO}$ \\
\hline AG2 & Água líquida $^{1}$ & $98 \% \mathrm{RE}+1 \% \mathrm{TiO}_{2}$ \\
\hline $\mathrm{AG} 2 *$ & Água líquida ${ }^{1}$ & $98 \% \mathrm{RE}+1 \% \mathrm{TiO}_{2}$ \\
\hline AG3 & Água líquida ${ }^{1}$ & $99 \% \mathrm{RE}+1 \% \mathrm{CaCO}_{3}$ \\
\hline $\mathrm{AG} 3 *$ & Água líquida ${ }^{1}$ & $99 \% \mathrm{RE}+1 \% \mathrm{CaCO}_{3}$ \\
\hline AG4 & Água líquida ${ }^{1}$ & $99 \% \mathrm{RE}+1 \% \mathrm{KI}$ \\
\hline AG5 & Água líquida ${ }^{1}$ & $99 \% \mathrm{RE}+1 \% \mathrm{CaF}_{2}$ \\
\hline AG6 & Água líquida ${ }^{1}$ & $99 \% \mathrm{RE}+1 \% \mathrm{CaO}$ \\
\hline MA1 & CIRS 70/30 & $97 \% \mathrm{RE}+3 \% \mathrm{MgO}$ \\
\hline MA7 & CIRS $70 / 30^{2}$ & $99 \% \mathrm{RE}+1 \% \mathrm{NaCl}$ \\
\hline MA8 & CIRS BR $12^{3}$ & $81 \% \mathrm{PP}+19 \% \mathrm{MgO}$ \\
\hline MA9 & CIRS BR $12^{3}$ & $93 \% \mathrm{PP}+7 \% \mathrm{CaF}_{2}$ \\
\hline TM1 & Tecido mole ${ }^{4}$ & $94 \% \mathrm{RE}+6 \% \mathrm{MgO}$ \\
\hline TM2 & Tecido mole ${ }^{4}$ & $98 \% \mathrm{RE}+2 \% \mathrm{TiO}_{2}$ \\
\hline TM3 & Tecido mole ${ }^{4}$ & $97 \% \mathrm{RE}+3 \% \mathrm{CaCO}_{3}$ \\
\hline TM6 & Tecido mole ${ }^{4}$ & $98 \% \mathrm{RE}+2 \% \mathrm{CaO}$ \\
\hline $\begin{array}{l}* \text { Repli } \\
{ }^{*} \text { (Hubl } \\
{ }^{2} \text { (Whit } \\
{ }^{3} \text { (Polet } \\
4 \text { (Whit }\end{array}$ & $\begin{array}{l}\text { d Seltzer, 1996) } \\
\text { 1977) } \\
., 2002) \\
\text { 1987) }\end{array}$ & \\
\hline
\end{tabular}

\subsubsection{Produção em laboratório}

A resina epóxi é um polímero termofixo e pode ser endurecida quando misturada com um agente catalisador (endurecedor) em um processo denominado reação de cura. Polímeros termofixos possuem uma estrutura tridimensional em rede com ligações cruzadas. Depois de endurecido, o material se torna duro e não se deforma com o aumento da temperatura.

Neste trabalho, quinze amostras foram produzidas com resina epóxi como materialbase. Para sua produção, primeiramente o aditivo foi incorporado ao endurecedor e, posteriormente, esta mistura foi adicionada à resina epóxi. A mistura foi homogeneizada manualmente e o endurecedor foi adicionado à resina na proporção indicada pelo fabricante. A mistura final, homogeneizada, foi depositada em um molde de alumínio de dimensão $35 \times 23,5 \times 2 \mathrm{~cm}^{3}$ e curada por 24 horas. Após a cura, as peças rígidas foram desmoldadas. A Figura 10 apresenta o processo de produção em laboratório das amostras e a Figura 11 apresenta em detalhe as amostras AG2 e TM2. Para a realização dos experimentos as peças foram cortadas 
em seis placas com espessura aproximada de $1 \mathrm{~cm}$.
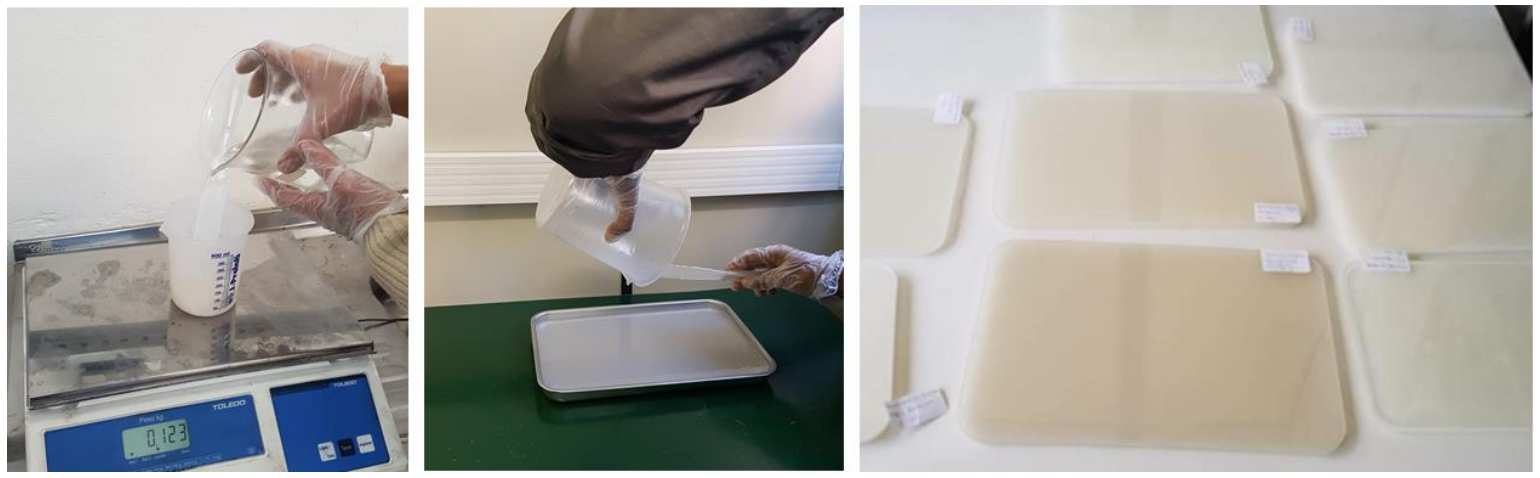

Figura 10 - Processo de produção em laboratório das amostras de materiais radiologicamente equivalentes ao tecido humano e à água. Experimento realizado no Laboratório do GDRFM do IFUSP. Fonte: a Autora, 2019.

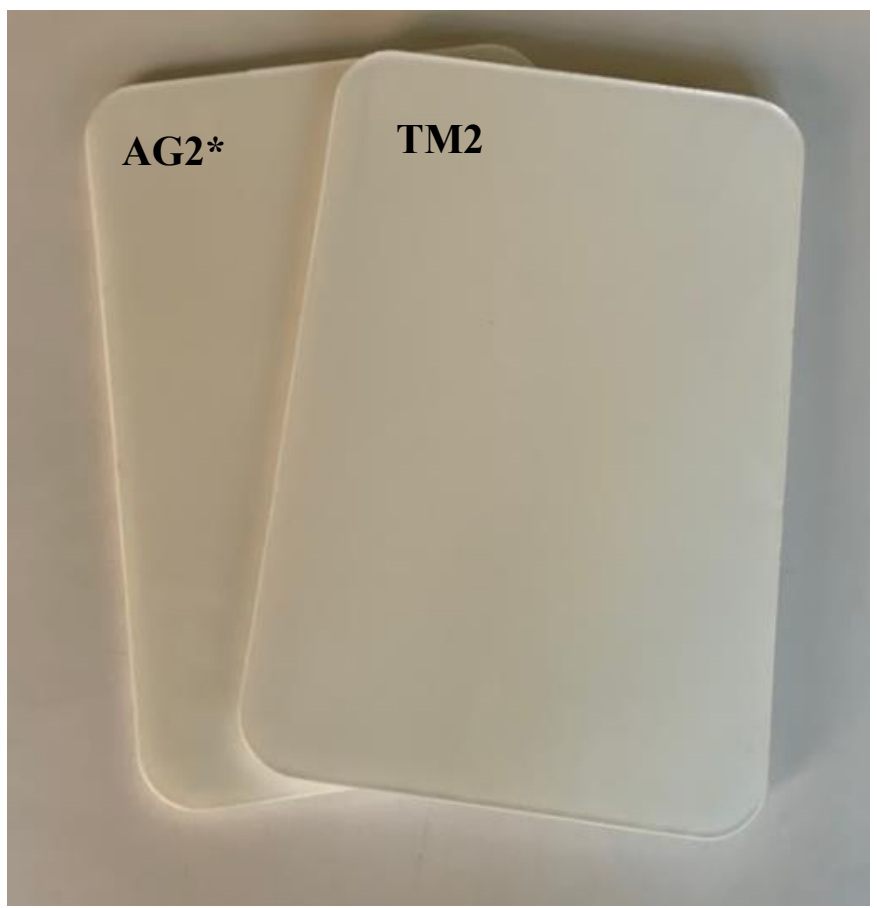

Figura 11 - Amostras AG2* e TM2 produzidos com base de resina epóxi e aditivos por reação de cura pela ação de um endurecedor. Fonte: (Frimaio, 2019).

\subsubsection{Produção industrial de moldagem por injeção}

Diferentemente dos termofixos, que se tornam permanentemente rígidos durante a sua formação, os termoplásticos amolecem quando aquecidos e endurecem quando resfriados, podendo ser conformados mecanicamente repetidas vezes. Por isso são considerados materiais 
facilmente recicláveis. Os termoplásticos compreendem a maioria dos polímeros lineares e alguns que possuem estruturas ramificadas e são fabricados normalmente com uma aplicação simultânea de calor e pressão (Callister, 2000).

O polipropileno foi utilizado neste trabalho como matéria prima para a produção de dois materiais estudados pelo processo de moldagem por injeção industrial. Um desenho esquemático de um equipamento utilizado neste processo está ilustrado na Figura 12. Neste processo, o material, em grânulos ou pó, é inserido através de uma moega ou funil para o interior de um cilindro pela movimentação de um pistão. O material é empurrado para uma câmara de aquecimento, onde é forçado ao redor de um espalhador para otimizar o contato com a parede aquecida. Ao ser aquecido, o material termoplástico se funde formado um líquido viscoso. Este líquido é empurrado pelo movimento do pistão para o interior da cavidade fechada do molde através de um bico injetor. Dentro da cavidade a pressão é mantida até que o material moldado tenha se solidificado. Após esse processo o molde é aberto e o material moldado é ejetado. Esta técnica também pode ser aplicada à materiais termofixos com a adição do processo de cura.

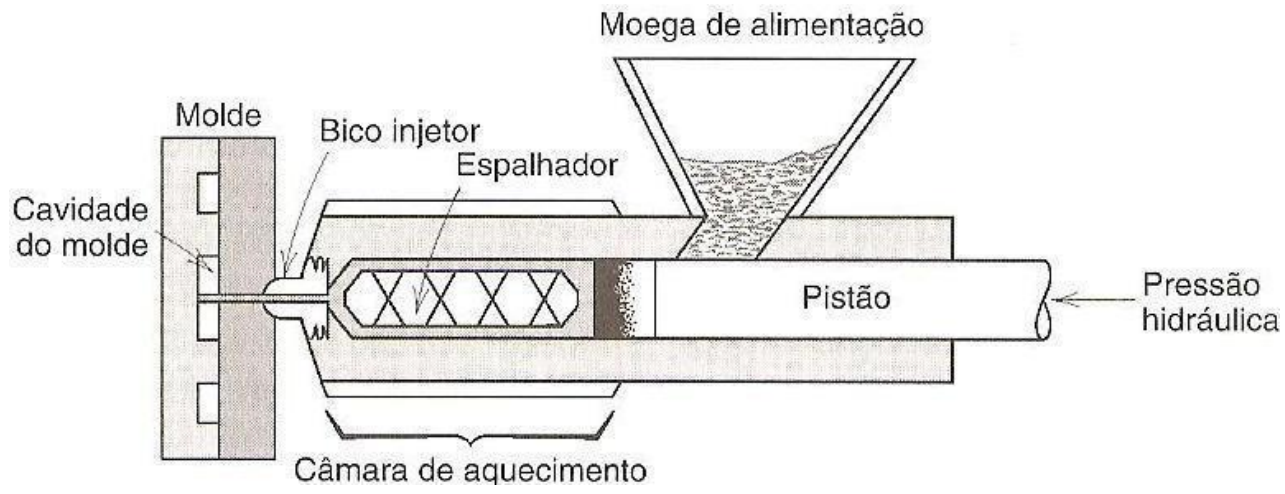

Figura 12 - Desenho esquemático de um equipamento de moldagem por injeção. Fonte: Callister (2000).

As duas amostras estudadas neste trabalho produzidas a partir do processo de moldagem por injeção foram feitas em parceria com a empresa Bevi Plastic Artefatos Plásticos Ltda. Foi utilizado uma injetora de polipropileno da marca Minzen, modelo MZ 160 e um molde exclusivo da própria empresa. Para cada material estudado foram produzidas cerca de 20 peças com espessuras aproximadas de $3 \mathrm{~mm}$. A Figura 13 apresenta uma imagem com duas dessas peças. O ciclo de produção total da peça tem duração total de 90 segundos, dos quais 35 segundos compreendem a etapa de injeção e 55 segundos compreendem ao resfriamento para desmoldagem. 


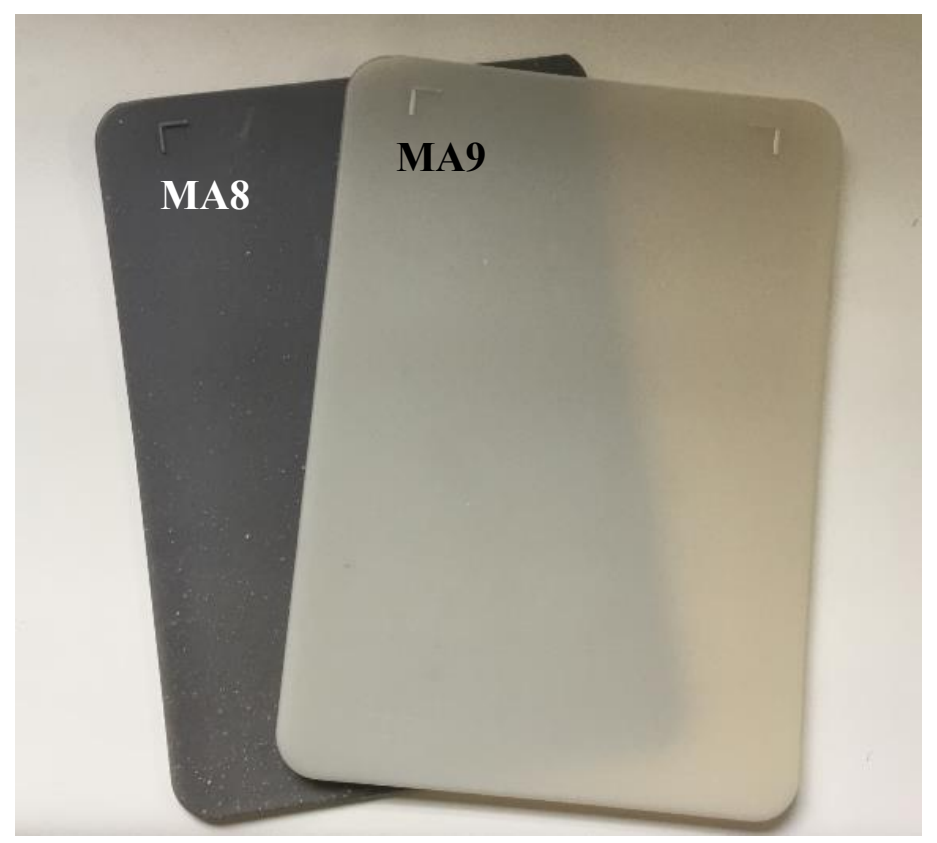

Figura 13 - Amostras MA8 e MA9 produzidas com base de polipropileno e aditivos pelo processo industrial de moldagem por injeção. Fonte: (Frimaio, 2019).

\subsection{Determinação da densidade de massa}

A densidade das amostras estudadas $\rho_{m}$ foi determinada pelo método de pesagem hidrostática, que se baseia no princípio proposto por de Arquimedes (Tomal, 2010). Para isso foram realizadas medições para determinar a massa real no ar da amostra, $M_{A}$, e a massa aparente quando a amostra está submersa em um recipiente com um líquido, $M_{L}$. A densidade pode ser então obtida por:

$$
\rho_{m}=\rho_{L} \frac{M_{A}}{M_{A}-M_{L}}
$$

em que $\rho_{L}$ é a densidade do líquido que preenche o recipiente.

O arranjo experimental utilizado está ilustrado na Figura 14. Para realização do experimento, foi retirada uma pequena seção triangular de cada material estudado. A seção foi submersa com o auxílio de um fio de náilon cuja contribuição foi determinada e extraída da estimativa de densidade das amostras.

A balança utilizada no experimento foi da marca Mettler-Toledo, modelo AE200 (Mettler-Toledo Ind. e Com. Ltda, Barueri, SP). Para cada amostra foram realizadas uma medição para a massa real e cinco medições para a massa aparente. Os materiais produzidos com base de resina-epóxi foram imersos em água destilada e os materiais produzidos com base 
de polipropileno foram imersos em álcool que possui densidade de $0,781\left(\mathrm{~g} / \mathrm{cm}^{3}\right)$ em $23^{\circ} \mathrm{C}$. Quando colocados em água destilada estas amostras não submergiam indicando possuírem uma densidade menor que a da água.

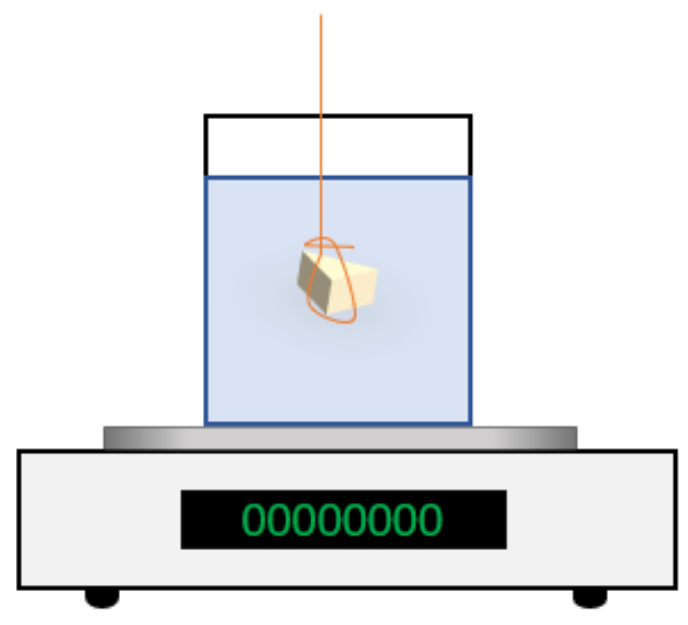

Figura 14 - Desenho do arranjo experimental utilizado para a determinação da massa aparente das amostras de materiais radiologicamente equivalentes ao tecido humano e à água.

\subsection{Algoritmo para determinação do número atômico efetivo}

Neste trabalho, os números atômicos efetivos dos materiais estudados foram calculados a partir de uma rotina desenvolvida em MATLAB versão R2015a (Matlab, 2015) pelo método descrito por Manohara et al. (Manohara et al., 2008) a partir da equação (14). Este método será identificado, daqui em diante no presente texto, por método de Manohara. Para a determinação do $Z_{e f}(E)$ o método utiliza o coeficiente de atenuação mássico, o número atômico, o peso molecular e a fração molar de cada elemento químico presente no material como informações de entrada.

$\mathrm{Na}$ validação das estimativas de $Z_{e f}(E)$ obtidas, os números atômicos dos materiais também foram calculados a partir do software Auto- $Z_{\text {eff }}$ (Taylor et al., 2012). Como parâmetros de entrada para o software foram introduzidos o número atômico e a fração mássica de cada elemento químico presente no material. O diagrama do procedimento para determinação do número atômico efetivo em função da energia $Z_{e f}(E)$ é apresentado na Figura 15. 


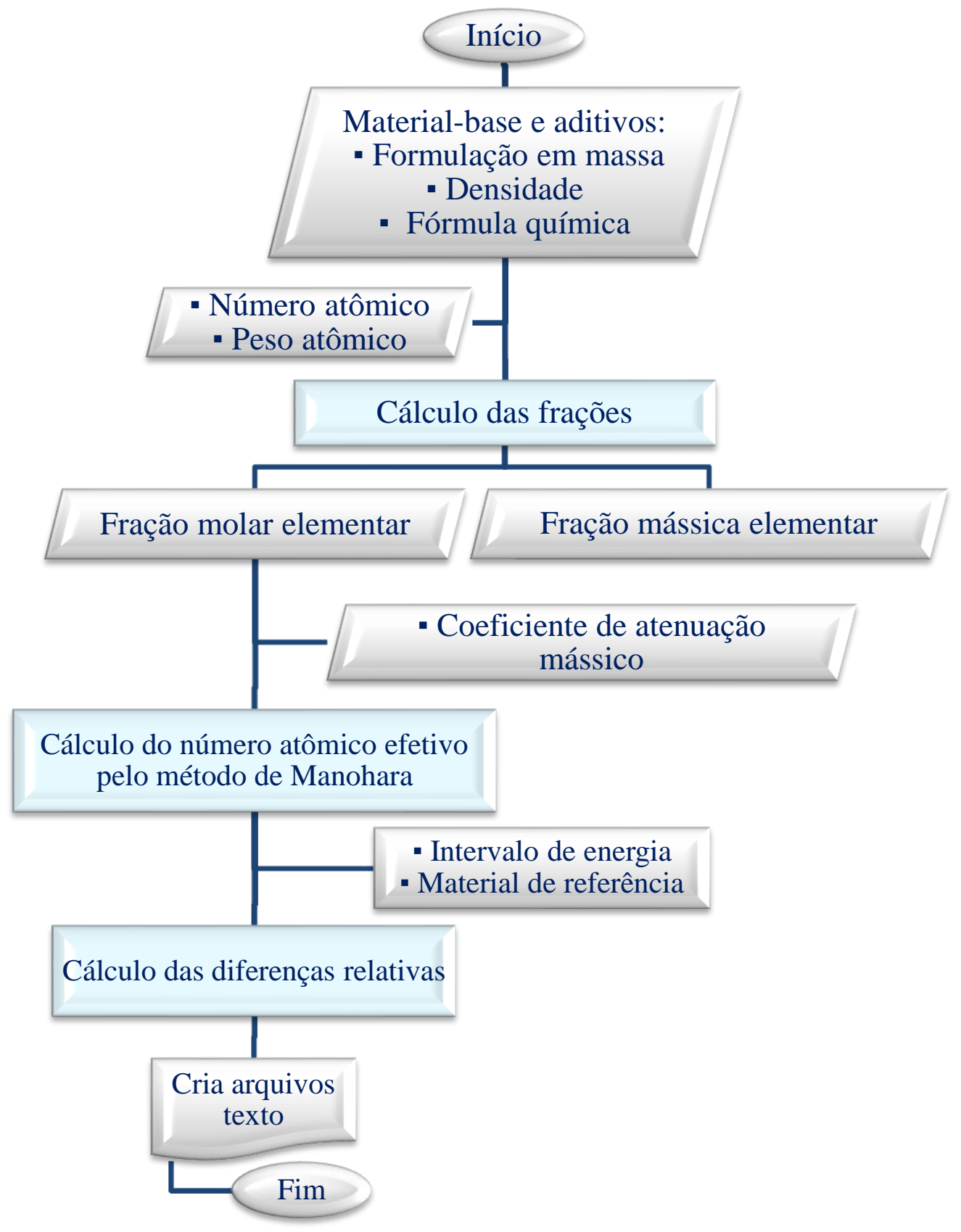

Figura 15 - Diagrama do procedimento para determinação do número atômico efetivo em função da energia dos materiais radiologicamente equivalentes ao tecido humano e à água estudados. 
As amostras estudadas no presente trabalho foram produzidas a partir de misturas de um material-base e aditivos. Sendo assim, a determinação das frações (em massa e molar) elementares foi feita a partir da rotina desenvolvida em MATLAB. Os parâmetros de entrada para esta rotina são: os valores de formulação em massa da mistura utilizada na produção do material (descrito na Tabela 3), as densidades das substâncias misturadas obtidas pelos fabricantes ou nominais e as fórmulas químicas das substâncias. O número atômico de cada elemento químico presente no material e os valores de massa atômica necessários para o cálculo de $Z_{e f}(E)$ foram extraídos do relatório técnico da IUPAC (Wieser et al., 2013).

A partir da fração molar foi realizado o cálculo de $Z_{e f}(E)$ como mostra a Figura 16. Os valores de coeficiente de atenuação mássico necessários para a rotina foram retirados do banco de dados XCOM (Berger et al., 2010). Para comparação dos resultados dos valores de $Z_{e f}(E)$ dos materiais produzidos e materiais de referência, a rotina faz o cálculo da diferença relativa em um intervalo de interesse como apresentado na Figura 17.

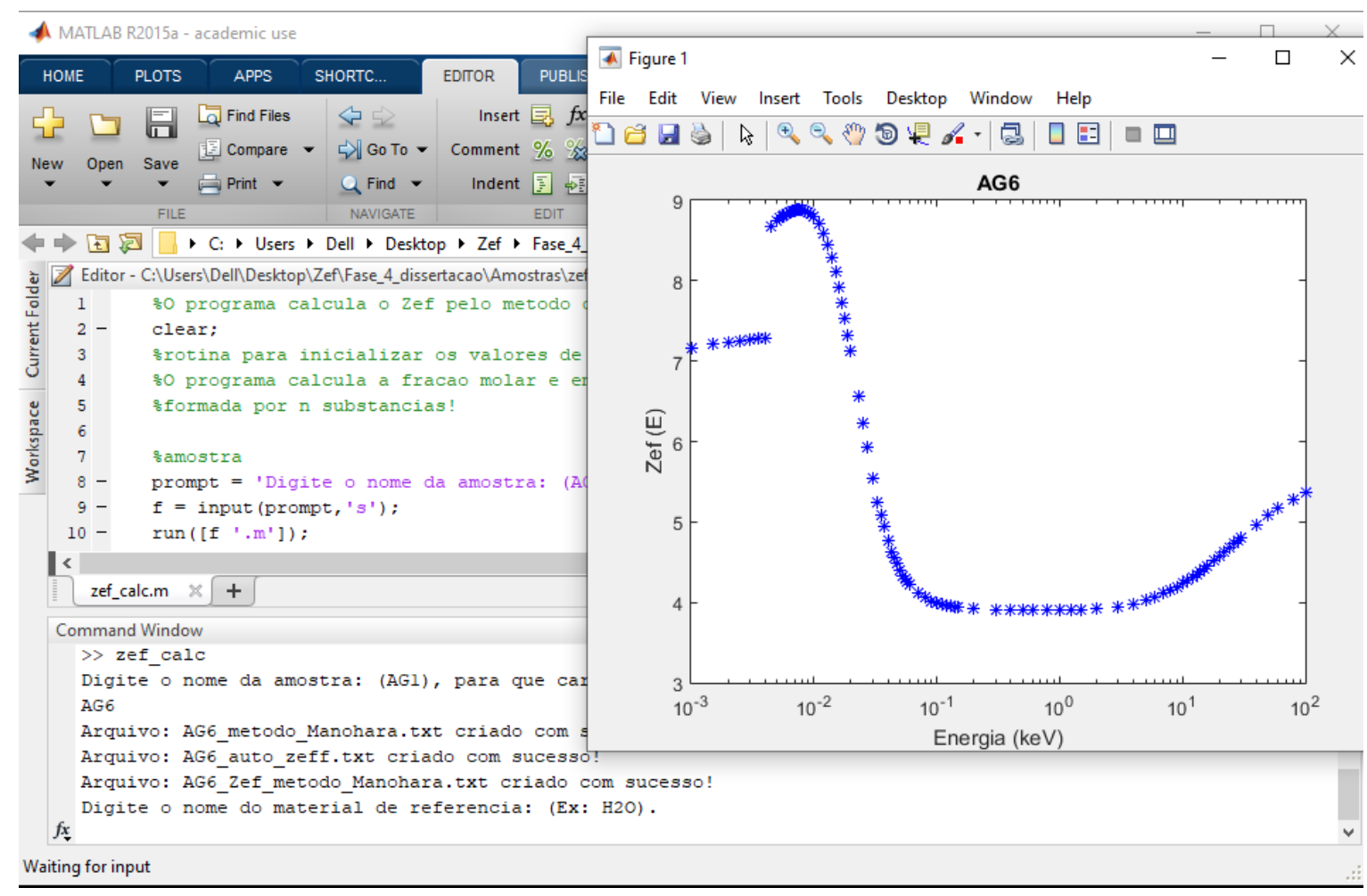

Figura 16 - Interface da rotina criada para o cálculo do número atômico efetivo. 


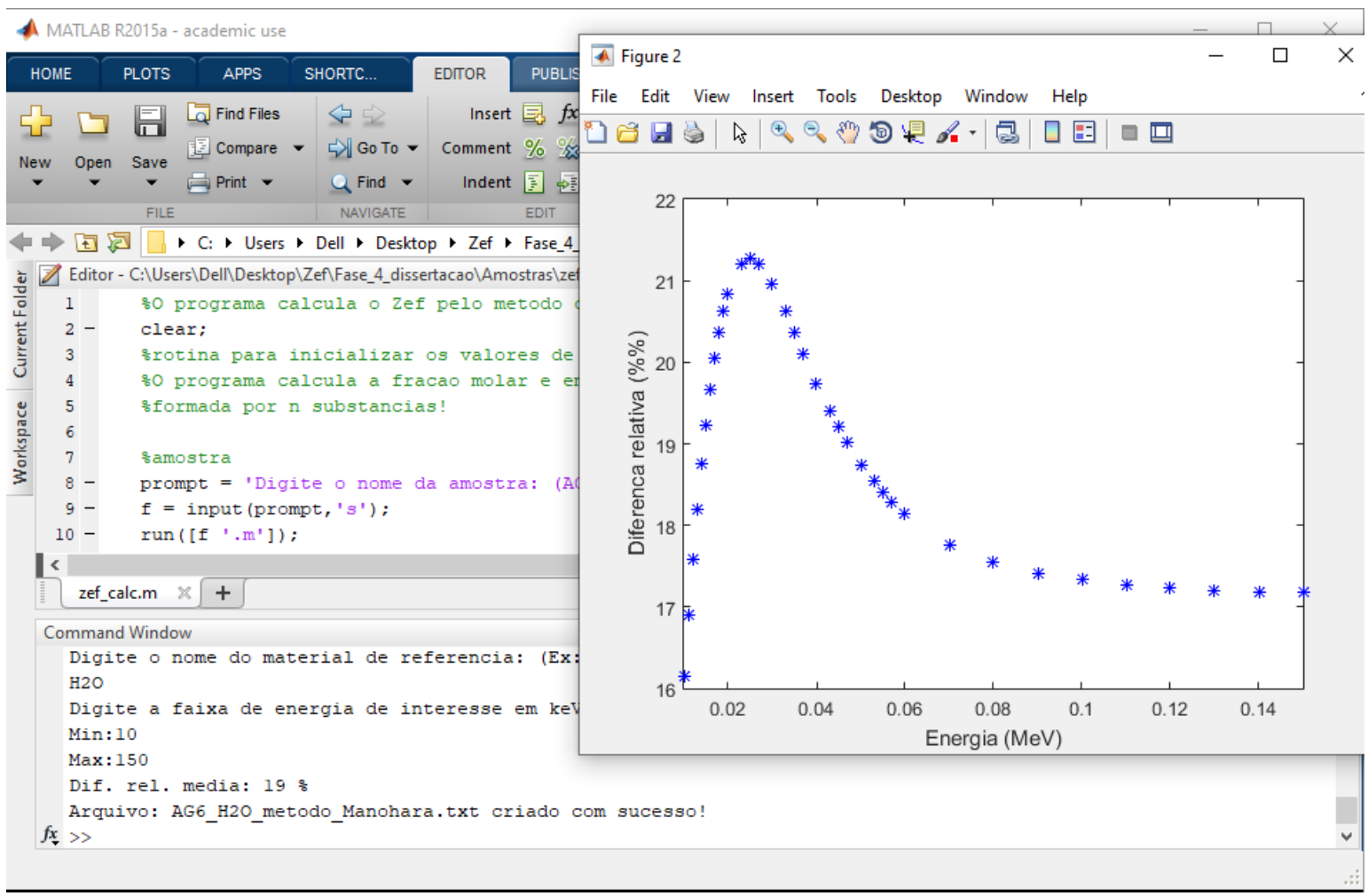

Figura 17 - Interface da rotina criada para cálculo da diferença relativa entre os valores de número atômico efetivo dos materiais produzidos em relação aos materiais de referência.

3.4 Estimativa do coeficiente de atenuação mássico utilizando imagens tomográficas

3.4.1 Metodologia utilizando números TC de imagens de tomografia computadorizada

As amostras AG1, AG2, AG3 e AG5 particionadas em seis placas com espessuras de aproximadamente $1 \mathrm{~cm}$ cada, foram agrupadas em blocos de aproximadamente $6 \mathrm{~cm}$ de comprimento. Os blocos foram posicionados no suporte de paciente de um equipamento de tomografia computadorizada de dupla energia GE Discovery CT 750 HD como apresentado na Figura 18.

As imagens de tomografia computadorizada foram obtidas seguindo os protocolos de aquisição apresentado na Tabela 4. As tensões utilizadas foram de 80, 100, 120 e $140 \mathrm{kV}$. O conjunto de imagens de cada bloco foi analisado utilizando o software ImageJ (National Institute of Health, USA) e os valores de número CT médios (NTC $\left.C_{\text {material }}\right)$ foram calculados para as amostras nas quatro tensões aplicadas. Os números CT foram obtidos a partir da definição de uma região de interesse na imagem como mostrado na Figura 19. A posição da região de interesse na imagem foi escolhida evitando regiões com bolhas ou imperfeições. 


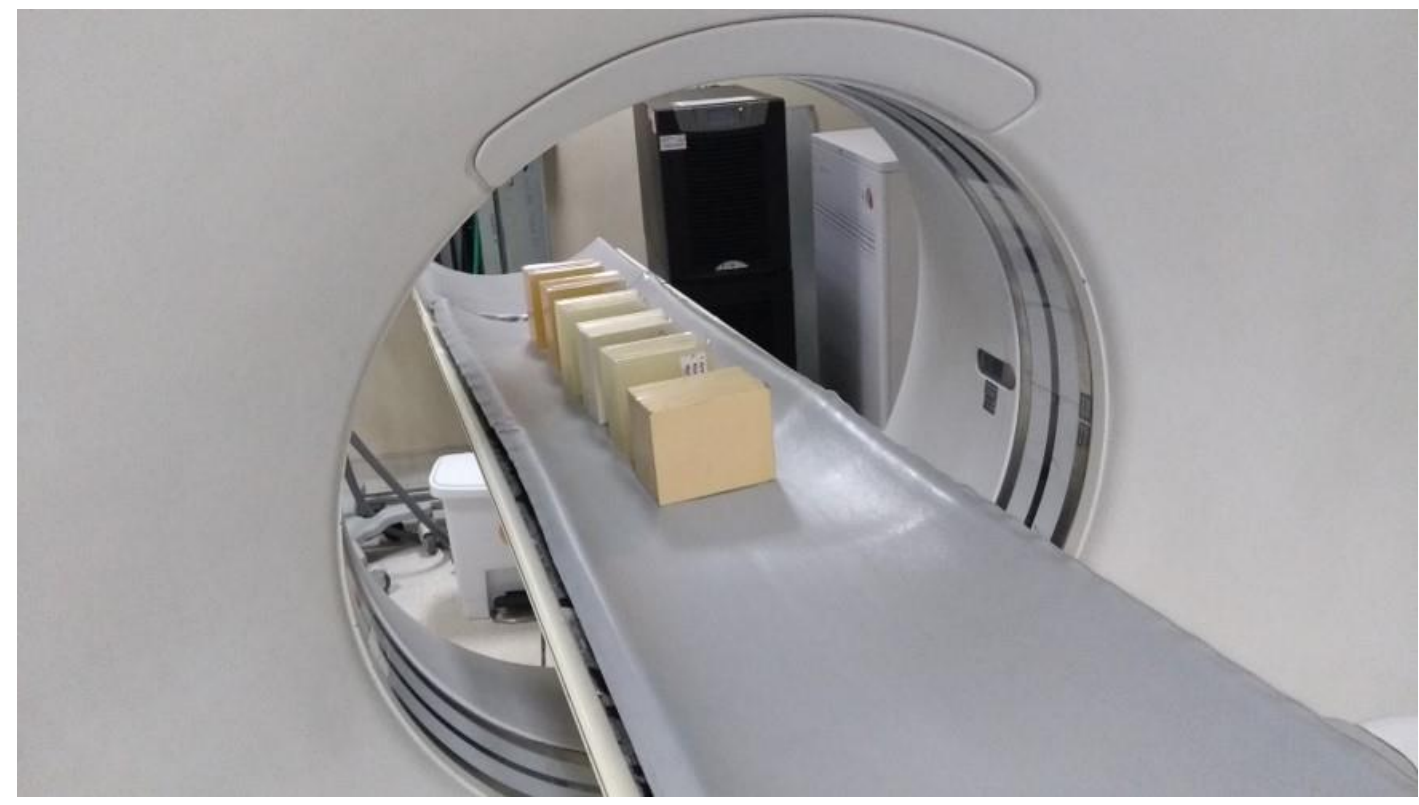

Figura 18 - Posicionamento das amostras no suporte de paciente do GE Discovery CT 750 HD do Instituto de Radiologia do HCFMUSP. Na imagem estão, também, apresentados outros materiais que não fizerem parte do presente estudo. Fonte: Denise Yanikian Nersisian, 2018.

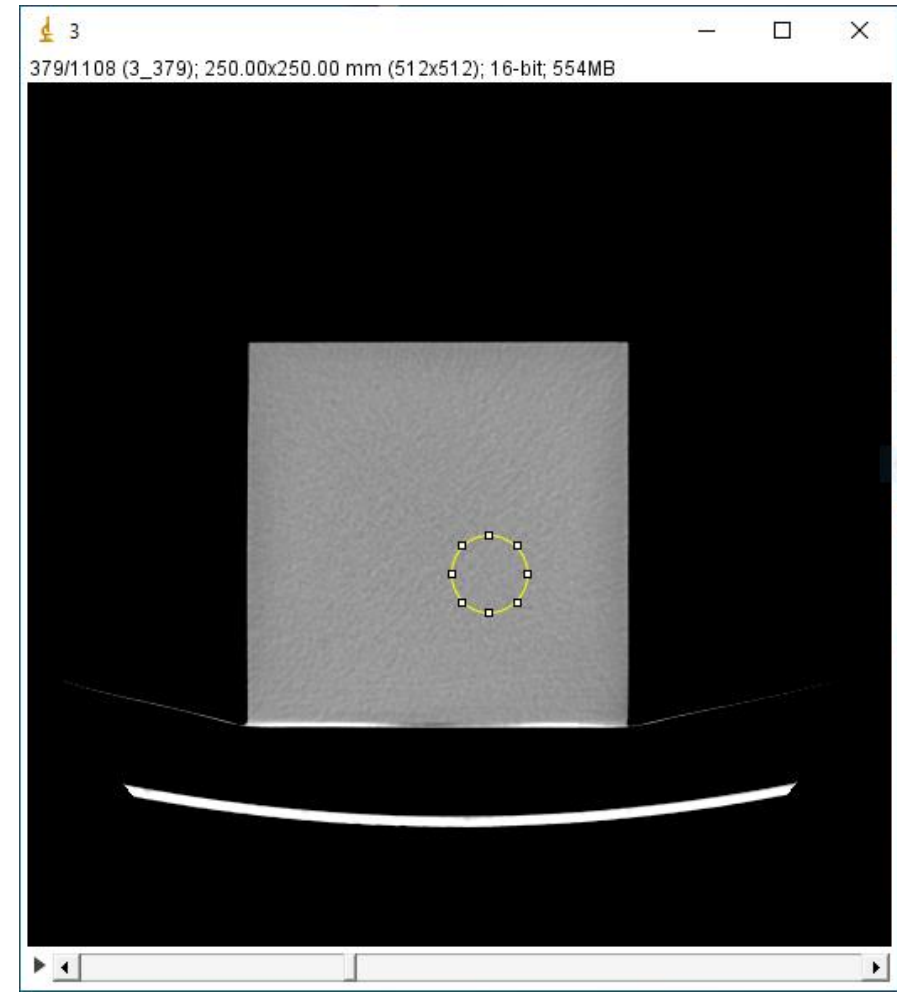

Figura 19 - Imagem de TC realizada para as amostras de materiais radiologicamente equivalentes à água estudados analisada no software ImageJ. Esta imagem representa a amostra AG3 e foi obtida utilizando a tensão de $100 \mathrm{kV}$. 
Tabela 4 - Parâmetros utilizados na aquisição das imagens de tomografia computadorizada a partir de um equipamento de tomografia de dupla energia.

\begin{tabular}{ll}
\hline Parâmetro & Valor \\
\hline Tensão $(\mathrm{kV})$ & $80,100,120$ e 140 \\
Corrente (mA) & 250 \\
Modo & Helicoidal \\
Tempo de rotação (s) & 1 \\
Pitch & 0,984 \\
Espessura de corte $(\mathrm{mm})$ & 2,5 \\
\hline
\end{tabular}

O modelo TBC modificado (Costa et al., 2007) foi utilizado para geração dos espectros de raios $\mathrm{X}$ aproximados para cada valor de tensão. Foi considerada uma filtração adicional de $6 \mathrm{~mm}$ de $\mathrm{Al}$ e um alvo de tungstênio com inclinação de $10^{\circ}$. A partir destes espectros, a energia efetiva, $E_{e f}$, associada a cada tensão aplicada é fornecida como parâmetro de saída da rotina que implementa o TBC modificado (Costa et al., 2007).

Os coeficientes de atenuação linear das amostras para cada energia efetiva determinada foram estimados utilizando a equação (26):

$$
\mu_{\text {material }}\left(E_{\text {ef }}\right)=\mu_{\text {água }}\left(E_{\text {ef }}\right)\left(1+\frac{N T C_{\text {material }}}{1000}\right)
$$

A partir dos valores dos coeficientes de atenuação linear calculados utilizando a equação (26) e das densidades mássicas experimentais foram obtidos os coeficientes mássicos para os conjuntos de amostras. Estes coeficientes foram comparados com seus correspondentes previstos utilizando a metodologia de Mariano \& Costa (Mariano and Costa, 2017, Mariano, 2017), nas mesmas energias efetivas.

3.4.2 Metodologia utilizando tomografia computadorizada de dupla energia

As amostras AG1, AG2, AG3 e AG5 radiologicamente equivalentes à água, a amostra MA7 radiologicamente equivalente ao material comercial CIRS 70/30 e as amostras MA8 e MA9 radiologicamente equivalentes ao material comercial CIRS BR12 foram avaliados pela técnica de tomografia computadorizada de dupla energia. Essas amostras foram agrupadas em blocos de duas ou três placas e foram posicionados no suporte de paciente do equipamento de tomografia computadorizada de dupla energia GE Discovery CT 750 HD como mostrado na Figura 20. 


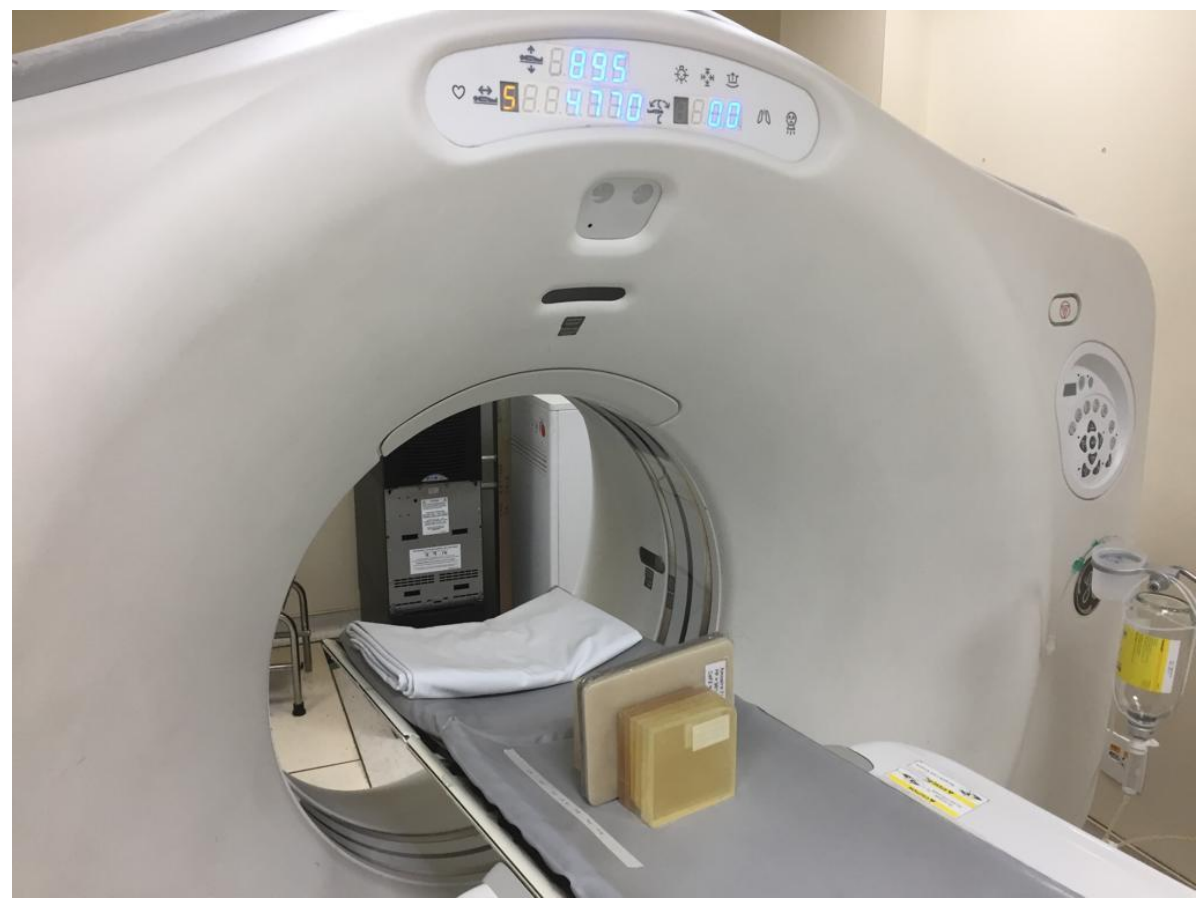

Figura 20 - Disposição das amostras estudadas em um equipamento de tomografia computadorizada de dupla energia GE Discovery CT 750 HD Gemstone Spectral Imaging (GSI) (General Electric, USA) do Instituto de Radiologia do HCFMUSP. Fonte: Denise Yanikian Nersissian, 2018.

Foram reconstruídas imagens monoenergéticas utilizando os protocolos de aquisição apresentados na Tabela 5. O conjunto de imagens foi analisado utilizando o software ImageJ (National Institute of Health, USA). Através de uma região de interesse circular desenhada na imagem foi possível obter o valor de número CT médio pela posição no suporte de paciente do tomógrafo.

Os valores de número $\mathrm{CT}$ foram calculados para os conjuntos de imagens monoenergéticas através da definição de uma região de interesse na imagem. Os coeficientes de atenuação linear das amostras produzidas foram estimados utilizando a equação (26).

Tabela 5 - Parâmetros utilizados na aquisição das imagens monoenergéticas a partir de um equipamento de tomografia de dupla energia.

\begin{tabular}{ll}
\hline Parâmetro & Valor \\
\hline Energia $(\mathrm{keV})$ & $60,70,80,90,100,110,120,130$ e 140 \\
Corrente $(\mathrm{mA})$ & 360 \\
Modo & Helicoidal \\
Tempo de rotação (s) & 0,5 \\
Pitch & 0,984 \\
Espessura de corte $(\mathrm{mm})$ & 2,5 \\
\hline
\end{tabular}


A partir dos valores dos coeficientes de atenuação linear calculados e das densidades mássicas experimentais foram obtidos os coeficientes mássicos para as amostras estudadas. Os coeficientes mássicos foram comparados com os valores correspondentes de coeficiente mássico da água e materiais comerciais CIRS BR12 e CIRS 70/30 pelo banco de dados do XCOM (Berger et al., 2010).

\subsection{Estimativa do coeficiente de atenuação linear utilizando espectroscopia por raios X}

\subsubsection{Arranjo experimental para aquisição dos espectros}

O arranjo experimental utilizado para a determinação dos coeficientes de atenuação dos materiais radiologicamente equivalentes ao tecido humano e à água foi montado no Laboratório do Grupo de Dosimetria das Radiações e Física Médica (GDRFM) do Departamento de Física Nuclear do Instituto de Física da Universidade de São Paulo. A Figura 21 mostra um esquema do arranjo experimental utilizado.

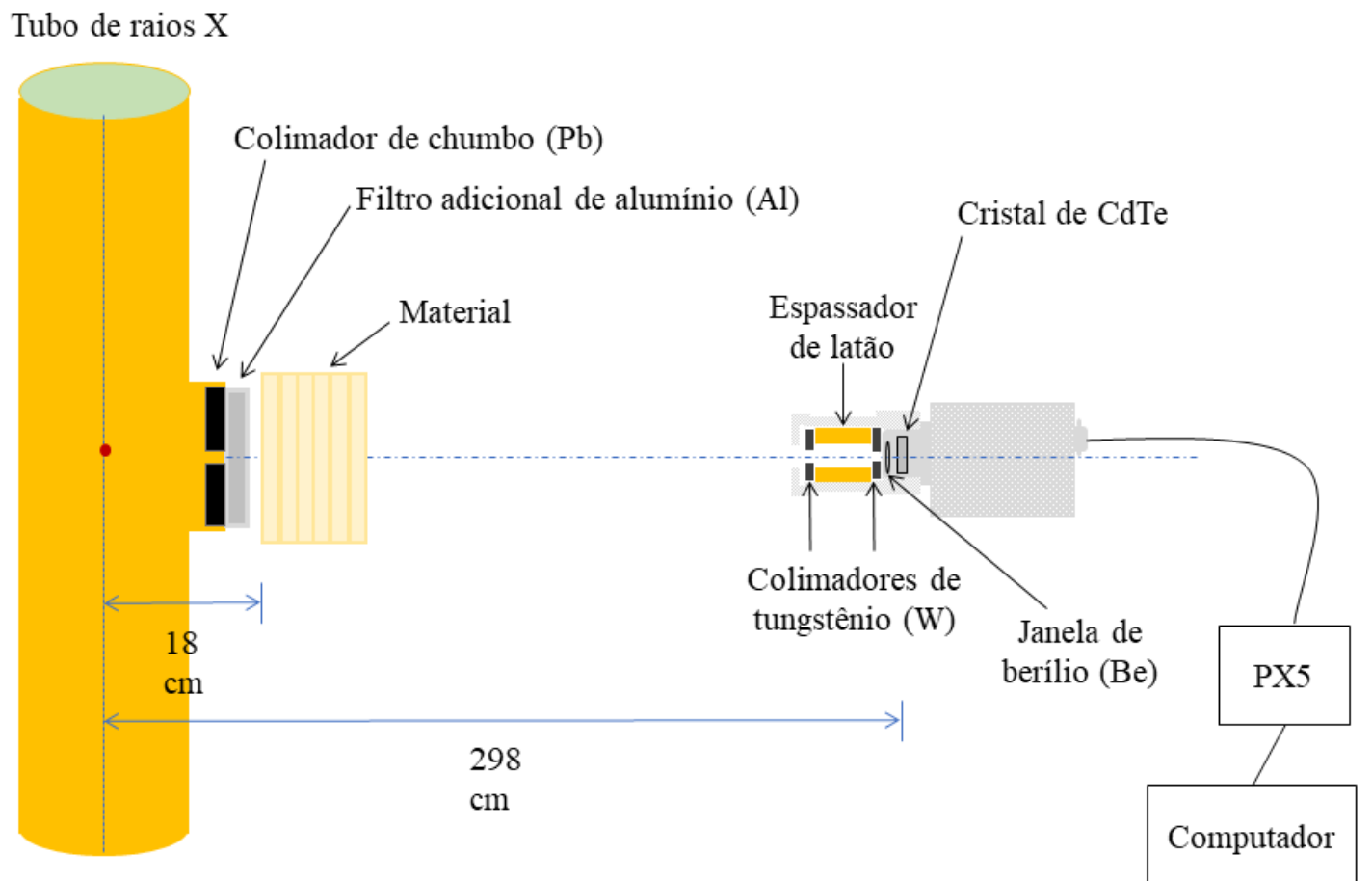

Figura 21 - Arranjo experimental utilizado na aquisição de espectros. Adaptado de (Gonzales et al., 2016). 
Para irradiação das amostras estudadas foi adotado um feixe estreito polienergético usando um tubo de raios X com alvo de tungstênio modelo X MG 450 fabricado pela Philips (Philips GmbH, Hamburgo, Alemanha), conectado a um gerador de potencial constante. Este equipamento possui uma unidade de controle modelo MGC 30 e um tubo de raios X modelo MCN 421. O equipamento possui um alvo fixo de tungstênio (W) e uma janela de berílio (Be) de 2,2 $\mathrm{mm}$. Um colimador cilíndrico de chumbo $(\mathrm{Pb})$ com espessura de 2,8 $\mathrm{cm}$ e diâmetro de $1,5 \mathrm{~mm}$ foi posicionado a $14 \mathrm{~cm}$ do ponto focal do tubo de raios $\mathrm{X}$ e um filtro adicional de 4,6 mm de alumínio foi usado após o colimador. Esta filtração foi adicionada para que o feixe correspondesse a um feixe padrão de qualidade RQR10 segundo o TRS 457 (IAEA, 2007). A Tabela 6 apresenta os parâmetros de produção do feixe de raios $\mathrm{X}$ utilizados no tubo de raios $\mathrm{X}$ para aquisição dos espectros.

Tabela 6 - Parâmetros utilizados no tubo de raios X para produção do feixe de raios X.

\begin{tabular}{ll}
\hline Parâmetro & Valor \\
\hline Tensão $(\mathrm{kV})$ & 150 \\
Corrente (mA) & 0,2 \\
Tempo de aquisição (s) & 300 \\
\hline
\end{tabular}

O sistema de detecção consistiu em um espectrômetro de telureto de cádmio (CdTe) modelo XR-100T (Amptek, inc., Bedford, MA) com $1 \mathrm{~mm}$ de espessura e 9 mm² de área, e uma janela de berílio (Be) de $100 \mu m$ (ver Figura 22). O detector é resfriado termoeletricamente (através do efeito Peltier) e manteve uma temperatura de operação de $220 \mathrm{~K}$. O detector e seu pré-amplificador estão conectados a um processador digital de pulsos modelo PX5. O PX5 fornece todas as fontes de alimentação (de alta e baixa voltagens) necessárias para o sistema e processa os pulsos de saída do pré-amplificador através de um analisador de altura de pulsos e um analisador multicanal (com até 2048). O PX5 foi conectado via USB a um computador com interface para o software de aquisição de dados DppMCA.

O detector foi posicionado a $298 \mathrm{~cm}$ do ponto focal do tubo de raios $\mathrm{X}$ e dois colimadores cilíndricos fabricados em liga de tungstênio, níquel e cobre $(90 \% \mathrm{~W}, 6 \%$ Ni e 4\% $\mathrm{Cu}$ ) e com diâmetros de $2 \mathrm{~mm}$ e $0,4 \mathrm{~mm}$, respectivamente, usados próximos do cristal de CdTe. Esses colimadores foram colocados dentro do invólucro de aço inoxidável do colimador separados por um espaçador de latão de $36 \mathrm{~mm}$ do kit de colimador de raios X EXVC da Amptek. A Tabela 7 apresenta os parâmetros para aquisição dos espectros utilizados no detector de CdTe. 


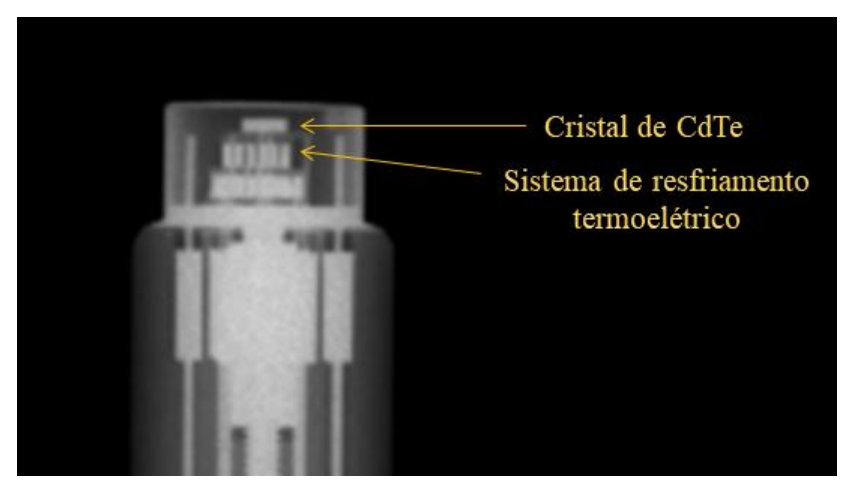

Figura 22 - Radiografia lateral do detector de CdTe realizada no Laboratório do GDRFM do IFUSP. Fonte: a Autora, 2019.

Tabela 7 - Parâmetros utilizados no detector de CdTe para aquisição dos espectros.

\begin{tabular}{ll}
\hline Parâmetro & Valor \\
\hline Canais & 1024 \\
Tempo de pico $(\mu s)$ & 5,6 \\
Ganho & 7,100 \\
Rise Time Discrimination (RTD) & Desligado \\
\hline
\end{tabular}

O detector foi alinhado utilizando um dispositivo projetado em acrílico possui em suas extremidades duas esferas de tungstênio (W) de $1 \mathrm{~mm}$ de diâmetro geometricamente alinhadas ao eixo central de detector (Santos et al., 2017). A Figura 23 apresenta o dispositivo de alinhamento acoplado a um sistema mecânico de precisão fabricados pela Optron Micromecânica Óptica Ltda que permite variações de posições lineares e angulares.

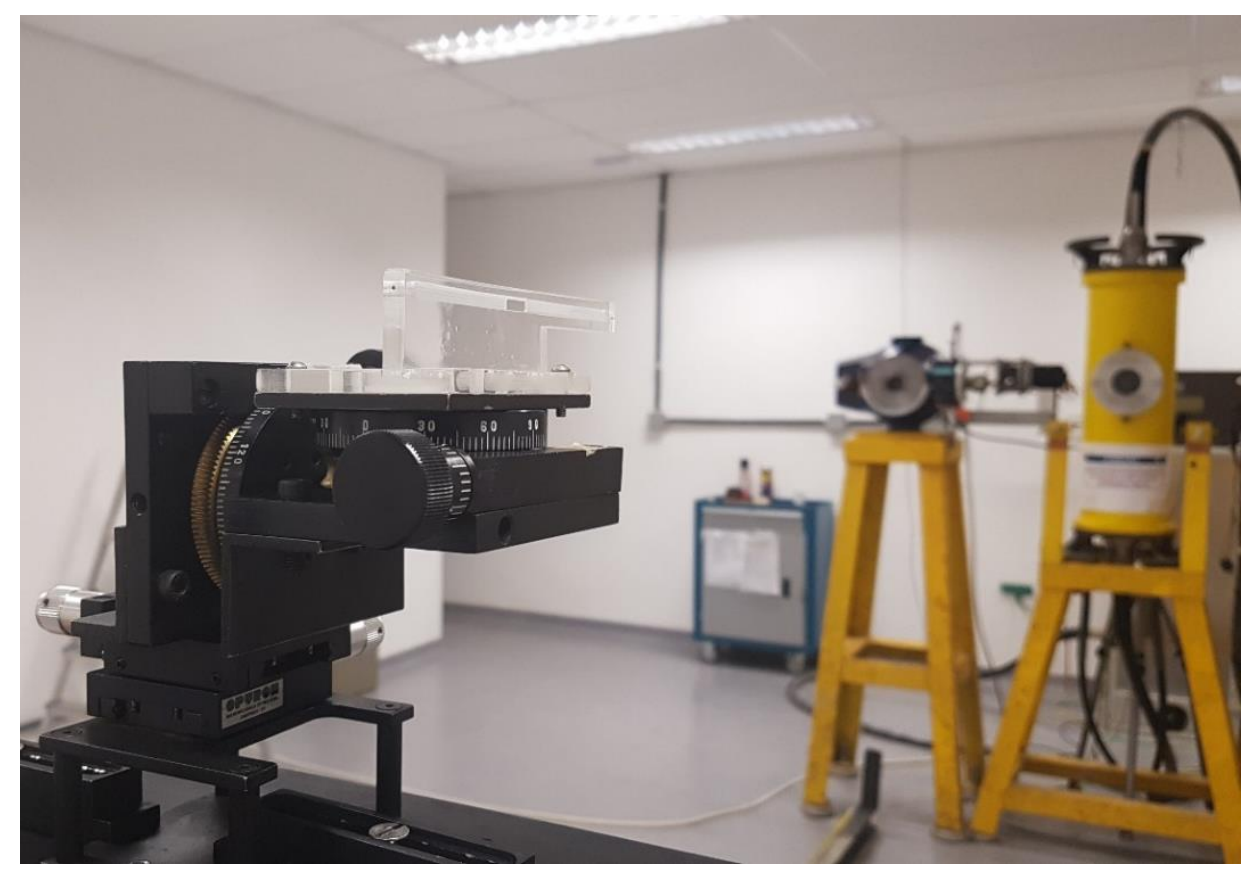

Figura 23 - Arranjo experimental para alinhamento do detector no Laboratório do GDRFM do IFUSP. Fonte: a Autora, 2019 
O procedimento para alinhamento do sistema é feito a partir da observação de imagens radiográficas adquiridas utilizando um sistema de radiografia computadorizada CR-30 (Agfa Healthcare, inc., Munique, Alemanha). A cada mudança variação de posição do sistema uma imagem é feita até que as esferas se encontrem superpostas como apresentado na Figura 24. Após o alinhamento o dispositivo foi substituído cuidadosamente pelo detector de CdTe.

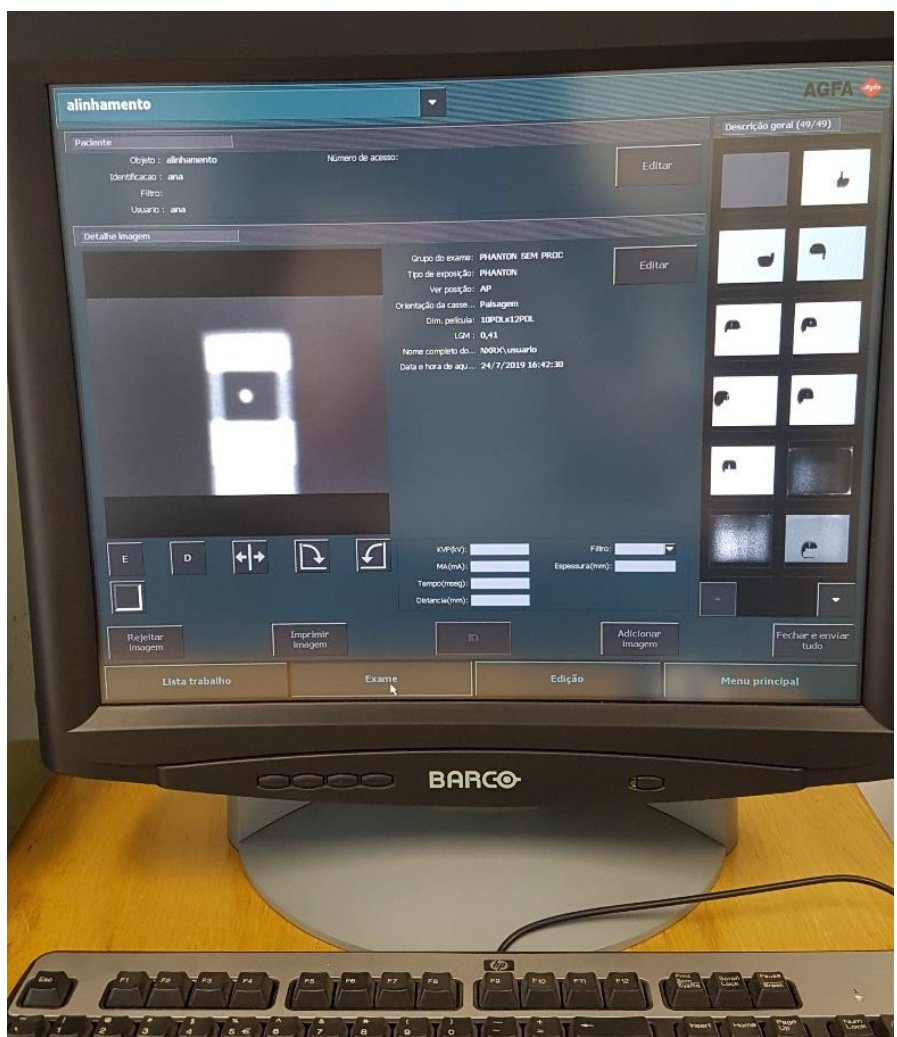

Figura 24 - Imagem radiográfica do dispositivo utilizado para alinhamento realizada no Laboratório do GDRFM do IFUSP. Fonte: a Autora, 2019.

Cada conjunto de amostras com base em resina epóxi consiste em grupos de seis placas de aproximadamente $1 \mathrm{~cm}$ de espessura cada. Em seis etapas, uma para cada corte, a espessura dos materiais foi gradualmente aumentada de aproximadamente $1 \mathrm{~cm}$ para $6 \mathrm{~cm}$. A primeira placa foi colocada a $18 \mathrm{~cm}$ da fonte do tubo de raios $\mathrm{X}$ e sucessivamente as demais placas foram adicionadas. Os materiais em base de polipropileno possuem 20 placas de aproximadamente $3 \mathrm{~mm}$ de espessura cada. Neste caso, as placas foram adicionadas em grupos de quatro, ou seja, em passos de $12 \mathrm{~mm}$. Foi utilizado um suporte de alumínio (Al) para fixar as placas de material como apresentada na Figura 25. 

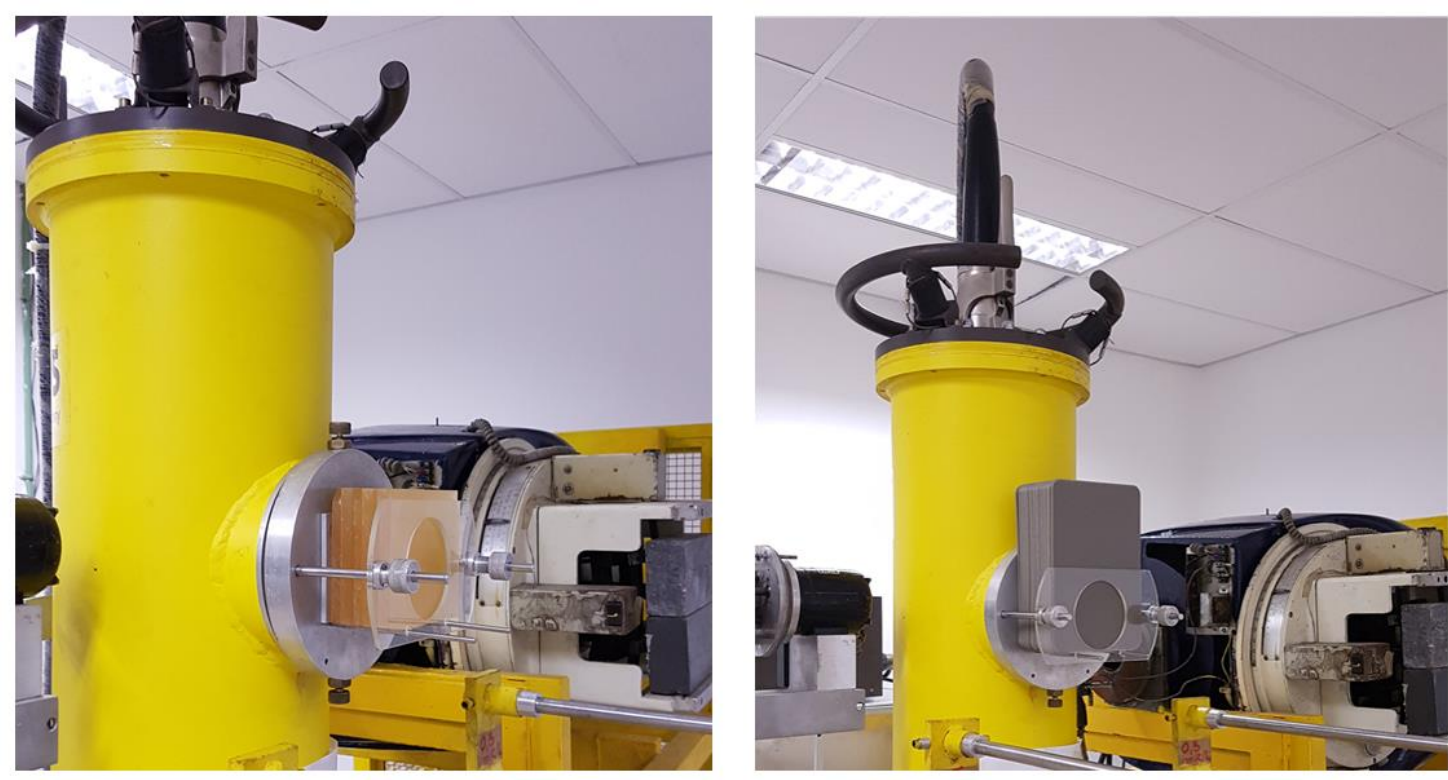

Figura 25 - Imagens do posicionamento das amostras e suporte utilizado no Laboratório do GDRFM do IFUSP. Fonte: a Autora, 2019.

\subsubsection{Calibração e correção dos espectros}

Após a aquisição, os espectros foram calibrados e corrigidos utilizando o método de stripping (Seelentag and Panzer, 1979, Miyajima et al., 2002) a fim de obter o espectro real incidente no detector. Este método consiste em corrigir as distorções espectrais causadas pelo efeito Compton, escape de fótons de raios X no material do detector, e a eficiência de detecção (Di Castro et al., 1984).

Para isso, foi utilizada uma rotina em MATLAB (Alves and Costa, 2010) que realiza o procedimento de stripping, a calibração de energia do detector, o cálculo da fluência de fótons a partir do espectro transmitido e o cálculo do Kerma no ar para cada intervalo de energia. A Figura 26 apresenta todas as etapas de correção implementadas na rotina. Kerma no ar é uma grandeza dosimétrica definida no ICRU Report 85 (ICRU, 2011). 


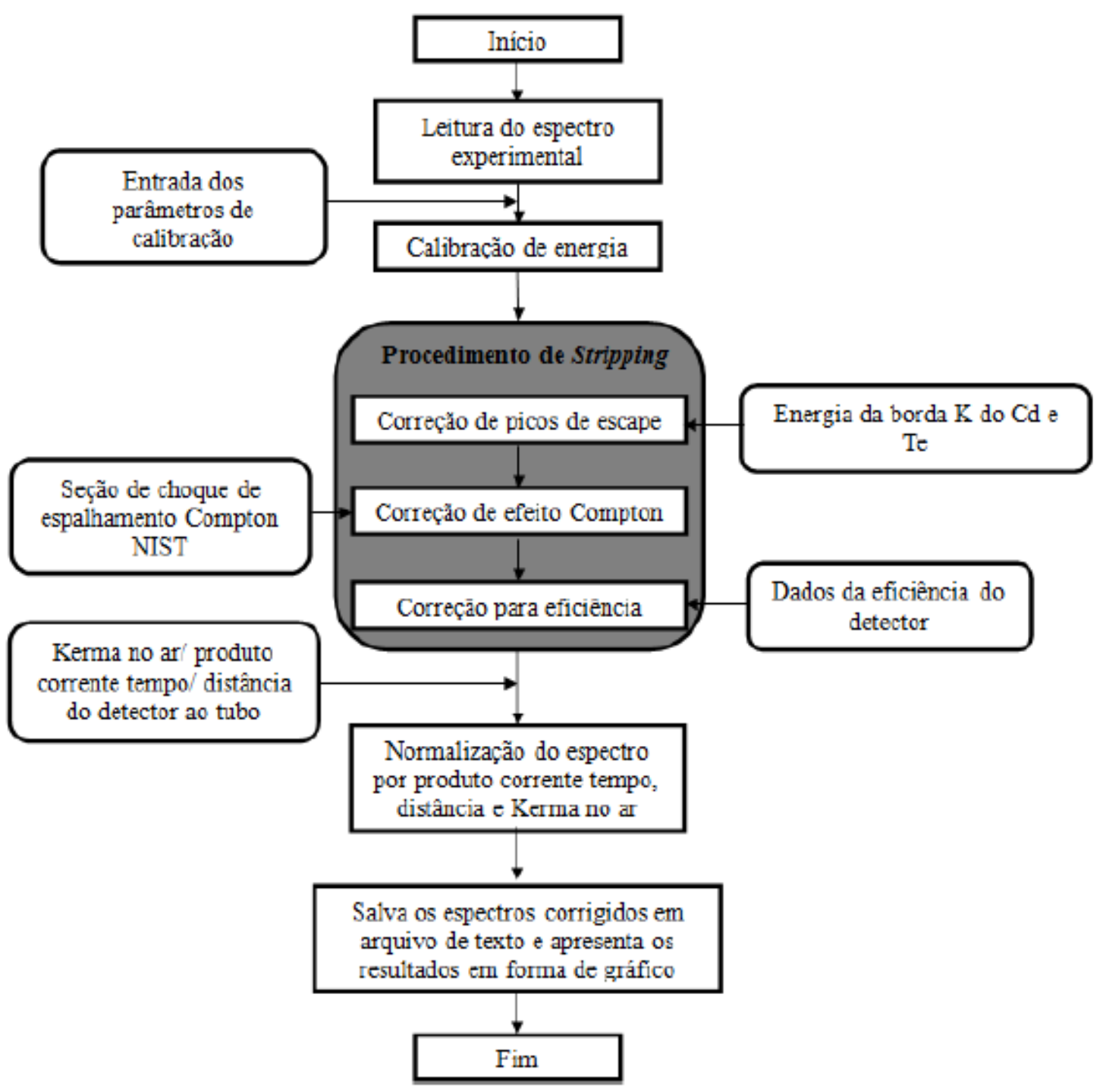

Figura 26 - Diagrama do programa de correção de espectros. Fonte: (Mariano, 2017).

\subsubsection{Determinação do coeficiente de atenuação linear}

O coeficiente de atenuação linear foi determinado experimentalmente com base na lei de atenuação exponencial, que é válida para a geometria de feixe estreito e feixes monoenergéticos. As quantidades de fótons incidentes, $I_{0}(E)$, e transmitidos, $I(E)$, para energias discretas $E$ foram obtidas para diferentes espessuras, $x$, dos materiais estudados. Durante os experimentos outros fatores devem ser levados em consideração. São eles: a atenuação de fótons pelo ar, $\mu_{a r}$, a contribuição da radiação de fundo, $I_{r}$ e a contribuição dos fótons que são espalhados pelo material irradiado $I_{s}$. Assim, os coeficientes de atenuação 
lineares, $\mu(E)$, dos materiais, para cada espessura, foram calculados pela equação (27) (Soares et al., 2020).

$$
\mu(E)=-\frac{1}{x} \ln \left(\frac{I(E)-I_{r}(E)}{I_{0}(E)-I_{r}(E)}\right)+\frac{1}{x} \ln (1+S P R)+\mu_{a r}
$$

em que $S P R=I_{S} / I$ (Midgley, 2006, Soares et al., 2020). Neste trabalho, a intensidade da radiação de fundo $I_{r}$ foi determinada experimentalmente e corresponde a menos que $0,1 \%$ da intensidade incidente no detector. O coeficiente de atenuação do ar, $\mu_{a r}$, foi obtido através do XCOM (Berger et al., 2010) e modifica o coeficiente de atenuação linear em menos de 0,7\%. O ângulo máximo de espalhamento foi estimado (Davisson and Evans, 1952, Midgley, 2006, Soares et al., 2020) em menor que $2^{\circ}$. Portanto, não foi realizada nenhuma correção para radiação espalhada.

Considerando que as contribuições de $\mu_{a r}, I_{r}$ e $I_{s}$ são muito pequenas, a incerteza na determinação do coeficiente de atenuação linear foi estimada por propagação de erros na equação (27) desprezando estas contribuições. Considerando que as intensidades obtidas em cada energia seguem a distribuição de Poisson, pode-se definir:

$$
\left(\frac{\sigma_{\mu}}{\mu}\right)^{2}=\left(\frac{\sigma_{x}}{x}\right)^{2}+\frac{1}{(\mu x)^{2}} \frac{1}{I_{0}}\left(e^{\mu x}+1\right)
$$

Neste trabalho foram obtidos, para cada amostra estudada, $\mathrm{N}$ espectros relativos às $\mathrm{N}$ placas ou agrupamentos de placas com o incremento da espessura. A fim de estimar um valor de coeficiente de atenuação para os $\mathrm{N}$ espectros foi realizado um ajuste não linear de modelo $I(N)=I_{0} e^{(-\mu N \Delta x)}$ em que $\Delta x$ representa o valor da espessura de cada placa. Esse modelo de ajuste é realizado uma vez para cada energia do espectro.

3.5.4 Análise comparativa entre os coeficientes de atenuação linear das amostras de materiais radiologicamente equivalentes ao tecido humano e à água e os materiais de referência

A análise comparativa dos resultados de coeficientes de atenuação linear das amostras de materiais radiologicamente equivalentes ao tecido humano e à água em relação aos materiais de referência foi realizada utilizando a equação (29): 


$$
\chi^{2}=\frac{1}{M} \sum_{i=1}^{M} \frac{\left(\mu_{i}-\mu_{\text {ref } i}\right)^{2}}{\sigma_{\mu_{i}}^{2}}
$$

em que $M$ corresponde ao total de energias estudadas, $\mu_{i}$ e $\mu_{\text {ref } i}$ correspondem respectivamente ao coeficiente de atenuação linear do material simulador e do material de referência na energia $i$ e $\sigma_{\mu_{i}}$ corresponde à incerteza experimental do coeficiente de atenuação linear do material simulador na energia $i$. 


\section{Resultados e discussões}

\subsection{Densidade mássica}

A Tabela 8 apresenta as densidades dos materiais de referência utilizados neste trabalho. Essas densidades foram comparadas com as densidades experimentais das amostras de materiais radiologicamente equivalentes ao tecido humano e à água determinadas pelo princípio descrito por Arquimedes. Os resultados experimentais e as diferenças percentuais em relação aos materiais de referência água líquida, tecido mole e para os materiais comerciais CIRS BR12 e CIRS 70/30 são apresentadas nas Tabelas 9, 10 e 11, respectivamente. Pode-se, também, comparar os valores medidos com as densidades dos materiais-base (resina epóxi e polipropileno) apresentados na Tabela 2. Como esperado, os resultados das densidades são, em geral, maiores que as densidades nominais dos materiais-base, uma vez que esses materiais são misturados com aditivos mais densos.

Tabela 8 - Valores de densidade dos materiais de referência utilizados neste trabalho.

\begin{tabular}{lr}
\hline Material & $\begin{array}{r}\text { Densidade } \\
\left(\mathrm{g} / \mathrm{cm}^{3}\right)\end{array}$ \\
\hline Água líquida (Hubbell and Seltzer, 1996) & 1,00 \\
CIRS BR12 (White et al., 1977) & 0,97 \\
CIRS 70/30 (Poletti et al., 2002) & $1,01(1)$ \\
Tecido mole (White et al., 1987) & 1,06 \\
\hline
\end{tabular}

Tabela 9 - Densidades experimentais das amostras de materiais radiologicamente equivalentes à água e sua diferença em relação ao material de referência.

\begin{tabular}{lrr}
\hline Nome & $\begin{array}{r}\text { Densidade } \\
\left(\mathrm{g} / \mathrm{cm}^{3}\right)\end{array}$ & $\begin{array}{r}\text { Diferença } \\
(\%)\end{array}$ \\
\hline AG1 & $1,152(1)$ & 15,2 \\
AG1* & $1,154(1)$ & 15,4 \\
AG2 & $1,144(1)$ & 14,4 \\
AG2* & $1,148(3)$ & 14,8 \\
AG3 & $1,141(1)$ & 14,1 \\
AG3* & $1,140(9)$ & 14,0 \\
AG4 & $1,144(1)$ & 14,4 \\
AG5 & $1,144(1)$ & 14,4 \\
AG6 & $1,145(3)$ & 14,5 \\
\hline *Replicatas & &
\end{tabular}

As amostras de materiais radiologicamente equivalentes à água apresentaram 
densidades sempre maiores que a densidade da água líquida (Hubbell and Seltzer, 1996) com diferença entre 14 e 15\%. Portanto, para que o fator de atenuação destes materiais seja o mesmo que o da água líquida é necessária uma espessura menor do material radiologicamente equivalente do que de água. Esta consideração também é importante para as amostras de materiais radiologicamente equivalentes ao tecido mole que apresentaram diferenças percentuais em relação à densidade do tecido mole entre 9 e $12 \%$.

Tabela 10 - Densidades experimentais das amostras de materiais radiologicamente equivalentes ao tecido mole e sua diferença em relação ao material de referência.

\begin{tabular}{lcc}
\hline Nome & Densidade $\left(\mathrm{g} / \mathrm{cm}^{3}\right)$ & Diferença $(\%)$ \\
\hline TM1 & $1,178(1)$ & 11,8 \\
TM2 & $1,149(3)$ & 8,9 \\
TM3 & $1,159(1)$ & 9,9 \\
TM4 & $1,148(2)$ & 8,8 \\
\hline
\end{tabular}

Tabela 11 - Densidades experimentais dos materiais radiologicamente equivalentes aos materiais comerciais CIRS BR12 e CIRS 70/30.

\begin{tabular}{lcc}
\hline Nome & Densidade $\left(\mathrm{g} / \mathrm{cm}^{3}\right)$ & Diferença $(\%)$ \\
\hline MA1 & $1,155(3)$ & 14,5 \\
MA7 & $1,141(3)$ & 13,1 \\
MA8 & $0,986(1)$ & 1,6 \\
MA9 & $0,901(1)$ & $-6,9$ \\
\hline
\end{tabular}

Dentre as amostras de materiais radiologicamente equivalentes ao CIRS BR12 e ao CIRS 70/30, o amostra MA8 apresentou um ótimo resultado, com 1,6\% de diferença em relação a densidade do material comercial CIRS BR12 (White et al., 1977). É possível perceber que os resultados da diferença relativa para as amostras produzidas com base de polipropileno como material-base são menores, indicando que este material é mais indicado para produção de materiais radiologicamente equivalentes ao tecido mamário levando em conta a densidade. É possível inferir que o polipropileno também seja indicado para produção de materiais radiologicamente equivalentes à água e ao tecido mole, uma vez que as densidades destes materiais são próximas.

A Figura 27 apresenta uma comparação entre as densidades mássicas dos materiais radiologicamente equivalentes ao tecido humano e à água e de órgãos e tecidos do corpo humano obtidos pelo ICRU Report 44. Observa-se que a amostra TM1 apresenta densidade muito próxima da densidade do osso esponjoso e o material MA8 apresenta densidade muito 
próxima da densidade da medula óssea.

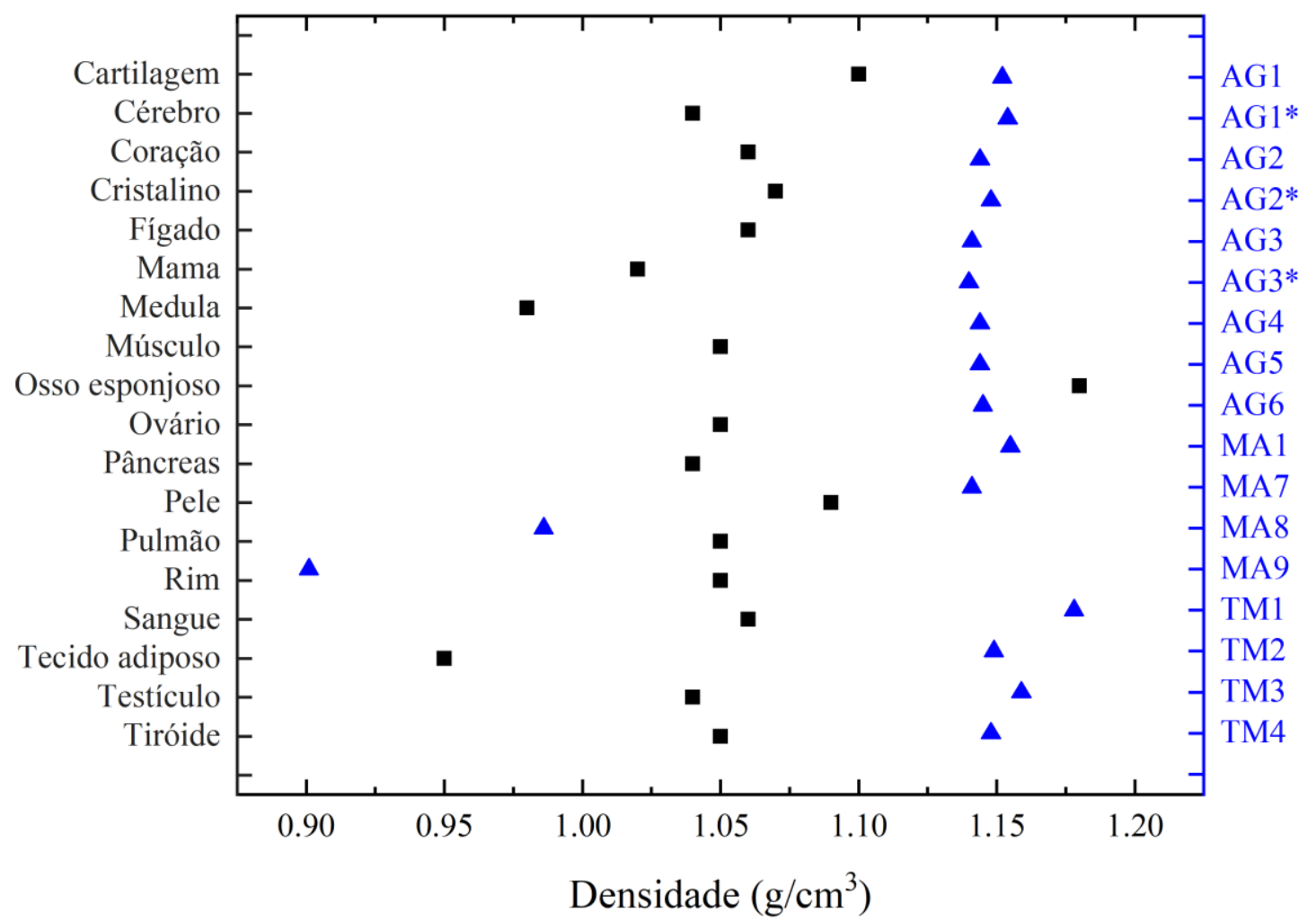

Figura 27 - Densidades mássicas de órgãos e tecidos do corpo humano obtidos pelo ICRU Report 44 e densidades mássicas dos materiais radiologicamente equivalentes ao tecido humano e à água estudados.

Os resultados experimentais e as diferenças percentuais em relação às densidades esperadas a partir do Método Mariano \& Costa são apresentados na Tabela 12. As diferenças percentuais entre as densidades mássicas experimentais e esperadas das amostras de materiais radiologicamente equivalentes à água, tecido mole e materiais comerciais CIRS BR12 e CIRS 70/30 são menores que $3 \%$. 
Tabela 12 - Densidades esperadas das amostras a partir do Método Mariano \& Costa e diferenças percentuais entre as densidades esperadas e os resultados experimentais das amostras de materiais radiologicamente equivalentes à água, tecido mole e materiais comerciais CIRS BR12 e CIRS 70/30.

\begin{tabular}{lrr}
\hline Nome & $\begin{array}{r}\text { Densidade } \\
\left(\mathrm{g} / \mathrm{cm}^{3}\right)\end{array}$ & $\begin{array}{r}\text { Diferença } \\
(\%)\end{array}$ \\
\hline AG1 & 1,121 & 3 \\
AG1* & 1,121 & 3 \\
AG2 & 1,115 & 3 \\
AG2* & 1,115 & 3 \\
AG3 & 1,117 & 2 \\
AG3* & 1,117 & 2 \\
AG4 & 1,110 & 3 \\
AG5 & 1,116 & 3 \\
AG6 & 1,115 & 3 \\
\hline MA1 & 1,156 & 0 \\
MA7 & 1,123 & 2 \\
MA8 & 0,986 & 0 \\
MA9 & 0,915 & -1 \\
\hline TM1 & 1,156 & 2 \\
TM2 & 1,123 & 3 \\
TM3 & 1,129 & 3 \\
TM4 & 1,122 & 3 \\
\hline
\end{tabular}

\subsection{Número atômico efetivo}

4.2.1 Validação do método de Manohara para cálculo do número atômico efetivo

A variação dos números atômicos efetivos para água líquida, tecido mole, CIRS BR12, CIRS 70/30 são apresentados na Figura 28. Os valores apresentados foram calculados tanto pelo método de Manohara, implementado computacionalmente no presente trabalho, quanto pelo software Auto- $Z_{\text {eff }}$ para energias entre $10 \mathrm{keV}$ e $150 \mathrm{keV}$. Esta avaliação comparativa teve como objetivo validar o software baseado no método de Manohara desenvolvido no presente trabalho.

A variação dos valores de número atômico efetivo com a energia observada é resultado das diferentes contribuições dos efeitos de interação dos fótons com a matéria. Na região de 10 a $60 \mathrm{keV}$, em que o efeito fotoelétrico é dominante, verifica-se um decréscimo brusco dos valores de número atômico efetivo. Com o aumento das contribuições dos espalhamentos coerente e Compton, os valores permanecem aproximadamente constantes no intervalo de 
$60-150 \mathrm{keV}$ (Sirico et al., 2019). Este comportamento aparece nos resultados de ambos os métodos de cálculo estudados.
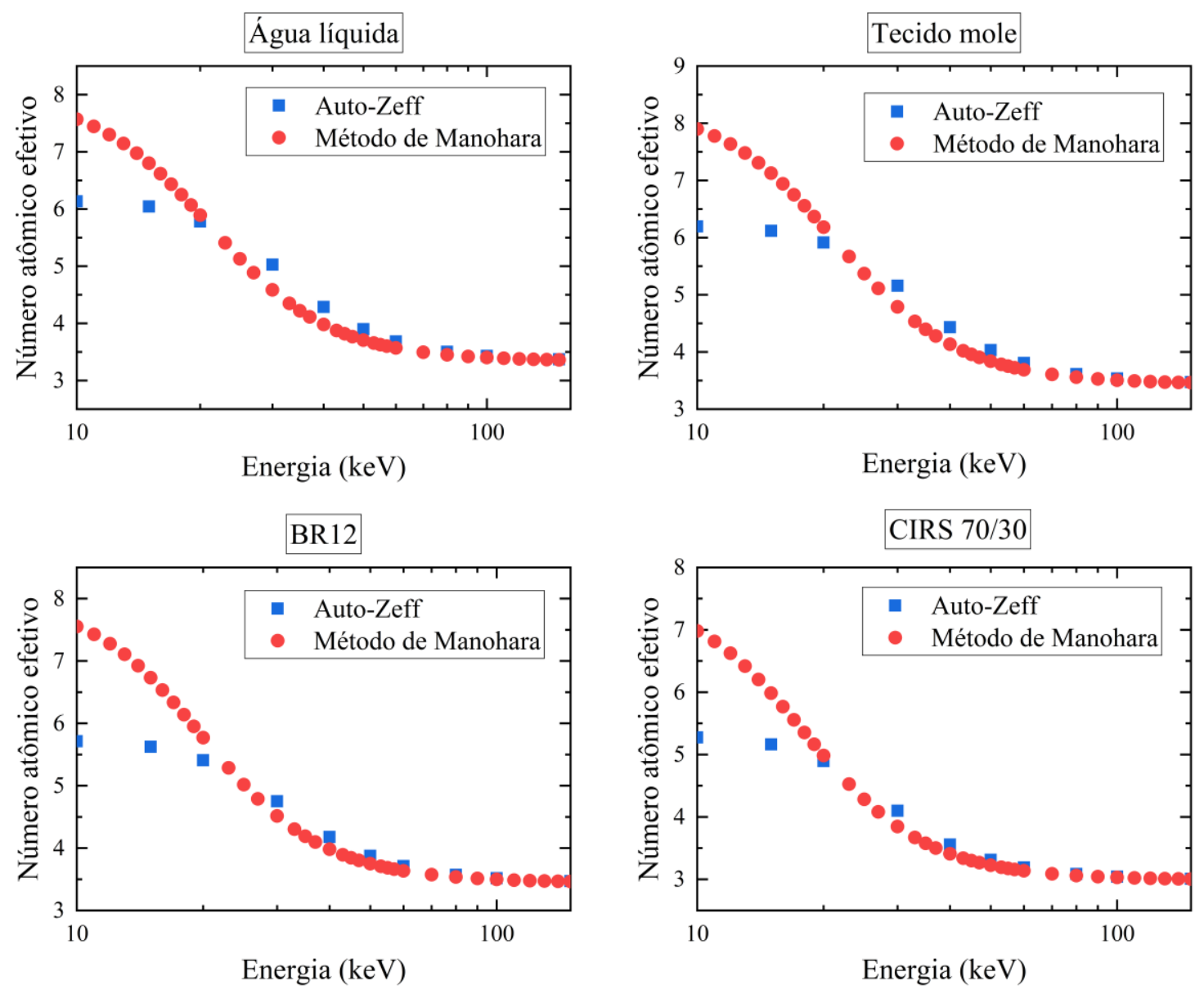

Figura 28 - Números atômicos efetivos para água líquida, tecido mole, CIRS BR12 e CIRS 70/30 a partir do método de Manohara e de software Auto- $Z_{\text {eff. }}$.

É possível observar discrepâncias nos valores de número atômico efetivo entre os métodos utilizados nestes intervalos de energia. Essas discrepâncias também verificadas em outros trabalhos comparativos (Singh et al., 2014a, Singh et al., 2014b) e podem ser resultado de parâmetros de entrada diferentes ou da aplicação de ferramentas matemáticas distintas em cada um desses métodos (Sirico et al., 2019).

A Tabela 13 apresenta a diferença entre os números atômicos efetivos obtidos utilizando o método de Manohara e calculados pelo software Auto- $Z_{\text {eff }}$ para a água como material de referência nestes diferentes intervalos de energia. Verifica-se que o valor absoluto das diferenças tende a diminuir em relação ao aumento da energia. Nota-se, ainda, que os métodos apresentam resultados muito similares dos valores de número atômico efetivo no intervalo de $60-150 \mathrm{keV}$. A diferença relativa média entre os valores de número atômico dos métodos para 
os materiais de referência estudados é de $1 \%$ para o intervalo de $60-150 \mathrm{keV}$ e menor que $12 \%$ para o intervalo de $10-50 \mathrm{keV}$ e de $10-150 \mathrm{keV}$.

A incerteza dos valores de número atômico efetivo pelo software Auto- $Z_{\text {eff }}$ são de 1-2\% para altas energias longe das bordas de absorção (Taylor et al., 2012). O cálculo do número atômico efetivo para energias até o limite inferior de $1 \mathrm{keV}$ podem ser realizadas a partir de solicitação aos desenvolvedores, neste caso as incertezas são de até 25\%-50\% (Taylor et al., 2012).

Em um trabalho comparativo de métodos para o cálculo do número atômico efetivo para materiais (resinas, plásticos e polímeros) comumente utilizados como simuladores de órgãos e tecidos humanos, Singh et al. (2014a) diz que o método de Manohara é apropriado para a determinação do número atômico efetivo para energias até o limite inferior de $10 \mathrm{keV}$.

Neste trabalho, o método direto descrito por Manohara et al. (Manohara et al., 2008) foi utilizado devido a possibilidade de determinação dos números atômicos efetivos em um maior número de valores de energias do que as possíveis com a utilização do software Auto- $Z_{\text {eff }}$ para o intervalo de interesse. Apesar das discrepâncias observadas acredita-se que o método pode ser utilizado em análise comparativa entre os materiais produzidos e materiais de referência.

Tabela 13 - Diferenças percentuais relativas entre os números atômicos efetivos obtidos e calculados pelo software Auto- $Z_{\text {eff }}$ para os materiais de referência em diferentes energias.

\begin{tabular}{ccccc}
\hline & \multicolumn{4}{c}{ Diferença relativa (\%) } \\
\cline { 2 - 5 } $\begin{array}{c}\text { Energia } \\
(\mathrm{keV})\end{array}$ & Água & Tecido mole & CIRS BR12 & CIRS 70/30 \\
\hline 10 & 23 & 27 & 32 & 32 \\
15 & 12 & 16 & 20 & 16 \\
20 & 2 & 4 & 7 & 2 \\
30 & -9 & -7 & -5 & -6 \\
40 & -7 & -7 & -5 & -4 \\
50 & -5 & -5 & -3 & -3 \\
60 & -3 & -3 & -2 & -2 \\
80 & -2 & -1 & -1 & -1 \\
100 & -1 & -1 & -1 & 0 \\
150 & 0 & 0 & 0 & 0 \\
\hline $10-50$ & 10 & 11 & 12 & 11 \\
$60-150$ & 1 & 1 & 1 & 1 \\
$10-150$ & 10 & 11 & 12 & 11 \\
\hline
\end{tabular}


4.2.2 Número atômico efetivo dos materiais radiologicamente equivalentes à água

Os números atômicos efetivos para os materiais radiologicamente equivalentes à água foram determinados pelo método de Manohara. A fim de comparar os resultados destes materiais ao da água líquida calculou-se as diferenças relativas entre os valores de número atômico efetivo para o material produzido e material de referência dentro dos intervalos de energias de interesse. As diferenças relativas são apresentadas na Figura 29 para o método de Manohara.

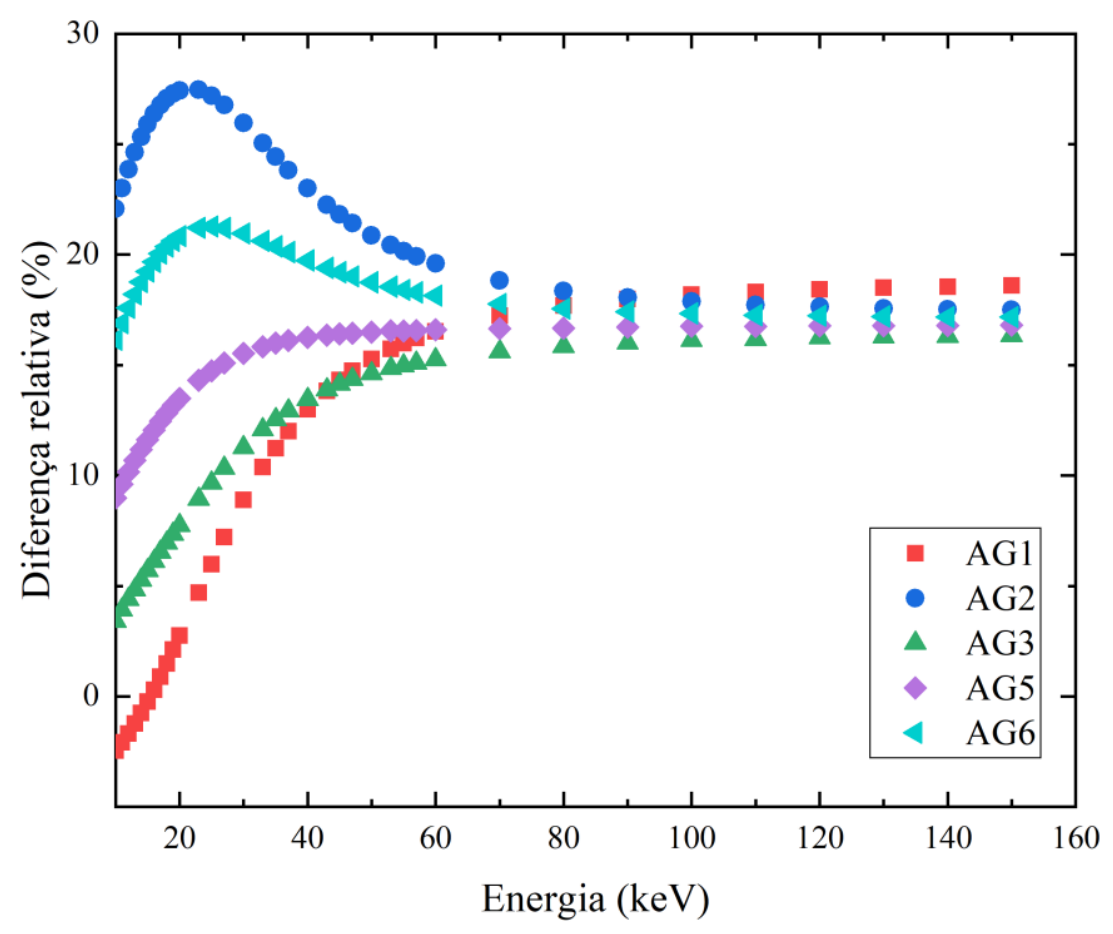

Figura 29 - Diferença relativa do número atômico efetivo dos materiais AG1, AG2, AG3, AG5 e AG6 em relação à água líquida utilizando o método de Manohara.

Para cada material foi calculada a diferença percentual relativa média no intervalo de energia de 10 a $150 \mathrm{keV}$. Os materiais AG2 e AG6 apresentaram as maiores discrepâncias com $23 \%$ e $19 \%$ de diferença relativa média, respectivamente. Os materiais AG1, AG3 e AG5 apresentaram os melhores resultados com 10\%, 12\% e 15\% de diferença relativa média respectivamente. Destaca-se que, no intervalo de energias entre 50 e $150 \mathrm{keV}$, esta diferença relativa média é de aproximadamente $17 \%$ para os três materiais e que, para o material AG1, a diferença percentual média é de $3 \%$ no intervalo de energias entre 10 e $30 \mathrm{keV}$. 
4.2.3 Número atômico efetivo dos materiais radiologicamente equivalentes ao tecido mole

A Figura 30 apresenta os valores de diferença relativa para o método de Manohara dos valores de número atômico efetivo para os materiais radiologicamente equivalentes em relação ao tecido mole.

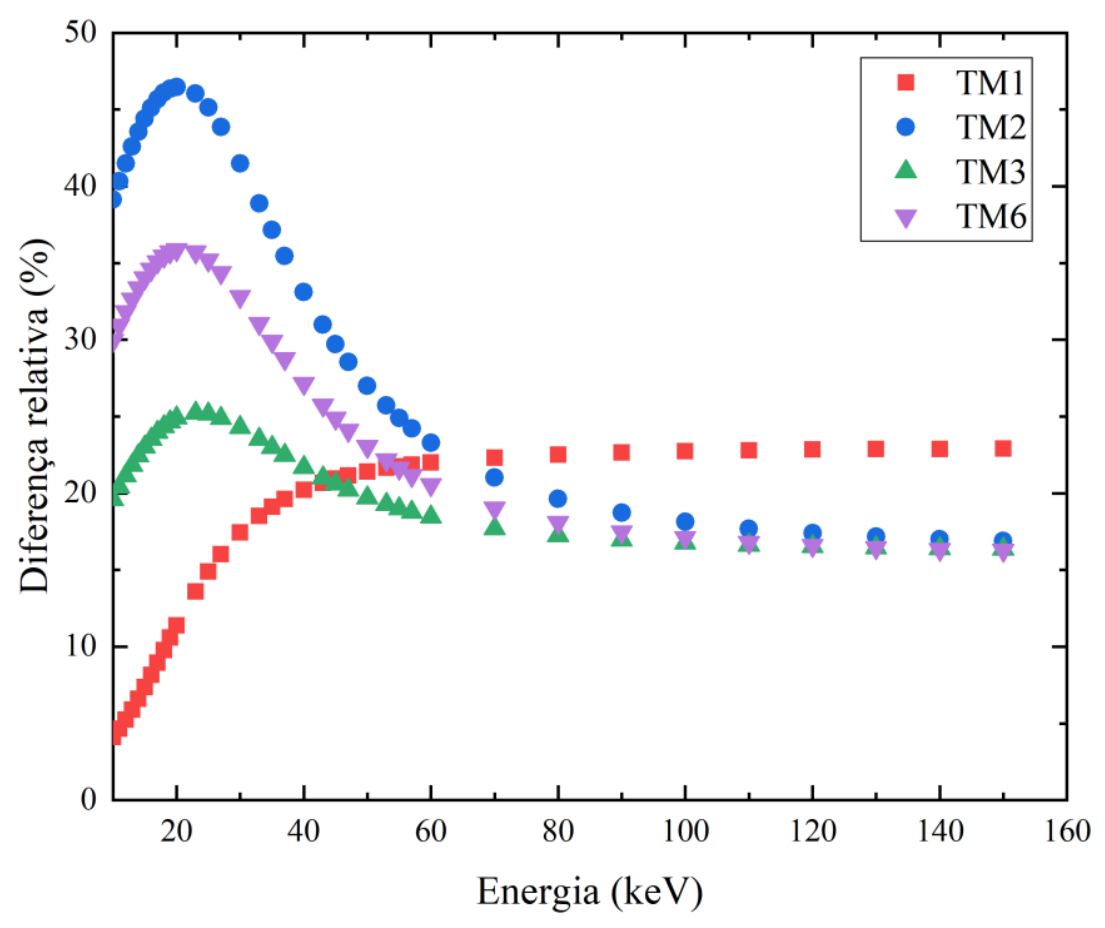

Figura 30 - Diferença relativa do número atômico efetivo dos materiais TM1, TM2, TM3 e TM6 em relação ao tecido mole utilizando o método de Manohara.

A diferença relativa média calculada no intervalo de energia de 10 a $150 \mathrm{keV}$ foi calculada para os materiais radiologicamente equivalentes ao tecido mole. Os materiais TM1 e TM3 apresentaram os resultados mais concordantes com $17 \%$ e $21 \%$ de diferença relativa média. Os materiais TM2 e TM6 apresentaram os resultados mais discrepantes de 33\% e 27\% de diferença relativa média. Destaca-se que, no intervalo de energias entre 10 e $30 \mathrm{keV}$ o material TM1 apresenta diferença relativa média de $9 \%$. 
4.2.4 Número atômico efetivo dos materiais radiologicamente equivalentes ao CIRS BR12 e ao CIRS 70/30

A Figura 31 apresenta a comparação dos números atômicos efetivos para as amostras de materiais radiologicamente equivalentes ao CIRS BR12 e ao CIRS 70/30 pelo método de Manohara.

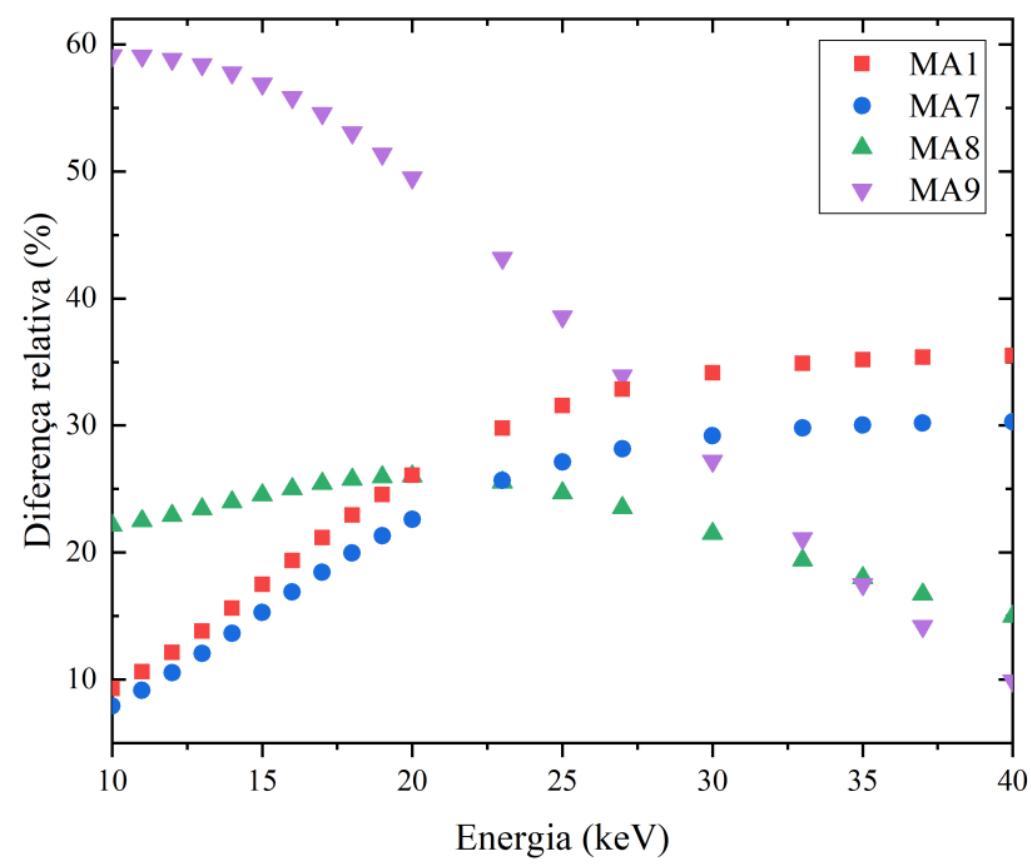

Figura 31 - Diferença relativa do número atômico efetivo dos materiais MA1 e MA7 em relação ao CIRS 70/30 e dos materiais MA8 e MA9 em relação ao CIRS BR12 utilizando o método de Manohara.

A diferença relativa média calculada no intervalo de 10 a $40 \mathrm{keV}$ foi calculada para os materiais radiologicamente equivalentes aos materiais comerciais CIRS BR12 e CIRS 70/30. Os materiais MA1, MA7 e MA8 apresentaram os melhores resultados com 23\%, 23\% e 20\% de diferença relativa média respectivamente e o material MA9 apresentou o pior resultado com $52 \%$ de diferença relativa média.

\subsubsection{Comparações com outros tecidos}

A Figura 32 apresenta a comparação dos números atômicos efetivos para os materiais produzidos e outros órgãos/tecidos do corpo humano. É possível perceber que os valores de 
número atômico efetivo entre os órgãos/tecidos são semelhantes verificando que a composição química elementar entre eles é similar. Observa-se, também, que os números atômicos efetivos dos órgãos e tecidos são muito próximos aos materiais AG3 e MA7. Foi verificado que as diferenças relativas dos materiais AG3 e MA7 são compatíveis com os órgãos/tecidos: ovário, cristalino, tecido pulmonar, músculo esquelético e testículo com menos de $6 \%$ no intervalo de 10-150 keV. Este resultado indica que os materiais produzidos devem ser avaliados também em relação a outros órgãos/tecidos do corpo humano e não apenas aos materiais de referência, principalmente se a composição química do tecido for similar ao do material produzido.

A determinação do número atômico efetivo computacionalmente é interessante na análise dos materiais produzidos em relação a outros órgãos/tecidos do corpo humano, pois pode ser realizada de forma rápida. Além disso, é possível avaliar os resultados em diferentes intervalos de energia, pois um material produzido pode ser compatível por exemplo com o tecido mole na região de 40-150 keV e tecido mamário entre 20-35 keV. Ressalta-se ainda que a determinação do número atômico efetivo pode ser feita em intervalos de energia de 1 até $100 \mathrm{MeV}$, que compreende a área da radioterapia em que materiais radiologicamente equivalentes são, também, bastante utilizados.

Por fim, a metodologia desenvolvida demonstrou ser eficiente para a classificação da adequação, em termos de seus números atômicos efetivos, dos materiais produzidos quanto à sua similaridade ou não com os materiais de referência que devem simular. A aplicação deste método permite considerar ou eliminar amostras destes materiais considerando critérios de similaridade quanto a este parâmetro. Permite, ainda, avaliar se um material desenvolvido para uma finalidade pode ser adequado para a simulação de um tecido distinto daquele para o qual foi originalmente elaborado. 


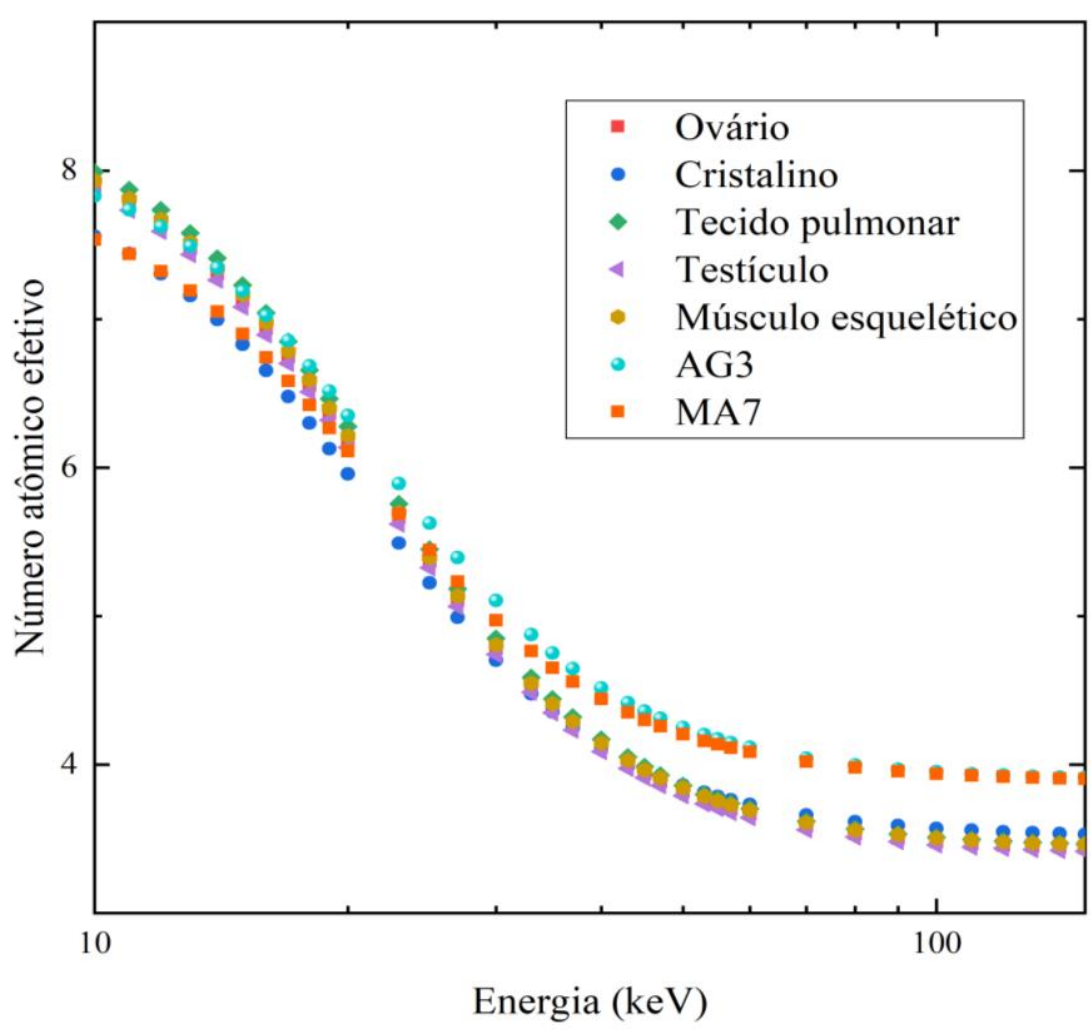

Figura 32 - Valores de número atômico efetivo dos materiais AG3 e MA7 em relação a outros tecidos. As composição química elementar dos tecidos foi obtida a partir do ICRU Report 44 (White et al., 1989).

\subsection{Imagens tomográficas}

\subsubsection{Tomografia computadorizada (TC)}

As amostras de materiais radiologicamente equivalentes à água AG1, AG2, AG3 e AG5 foram irradiadas em um equipamento de tomografia computadorizada nas tensões: $80,100,120$ e $140 \mathrm{kV}$. A partir da energia efetiva associada a cada tensão aplicada ao tubo de raios $\mathrm{X}$ foi obtido o valor correspondente do coeficiente mássico da água pelo banco de dados do XCOM (Berger et al., 2010). A Figura 33 apresenta um gráfico comparativo dos coeficientes mássicos determinados a partir do número CT médio na imagem de TC para cada amostra de material radiologicamente equivalente à água e para os coeficiente mássicos previstos na metodologia de Mariano \& Costa (Mariano and Costa, 2017, Mariano, 2017). 


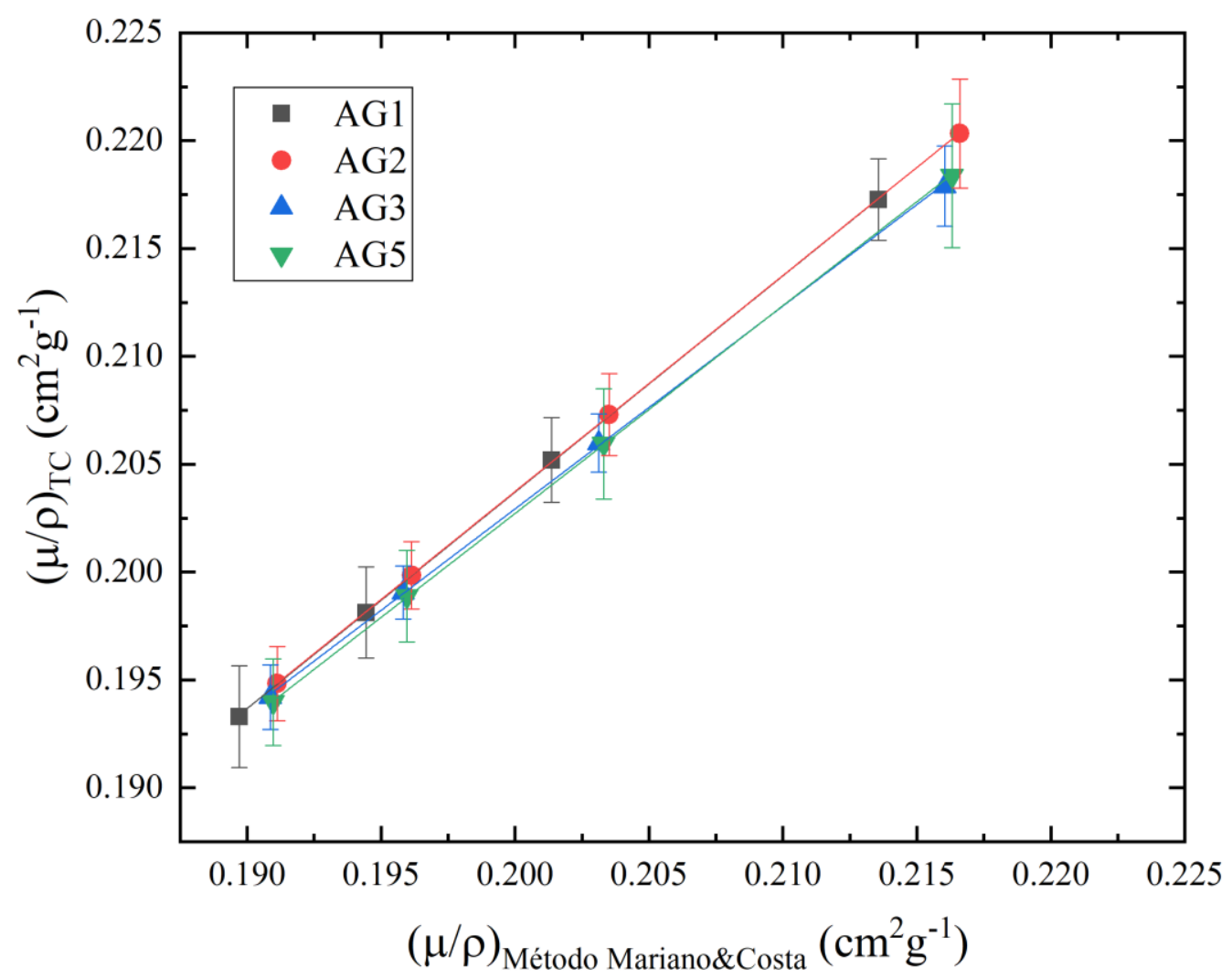

Figura 33 - Gráfico comparativo dos coeficientes mássicos determinados para cada amostra de material radiologicamente equivalente e para os coeficiente mássicos previstos na metodologia (Mariano, 2017).

Os resultados dos ajustes lineares apresentados na Tabela 14 mostram que os coeficientes lineares e angular ajustados são compatíveis com zero e com a unidade, respectivamente, o que permite inferir que os coeficientes de atenuação mássico calculados são compatíveis aos coeficientes mássicos previstos pela metodologia de Mariano \& Costa.

Tabela 14 - Valores de coeficiente linear $\left(\mathrm{a}_{0}\right)$, coeficiente angular $\left(\mathrm{a}_{1}\right)$ e coeficiente de determinação $\left(\mathrm{R}^{2}\right)$ obtidos a partir de um ajuste linear dos valores de coeficiente mássico determinados a partir do número CT médio na imagem de TC em relação aos valores de coeficiente mássico da água obtido utilizando o XCOM(Berger et al., 2010).

\begin{tabular}{lccc} 
Nome & $\mathrm{a}_{0}$ & $\mathrm{a}_{1}$ & $\mathrm{R}^{2}$ \\
\hline AG1 & $0,003(1)$ & $1,003(6)$ & 0,9999 \\
AG2 & $0,003(1)$ & $1,002(2)$ & 1,0000 \\
AG3 & $0,015(2)$ & $0,941(9)$ & 0,9997 \\
AG5 & $0,010(1)$ & $0,964(5)$ & 0,9999 \\
\hline
\end{tabular}


A comparação dos coeficientes mássicos determinados a partir do número CT médio na imagem de TC com os coeficiente mássicos da água obtidos pelo banco de dados XCOM (Berger et al., 2010) foi feita a partir do cálculo da diferença relativa média. Os materiais estudados apresentam diferenças de 4 a $7 \%$.

\subsubsection{Tomografia computadorizada de dupla energia (TCDE)}

A Figura 34 apresenta a comparação dos coeficientes de atenuação mássico das amostras AG1, AG2, AG3 e AG5 com os coeficientes mássicos da água obtidos pelo banco de dados XCOM (Berger et al., 2010). A diferença relativa entre os valores do coeficiente de atenuação mássico determinados e da água é menor que 7\%. A Tabela 15 apresenta os resultados dos ajustes lineares realizados. As amostras AG2 e AG5 apresentaram coeficientes angulares compatíveis com a unidade e coeficientes lineares ligeiramente maiores que zero indicando que os coeficientes mássicos dos materiais produzidos são sempre maiores que o da água.

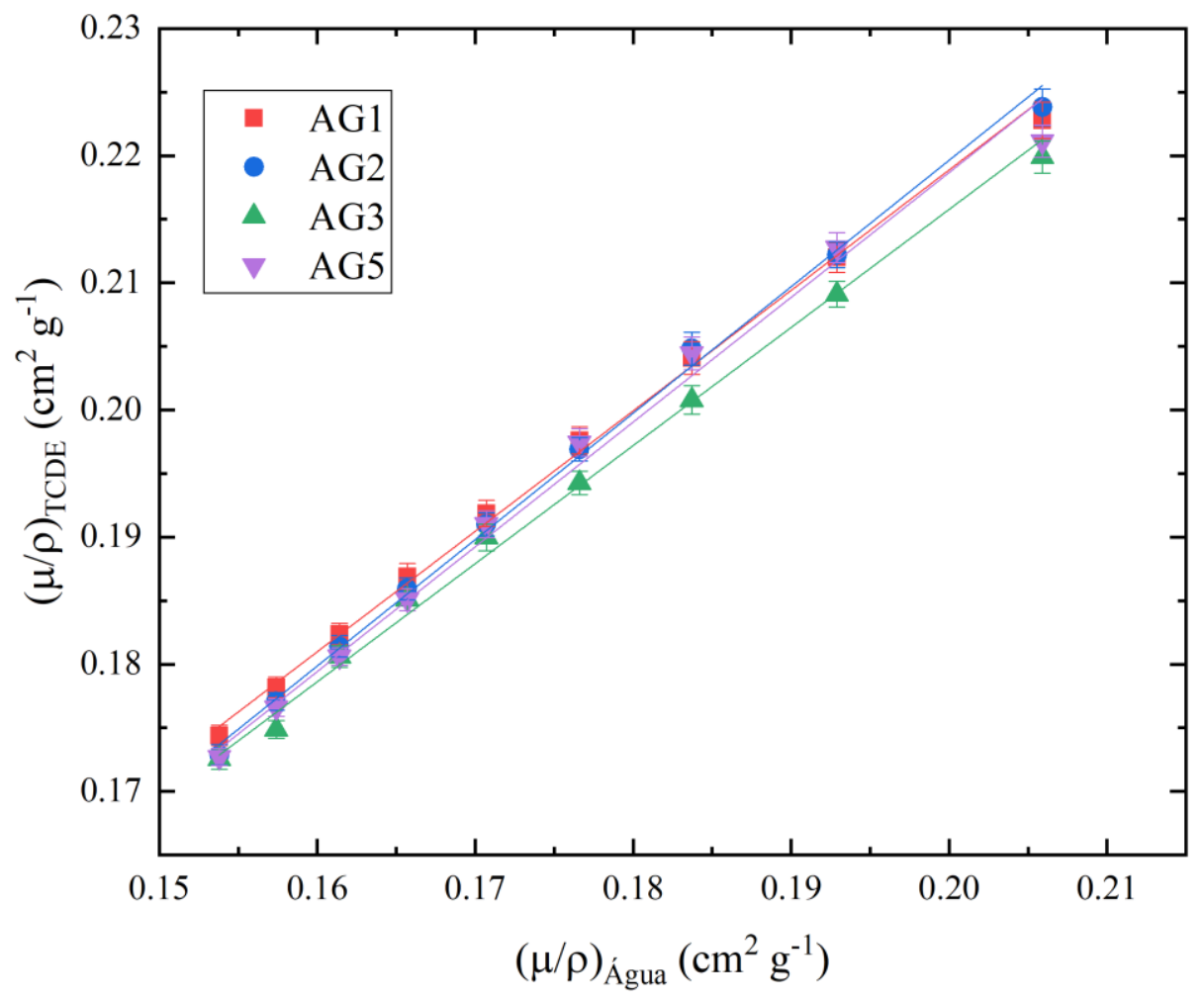

Figura 34 - Gráfico comparativo dos coeficientes de atenuação mássicos determinados das amostras de materiais radiologicamente equivalentes à água calculados a partir de imagens de TCDE em relação aos valores de coeficiente mássico da água nas mesmas energias. 
Tabela 15 - Valores de coeficiente linear (a), coeficiente angular $\left(\mathrm{a}_{1}\right)$ e coeficiente de determinação $\left(\mathrm{R}^{2}\right)$ obtidos a partir de um ajuste linear dos valores de coeficientes de atenuação linear das amostras obtidos por meio de imagens de TCDE em relação aos valores de coeficiente de atenuação linear da água obtido utilizando o XCOM (Berger et al., 2010).

\begin{tabular}{lccl}
\hline Nome & $\mathrm{a}_{0}$ & $\mathrm{a}_{1}$ & $\mathrm{R}^{2}$ \\
\hline AG1 & $0,029(3)$ & $0,95(2)$ & 0,997 \\
AG2 & $0,021(3)$ & $0,99(2)$ & 0,997 \\
AG3 & $0,030(4)$ & $0,93(2)$ & 0,995 \\
AG5 & $0,022(4)$ & $0,98(3)$ & 0,993 \\
\hline
\end{tabular}

A Figura 35 apresenta a comparação dos coeficientes mássicos da amostra MA7 em relação ao material comercial CIRS 70/30 e a Figura 36 apresenta a comparação dos coeficientes mássicos das amostras MA8 e MA9 em relação ao material comercial CIRS BR12 obtidos pelo banco de dados XCOM (Berger et al., 2010).

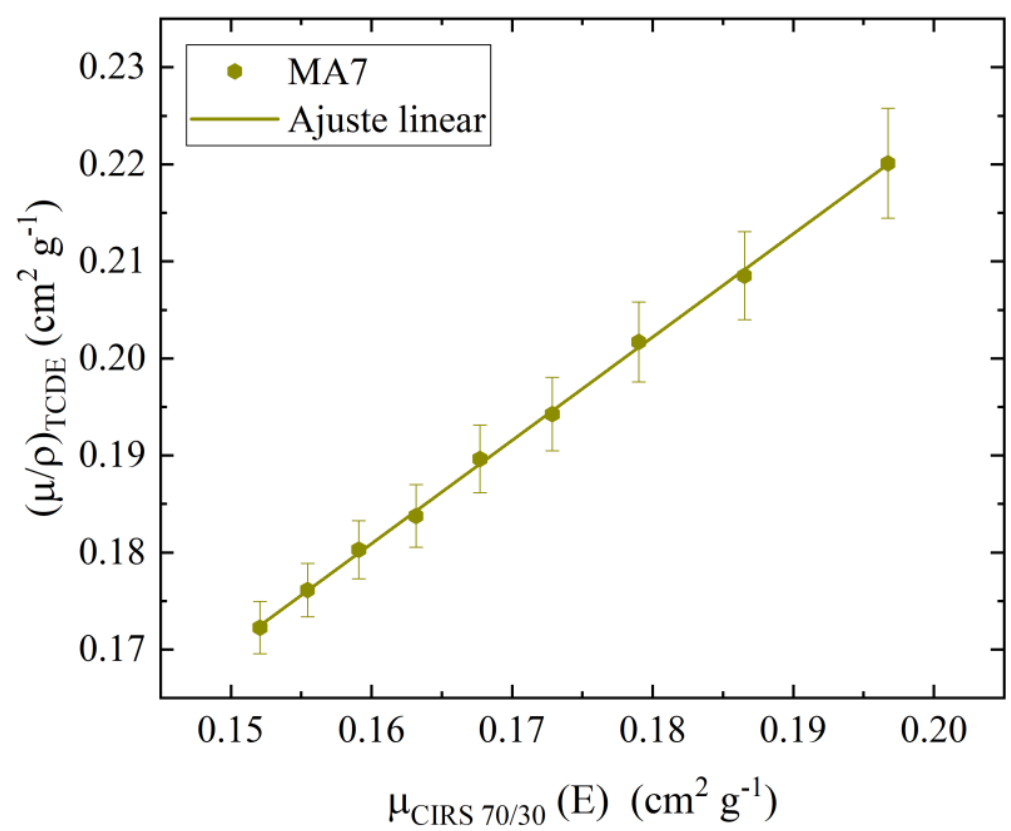

Figura 35 - Gráfico comparativo do coeficiente mássico da amostra MA7 obtido em relação aos valores de coeficiente mássico do CIRS 70/30 nas mesmas energias.

A Tabela 16 apresenta os resultados dos ajustes lineares realizados. Destaca-se a amostra MA8, que possui atenuação compatível com o material de referência. Além disso, a amostra MA8 apresentou valores de número CT próximos a -21 HU que é compatível com o valor de - 22 (14) HU obtido para o material radiologicamente equivalente à mama (50/50) do objeto simulador modelo CIRS 062 em tomografia convencional para tensão 130 kV (Martinez et al., 2012). O ajuste linear realizado permite inferir que o material MA9 não é compatível com 
o material comercial CIRS BR12. Esse material apresenta valores negativos entre -126 e -87 indicando um material semelhante ao tecido adiposo. Esse resultado é comparável com resultados medidos para o material radiologicamente equivalente ao tecido adiposo do objeto simulador modelo CIRS 062 em tomografia convencional para tensão de 100, 120, 130 e $140 \mathrm{kV}$ (Martinez et al., 2012).

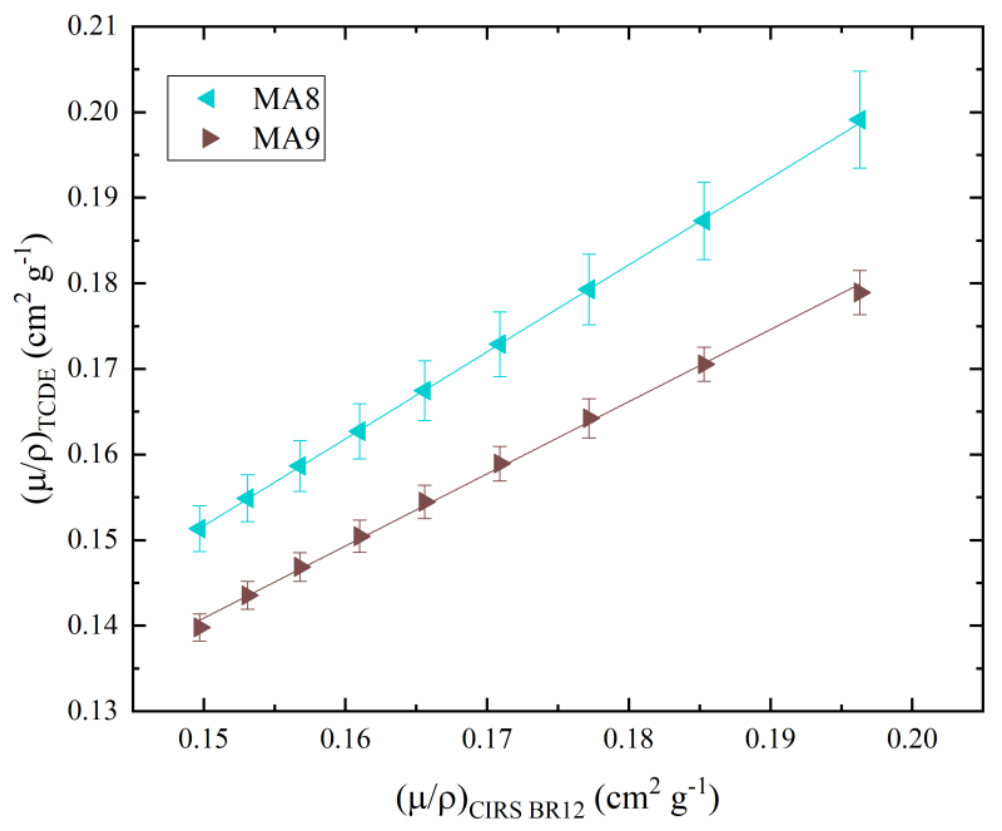

Figura 36 - Gráfico comparativo do coeficiente mássico das amostras MA8 e MA9 obtidos em relação aos valores de coeficiente mássico do CIRS BR12 nas mesmas energias.

Tabela 16 - Valores de coeficiente linear $\left(\mathrm{a}_{0}\right)$, coeficiente angular $\left(\mathrm{a}_{1}\right)$ e coeficiente de determinação $\left(\mathrm{R}^{2}\right)$ obtidos a partir de um ajuste linear dos valores de coeficientes de atenuação linear das amostras obtidos por meio de imagens de TCDE em relação aos valores de coeficiente de atenuação linear dos materiais comerciais CIRS BR12 e CIRS 70/30 obtidos utilizando o XCOM (Berger et al., 2010).

\begin{tabular}{lrrl}
\hline Nome & \multicolumn{1}{c}{$\mathrm{a}_{0}$} & \multicolumn{1}{c}{$\mathrm{a}_{1}$} & $\mathrm{R}^{2}$ \\
\hline MA7 & $0,0106(2)$ & $1,07(1)$ & 0,999 \\
MA8 & $-0,0008(6)$ & $1,017(4)$ & 1,000 \\
MA9 & $0,0144(2)$ & $0,84(1)$ & 0,998 \\
\hline
\end{tabular}

4.4 Estimativa do coeficiente de atenuação linear utilizando espectroscopia por raios $\mathrm{X}$

\subsubsection{Calibração dos espectros}

A curva de calibração em energia do detector de CdTe foi obtida a partir de espectros experimentais de fontes radioativas com energias de fotopico bem conhecidas $\left({ }^{241} \mathrm{Am},{ }^{133} \mathrm{Ba} \mathrm{e}\right.$ 
$\left.{ }^{152} \mathrm{Eu}\right)$ no intervalo de interesse para radiodiagnóstico. A fim de determinar o número do canal associado à energia correspondente dos picos de energia destas fontes foi realizado um ajuste linear. A Figura 37 apresenta a curva de calibração do detector e a reta ajustada com coeficiente de determinação $R^{2}>0,999$.

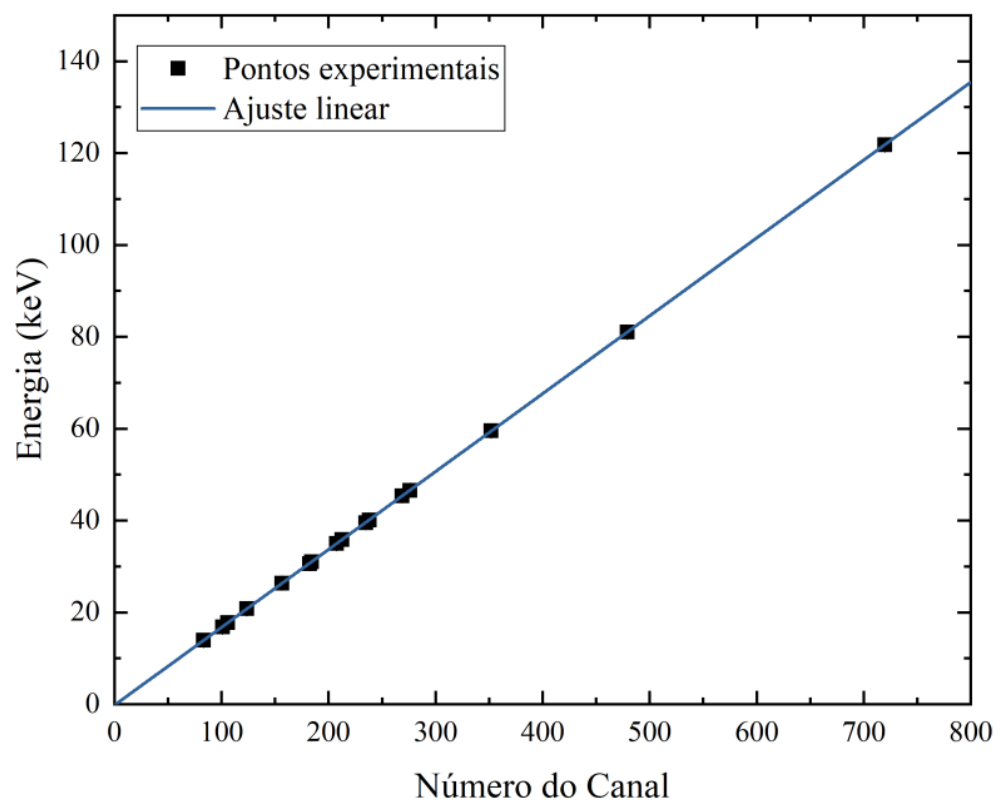

Figura 37 - Curva de calibração em energia do detector de CdTe. As incertezas dos pontos experimentais são menores que $2 \%$ do valor da energia, as incertezas no número do canal foram incorporadas nestes valores.

\subsubsection{Resolução em energia do detector de CdTe}

A resolução em energia do detector relaciona a largura à meia altura (FWHM, do inglês Full Width at Half Maximum) dos fotopicos das fontes radioativas medidos com a energia dos fótons incidentes. A relação entre FWHM e energia é (Knoll, 2010):

$$
F W H M^{2}=(2,355)^{2} W F E+(\Delta E)_{\text {ruído eletrônico }}^{2}+(\Delta E)_{\text {coleta de cargas }}^{2}
$$

em que $F$ é o fator Fano, $w$ a energia necessária para criar um par elétron-buraco $(4,43 \mathrm{eV}$ para o detector de $\mathrm{CdTe}$ ) e $E$ a energia do fóton incidente. O primeiro termo corresponde a flutuação estatística inerente no número de portadores de carga produzidos. O segundo e terceiro termos representam a contribuição para o alargamento do pico em energia devido o ruído gerado pelos componentes eletrônicos e a coleta de cargas incompleta pelo detector, respectivamente. 
Os valores de FWHM foram obtidos a partir de ajustes de gaussianas e bi-gaussianas aos picos das fontes radioativas estudadas como mostrado na Figura 38. A Figura 39 apresenta a curva de resolução em energia do detector de CdTe. Foi realizado um ajuste linear aos pontos experimentais e, a partir dos resultados o Fator Fano do detector, foi determinado como 0,23(2) keV. O coeficiente linear obtido referente ao ruído eletrônico e coleta de cargas foi de 255(92) eV. O Fator Fano para um detector de CdTe à temperatura ambiente foi determinado como 0,24(2) keV (Sammartini et al., 2018).

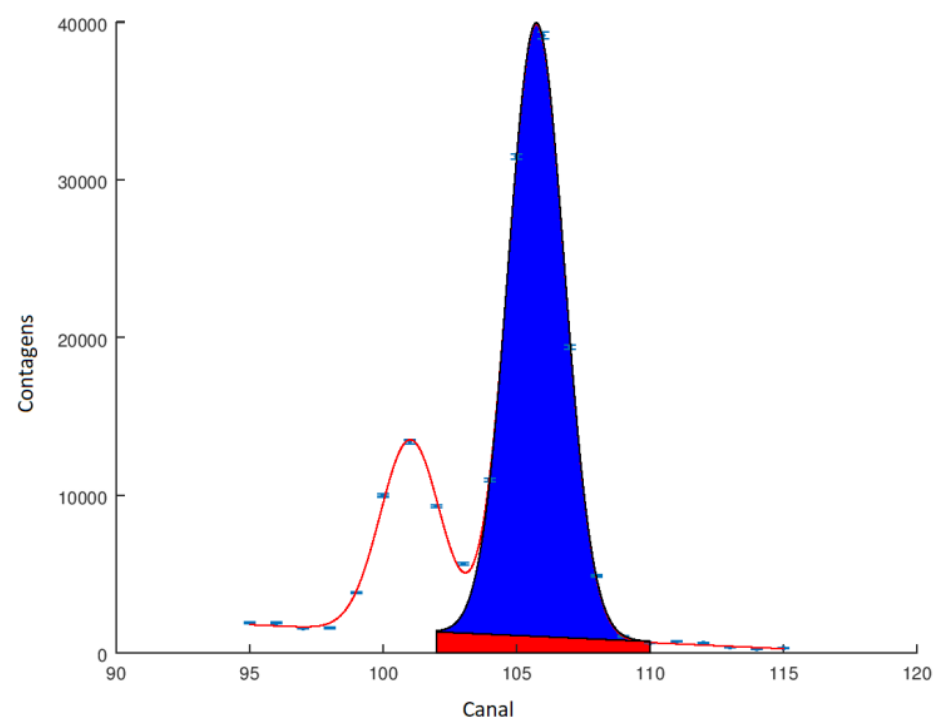

Figura 38 - Ajuste de uma distribuição bi-gaussiana para picos em energia de uma fonte radioativa de ${ }^{241} \mathrm{Am}$. No ajuste, o ruído foi modelado como uma reta.

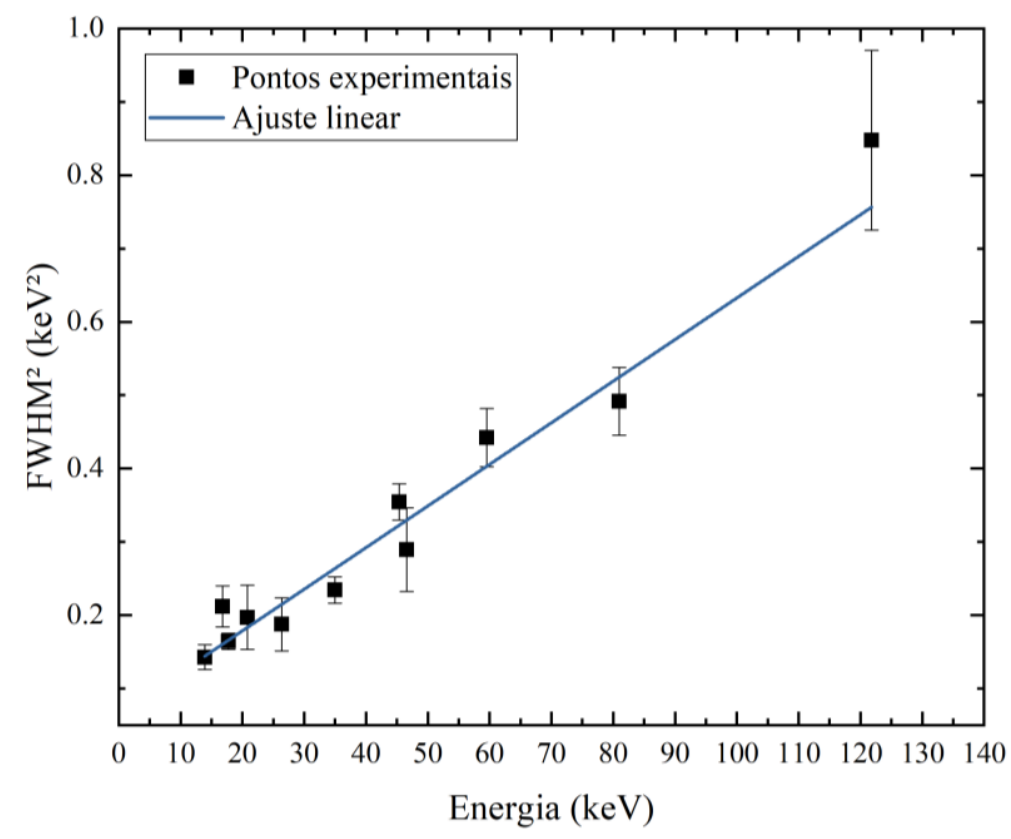

Figura 39 - Resolução em energia do detector de CdTe utilizado. 
4.4.3 Estimativa dos coeficientes de atenuação linear de materiais radiologicamente equivalentes à água

A Figura 40 apresenta os valores de coeficiente de atenuação linear determinados experimentalmente e a diferença entre estes valores e os coeficientes de atenuação linear da água obtidos utilizando a base de dados do XCOM (Berger et al., 2010) no intervalo de energia de interesse entre 10 e $150 \mathrm{keV}$ das amostras AG2, AG4 e AG6. Os valores de coeficiente de atenuação linear para os outros materiais produzidos são apresentados no Apêndice A. A amostra AG2 apresentou o melhor resultado segundo a Tabela 17 considerando o $\chi^{2}$.

Observa-se que a amostra AG4 apresenta um aumento brusco dos valores de coeficiente de atenuação linear em aproximadamente $34 \mathrm{keV}$. Este aumento acontece devido à absorção pela camada $\mathrm{K}$ do Iodo, que é um dos componentes da formulação AG4. Este resultado é interessante para verificar que a adição de um elemento como o Iodo, de número atômico elevado, mesmo em pequenas proporções, pode alterar significativamente os resultados.

É possível verificar que as amostras replicatas apresentam valores similares de $\chi^{2}$, o que permite inferir que os materiais podem ser produzidos com boa reprodutibilidade.

Os valores de coeficiente de atenuação linear da amostra AG2 é compatível com água no intervalo 40 a $100 \mathrm{keV}$ com $\pm 5 \%$ de diferença. Para a amostra AG6 o intervalo de compatibilidade é entre 40 e $80 \mathrm{keV}$.

Tabela 17 - Valores de $\chi^{2}$ calculados a partir da diferença para as amostras produzidas em relação à água.

\begin{tabular}{lr}
\hline Nome & $\chi^{2}$ \\
\hline AG1 & 4,5 \\
AG1* & 3,8 \\
AG2 & 2,9 \\
AG2* & 4,1 \\
AG3 & 3,7 \\
AG3* & 4,7 \\
AG4 & 28,4 \\
AG5 & 3,3 \\
AG6 & 4,6 \\
\hline
\end{tabular}



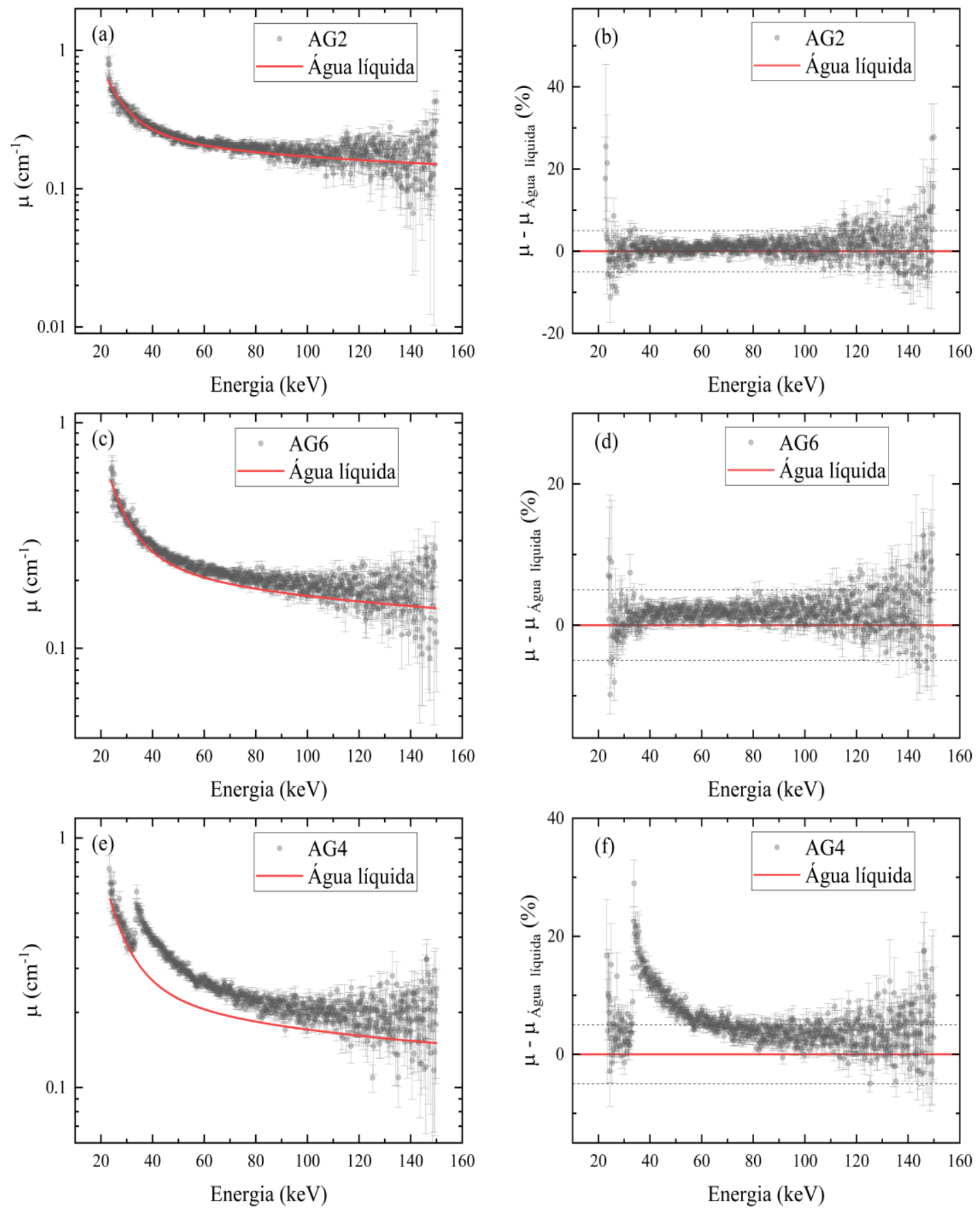

Figura 40 - (a), (c) e (e) valores de coeficiente de atenuação linear das amostras AG2, AG6 e AG4 respectivamente. (b), (d) e (f) diferença entes valores e os valores de coeficiente de atenuação linear da água. As retas pontilhadas demarcam uma diferença de $\pm 5 \%$.

Os valores de coeficiente de atenuação linear também foram analisados em relação aos coeficientes de atenuação dos materiais de referência a partir de ajustes lineares. A Figura 41 
apresenta a reta ajustada para os valores de coeficiente de atenuação linear para a amostra TM6 e os valores da água obtidos a partir do banco de dados XCOM (Berger et al., 2010). A Tabela 18 apresenta os resultados de coeficiente linear e angular e o coeficiente de determinação $\left(\mathrm{R}^{2}\right)$ obtidos a partir do ajuste. A análise da amostra AG4 não foi apresentada, pois os valores de coeficiente de atenuação linear determinados são afetados pela presença de Iodo $(Z=53)$ como apresentado anteriormente.
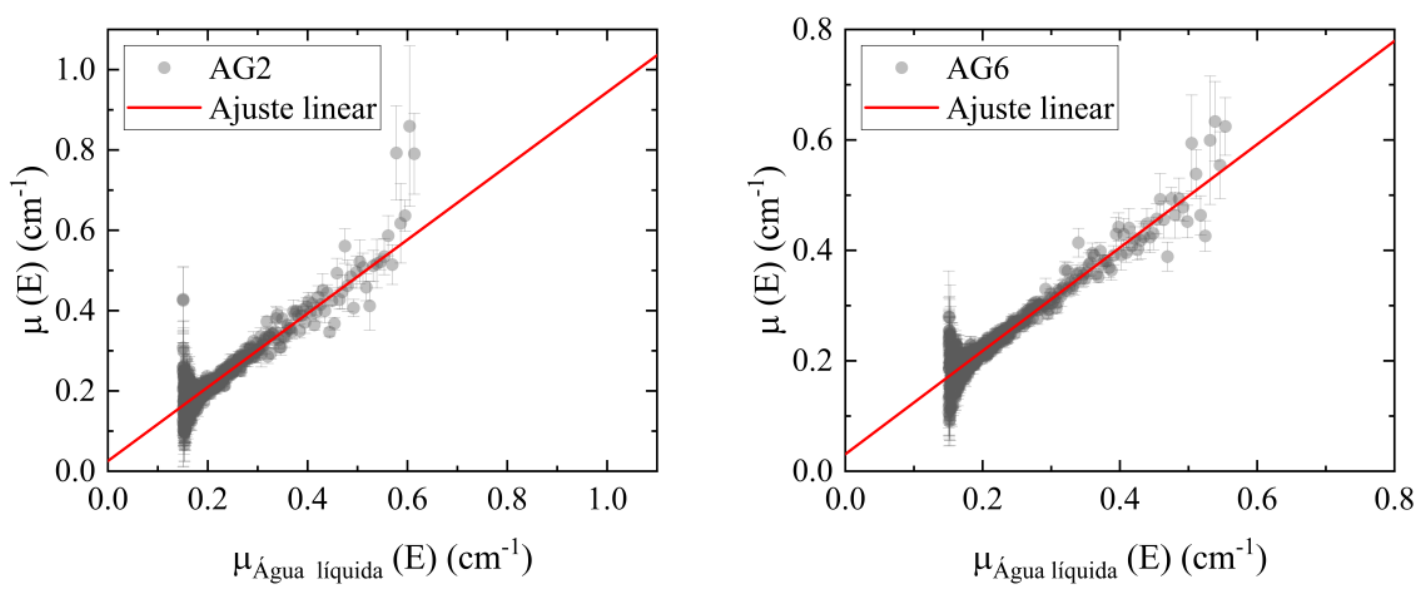

Figura 41 - Valores de coeficiente de atenuação linear das amostras AG2 e AG6 em relação aos valores da água obtidos utilizando o banco de dados XCOM (Berger et al., 2010).

Tabela 18 - Valores de coeficiente linear (a), coeficiente angular $\left(\mathrm{a}_{1}\right)$ e coeficiente de determinação $\left(\mathrm{R}^{2}\right)$ obtidos a partir de um ajuste linear dos valores de coeficientes de atenuação linear das amostras em relação aos valores de coeficiente de atenuação linear da água obtido utilizando o XCOM (Berger et al., 2010).

\begin{tabular}{lrrr}
\hline Nome & $\mathrm{a}_{0}$ & $\mathrm{a}_{1}$ & \multicolumn{1}{c}{$\mathrm{R}^{2}$} \\
\hline AG1 & $0,054(2)$ & $0,81(1)$ & 0,87 \\
AG1* & $0,043(2)$ & $0,86(1)$ & 0,86 \\
AG2 & $0,026(3)$ & $0,92(1)$ & 0,87 \\
AG2* & $0,049(3)$ & $0,94(1)$ & 0,87 \\
AG3 & $0,044(3)$ & $0,85(1)$ & 0,86 \\
AG3* & $0,042(3)$ & $0,88(1)$ & 0,85 \\
AG4 & - & - & - \\
AG5 & $0,041(3)$ & $0,87(1)$ & 0,85 \\
AG6 & $0,031(2)$ & $0,94(1)$ & 0,88 \\
\hline
\end{tabular}

4.4.4 Estimativa dos coeficientes de atenuação linear de materiais radiologicamente equivalentes ao tecido mole

A Figura 42 apresenta os valores de coeficiente de atenuação linear da amostra TM2 determinados experimentalmente e a diferença entre estes valores e os coeficientes de atenuação 
linear do tecido mole obtido utilizando a base de dados do XCOM (Berger et al., 2010). A amostra TM2 apresentou o melhor resultado para o $\chi^{2}$ segundo a Tabela 19. Apesar disso é possível observar que seus valores de coeficiente de atenuação linear possuem uma pequena tendência, sendo sempre maiores que os valores de coeficiente de atenuação linear do tecido mole. Essa tendência também foi observada nos valores de coeficiente de atenuação das amostras TM1, TM2 e TM3 (vide Apêndice B).
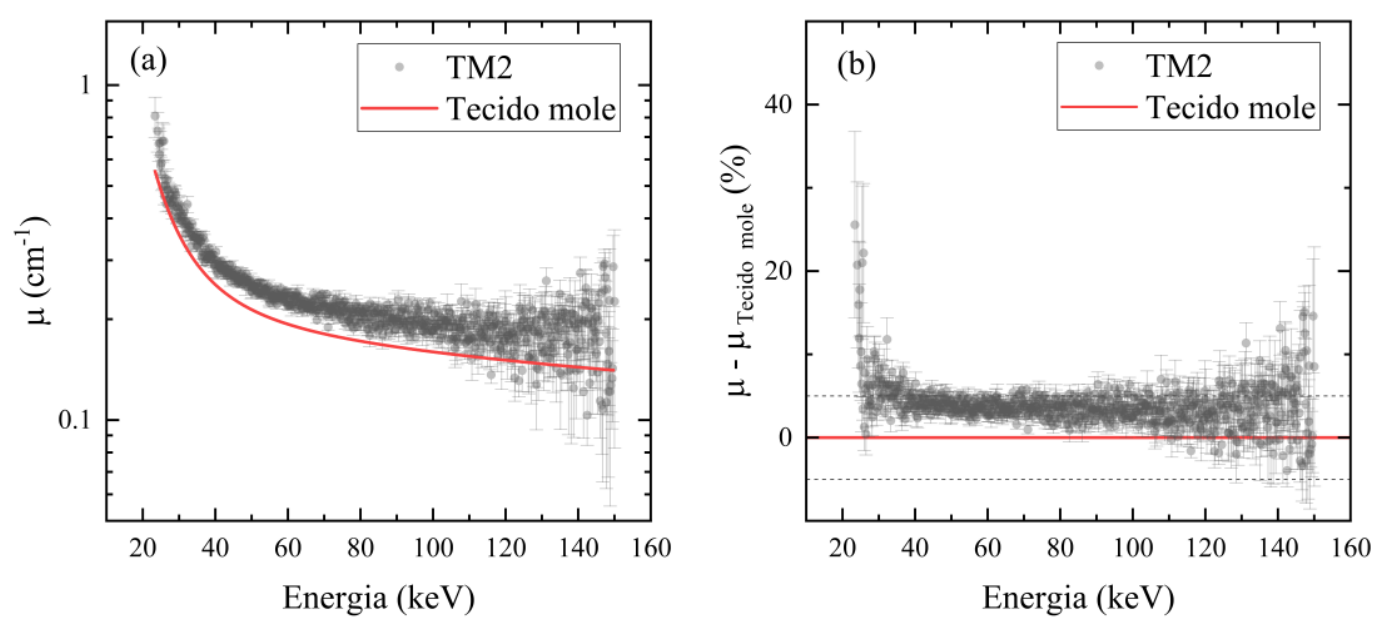

Figura 42 - (a) valores de coeficiente de atenuação linear da amostra TM2 e (b) diferença entre estes valores e os valores de coeficiente de atenuação linear do tecido mole. As retas pontilhadas demarcam uma diferença de $\pm 5 \%$.

Tabela 19 - Valores de $\chi^{2}$ calculados a partir da diferença para as amostras TM1, TM2, TM3 e TM6 em relação ao tecido mole.

\begin{tabular}{lr}
\hline Nome & $\chi^{2}$ \\
\hline TM1 & 14,1 \\
TM2 & 13,5 \\
TM3 & 15,5 \\
TM6 & 14,5 \\
\hline
\end{tabular}

Os valores de coeficiente de atenuação linear também foram analisados a partir de ajustes lineares em relação aos coeficientes de atenuação linear dos materiais de referência. A Figura 43 apresenta a reta ajustada para os valores de coeficiente de atenuação linear para a amostra TM2 e os valores do tecido mole obtidos a partir do banco de dados XCOM (Berger et al., 2010). A Tabela 20 apresenta os resultados de coeficiente linear e angular e o coeficiente de determinação $\left(\mathrm{R}^{2}\right)$ obtidos a partir do ajuste. 


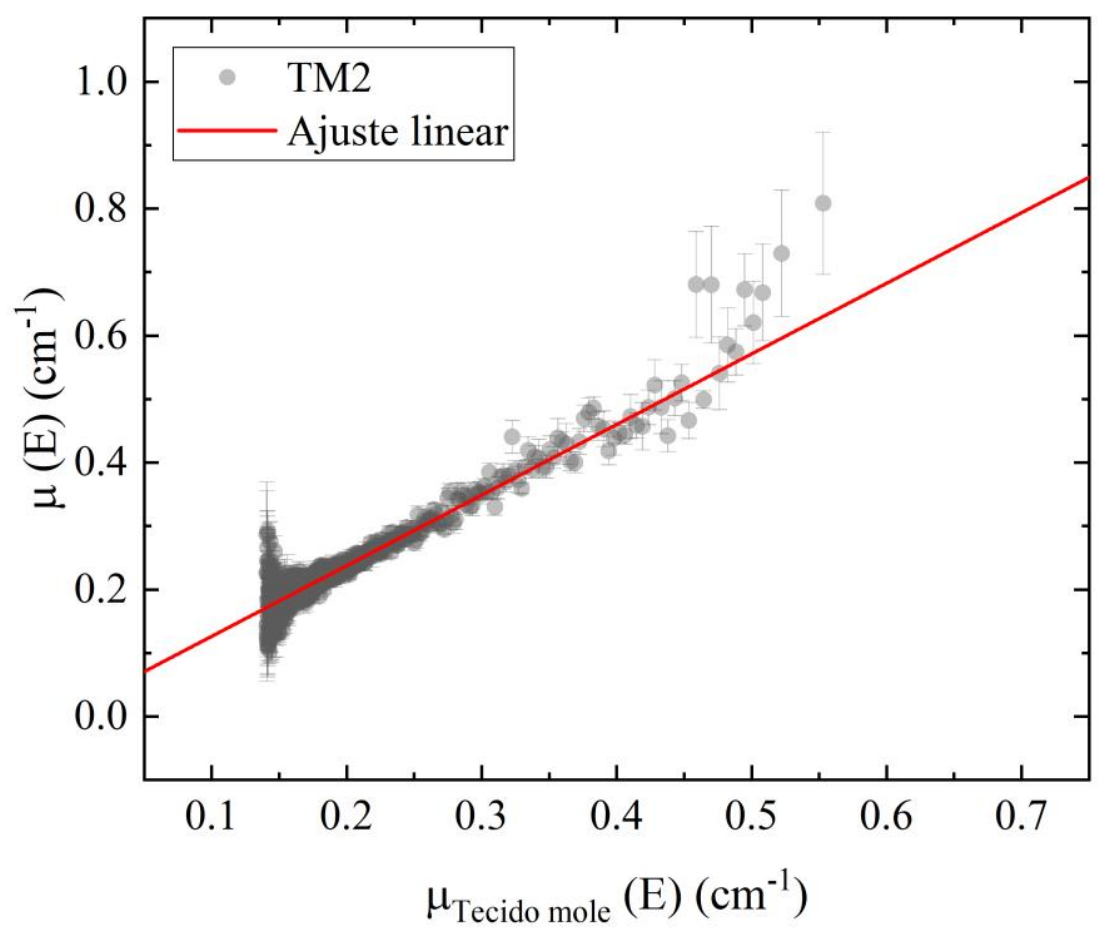

Figura 43 - Valores de coeficiente de atenuação linear da amostra TM2 em relação aos valores do tecido mole obtidos utilizando o banco de dados XCOM (Berger et al., 2010).

Tabela 20 - Valores de coeficiente linear $\left(\mathrm{a}_{0}\right)$, coeficiente angular $\left(\mathrm{a}_{1}\right)$ e coeficiente de determinação $\left(\mathrm{R}^{2}\right)$ obtidos a partir de um ajuste linear dos valores de coeficientes de atenuação linear das amostras em relação aos valores de coeficiente de atenuação linear do tecido mole obtido utilizando o XCOM (Berger et al., 2010).

\begin{tabular}{rccc}
\hline Nome & $\mathrm{a}_{0}$ & $\mathrm{a}_{1}$ & $\mathrm{R}^{2}$ \\
\hline TM1 & $0,048(2)$ & $0,94(1)$ & 0,91 \\
TM2 & $0,015(2)$ & $1,11(1)$ & 0,93 \\
TM3 & $0,019(2)$ & $1,10(1)$ & 0,92 \\
TM6 & $0,009(2)$ & $1,15(1)$ & 0,93 \\
\hline
\end{tabular}

4.4.5 Estimativa dos coeficientes de atenuação linear de materiais equivalentes aos materiais comerciais CIRS BR12 e CIRS 70/30

A Figura 44 apresenta os valores de coeficiente de atenuação linear da amostra MA8 determinados experimentalmente e a diferença entre estes valores e os coeficientes de atenuação linear do material comercial CIRS BR12 obtidos utilizando a base de dados do XCOM (Berger et al., 2010). A amostra MA8 apresentou o melhor resultado segundo a Tabela 21 para o $\chi^{2}$. Os 
valores de coeficiente de atenuação linear para os das amostras MA1, MA7 e MA9 são apresentados no Apêndice C.
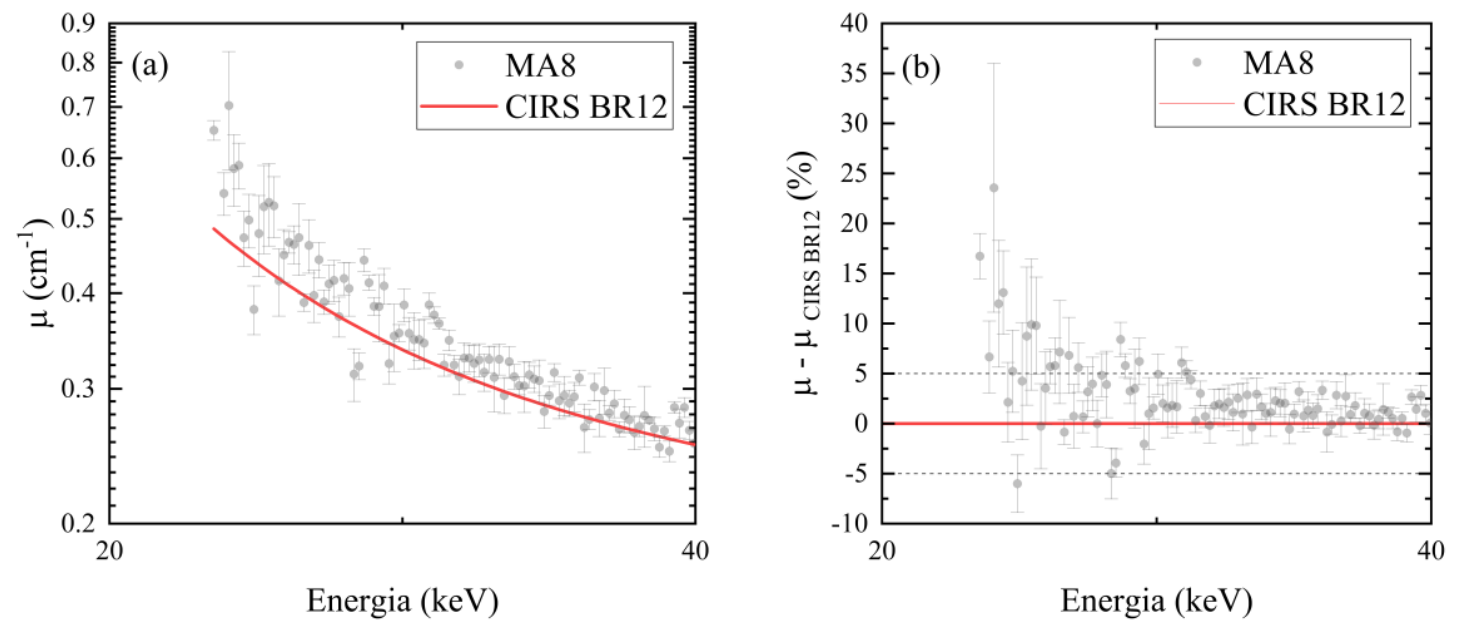

Figura 44 - (a) valores de coeficiente de atenuação linear da amostra MA8 e (b) diferença entre estes valores e os valores de coeficiente de atenuação linear do material comercial CIRS BR12. As retas pontilhadas demarcam uma diferença de $\pm 5 \%$.

Tabela 21 - Valores de $\chi^{2}$ calculados a partir da diferença para as amostras MA1 e MA7 em relação ao material comercial CIRS 70/30 e para as amostras MA8 e MA9 em relação ao material comercial CIRS BR12.

\begin{tabular}{lr}
\hline Nome & $\chi^{2}$ \\
\hline MA1 & 9,5 \\
MA7 & 18,1 \\
MA8 & 3,9 \\
MA9 & 16,7 \\
\hline
\end{tabular}

Os valores de coeficiente de atenuação linear também foram analisados a partir de ajustes lineares em relação aos valores de coeficiente de atenuação linear dos materiais de referência. A Figura 45 apresenta a reta ajustada para os valores de coeficiente de atenuação linear obtidos para a amostra MA8 e os valores do material comercial CIRS BR12 obtidos a partir do banco de dados XCOM (Berger et al., 2010). A Tabela 22 apresenta os resultados de coeficiente linear e angular e o coeficiente de determinação $\left(\mathrm{R}^{2}\right)$ obtidos a partir do ajuste.

A amostra MA8 apresentou o melhor resultado e é compatível com o material comercial CIRS BR12 no intervalo 31 a $40 \mathrm{keV}$ com $\pm 5 \%$ de diferença. 


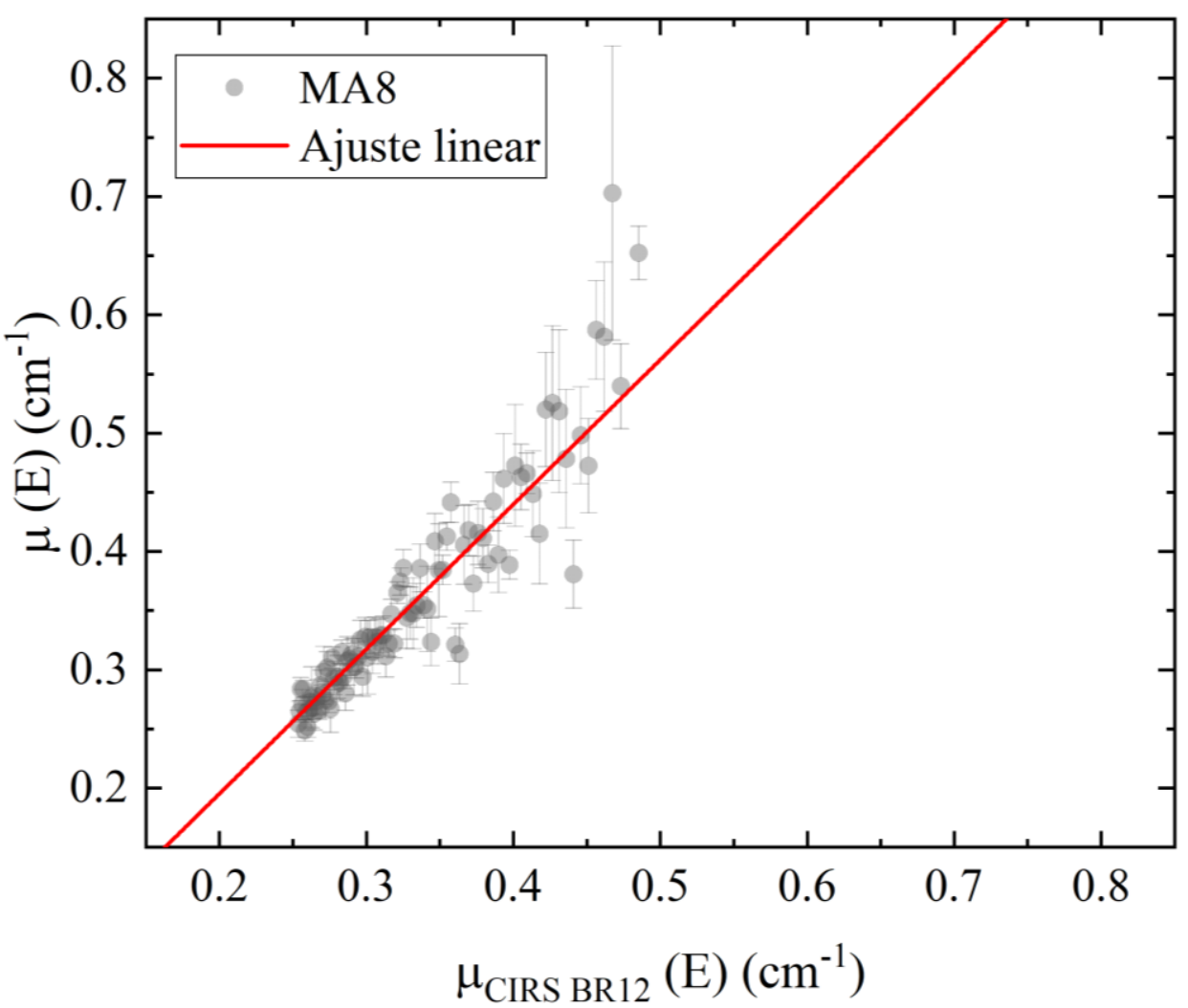

Figura 45 - Valores de coeficiente de atenuação linear da amostra MA8 em relação aos valores do material comercial CIRS BR12 obtidos a partir do banco de dados XCOM (Berger et al., 2010).

Tabela 22 - Valores de coeficiente linear $\left(\mathrm{a}_{0}\right)$, coeficiente angular $\left(\mathrm{a}_{1}\right)$ e coeficiente de determinação $\left(\mathrm{R}^{2}\right)$ obtidos a partir de um ajuste linear dos valores de coeficientes de atenuação linear das amostras em relação aos valores de coeficiente de atenuação linear dos materiais comerciais CIRS BR12 e CIRS 70/30 obtidos utilizando o XCOM (Berger et al., 2010).

\begin{tabular}{rrrr}
\hline Nome & $\mathrm{a}_{0}$ & $\mathrm{a}_{1}$ & $\mathrm{R}^{2}$ \\
\hline MA1 & $-0,01(1)$ & $1,16(4)$ & 0,88 \\
MA7 & $-0,08(1)$ & $1,48(5)$ & 0,90 \\
MA8 & $-0,05(1)$ & $1,22(5)$ & 0,87 \\
MA9 & $0,03(8)$ & $0,76(3)$ & 0,88 \\
\hline
\end{tabular}

Os valores de coeficiente de atenuação linear também foram comparados com os valores de coeficiente de atenuação linear obtidos pelo banco de dados XCOM (Berger et al., 2010) para o tecido mamário definido no ICRU Report 44 (White et al., 1989). A Tabela 23 apresenta os resultados de $\chi^{2}$ obtidos. Em relação ao tecido mamário, a amostra MA1 apresentou o melhor resultado de $\chi^{2}$. 
Tabela 23 - Valores de $\chi^{2}$ calculados a partir da diferença para as amostras MA1, MA7, MA8 e MA9 em relação ao tecido mamário definido no ICRU Report 44.

\begin{tabular}{lr}
\hline Nome & $\chi^{2}$ \\
\hline MA1 & 3,9 \\
MA7 & 9,7 \\
MA8 & 5,0 \\
MA9 & 14,2 \\
\hline
\end{tabular}

A Figura 46 apresenta os valores de coeficiente de atenuação linear da amostra MA1 determinados experimentalmente e a diferença entre estes valores e os coeficientes de atenuação linear do tecido mamário obtidos pelo banco de dados XCOM (Berger et al., 2010).
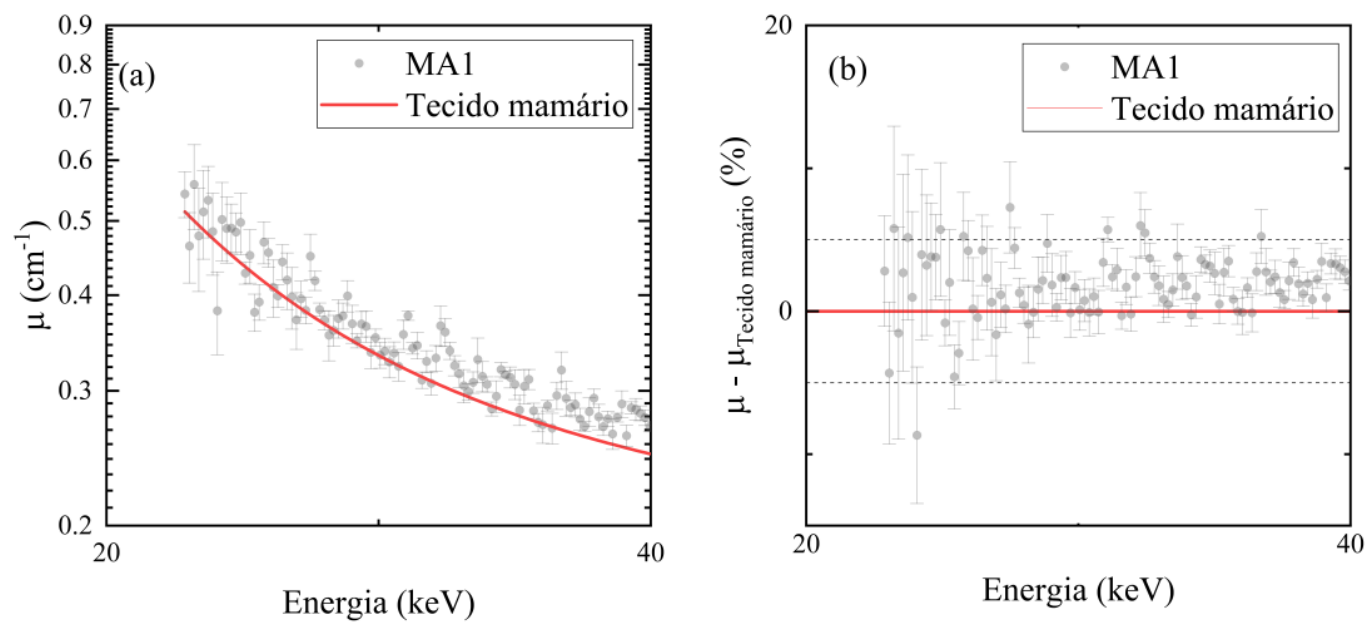

Figura 46 - (a) valores de coeficiente de atenuação linear da amostra MA8 e (b) diferença entre estes valores e os valores de coeficiente de atenuação linear do material comercial CIRS BR12. As retas pontilhadas demarcam uma diferença de $\pm 5 \%$. 


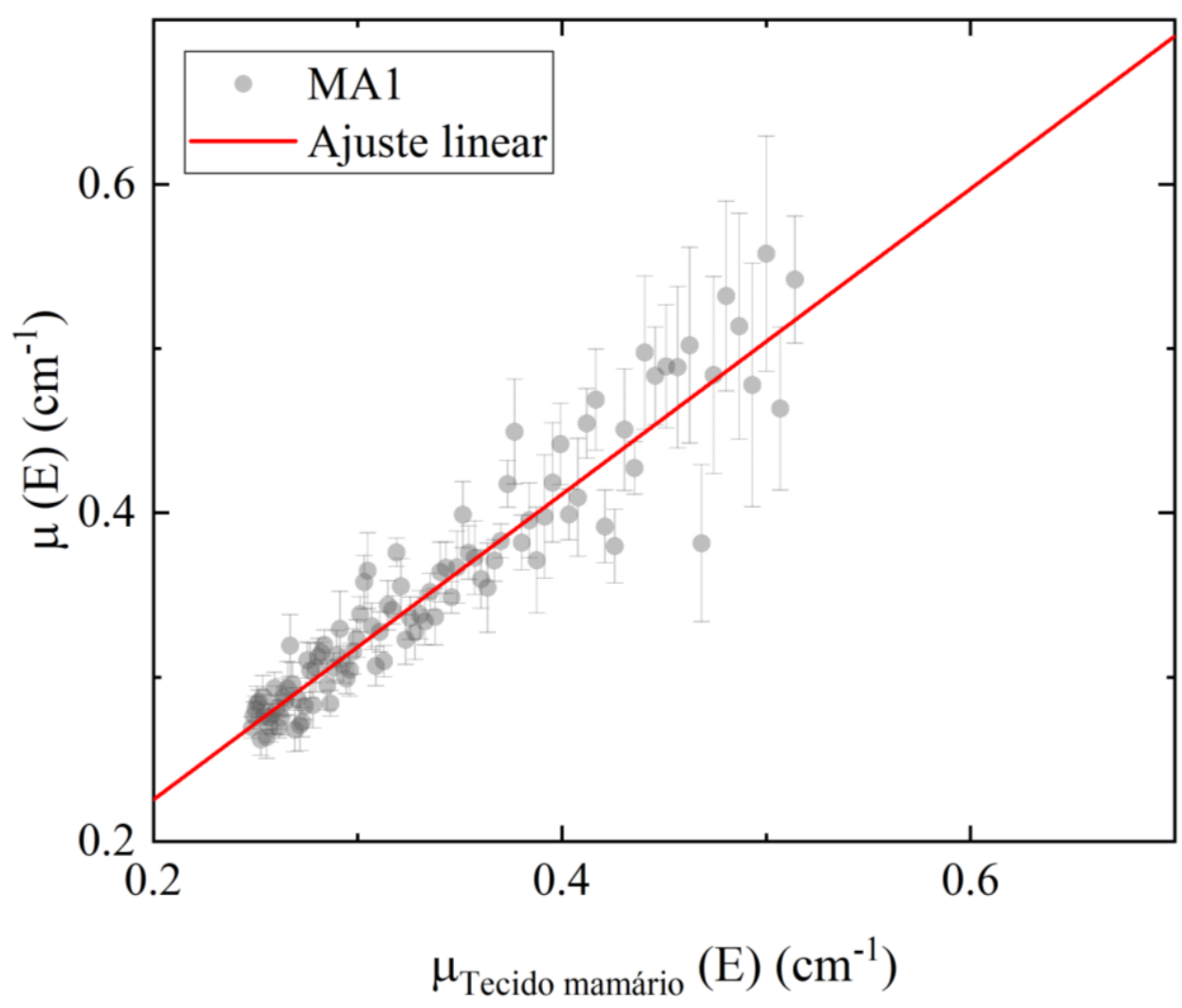

Figura 47 - Valores de coeficiente de atenuação linear da amostra MA8 em relação aos valores do tecido mamário obtidos a partir do banco de dados XCOM (Berger et al., 2010).

Tabela 24 - Valores de coeficiente linear (a), coeficiente angular $\left(\mathrm{a}_{1}\right)$ e coeficiente de determinação $\left(\mathrm{R}^{2}\right)$ obtidos a partir de um ajuste linear dos valores de coeficientes de atenuação linear das amostras em relação aos valores de coeficiente de atenuação linear do tecido mamário obtidos utilizando o XCOM (Berger et al., 2010).

\begin{tabular}{rrrr}
\hline Nome & \multicolumn{1}{c}{$\mathrm{a}_{0}$} & $\mathrm{a}_{1}$ & $\mathrm{R}^{2}$ \\
\hline MA1 & $0,04(1)$ & $0,93(3)$ & 0,88 \\
MA7 & $-0,02(1)$ & $1,19(4)$ & 0,90 \\
MA8 & $-0,04(1)$ & $1,21(5)$ & 0,90 \\
MA9 & $0,04(8)$ & $0,74(3)$ & 0,88 \\
\hline
\end{tabular}




\section{Conclusões}

O presente trabalho propôs estudar métodos para validar materiais radiologicamente equivalentes ao tecido humano e à água quanto as suas características radiológicas através da determinação do coeficiente de atenuação linear a partir de espectroscopia por raios $\mathrm{X}$ e determinação do coeficiente de atenuação mássico a partir de tomografia computadorizada e quanto as suas características físicas pela avaliação das densidades mássicas e número atômico efetivo.

Ao total, dezessete amostras com base de polipropileno e resina epóxi foram estudadas. As amostras estudadas apresentaram diferenças percentuais entre 9 e $15 \%$ em relação a densidade do material de referência, com exceção dos materiais MA8 e MA9 radiologicamente equivalentes ao CIRS BR12 com 1,6\% e -6,9\% de diferença, respectivamente. É possível perceber que os resultados da diferença relativa para as amostras produzidas com base de polipropileno como material-base foram menores que as amostras produzidas com base de resina epóxi, indicando que o polipropileno, com densidade nominal de $0,89 \mathrm{~g} / \mathrm{cm}^{3}$, é um material indicado para produção dos materiais radiologicamente equivalentes ao tecido humano e água. Além disso, o polipropileno é um material reciclável, isto faz com que seu uso seja preferível em relação, por exemplo, ao da resina epóxi que não é um material reciclável.

Os valores de número atômico efetivo foram determinados a partir do método de Manohara (Manohara et al., 2008) e apresentaram discrepâncias entre os materiais radiologicamente equivalentes e os materiais de referência utilizados. Observou-se que estas discrepâncias são sempre positivas indicando que os valores de número atômico efetivo são sempre maiores do que os valores de número atômico efetivo previstos dos materiais de referência. Este resultado pode indicar a necessidade de correções na metodologia de produção. Como a determinação dos valores de número atômico efetivo neste trabalho é feita a partir de métodos teóricos é possível, por exemplo, incluir o cálculo de $Z_{e f}(E)$ na metodologia de produção considerando limites de aceitação. Para complementar esta análise, é indicado realizar o cálculo do número atômico efetivo para as amostras a partir da composição química elementar determinada experimentalmente e não apenas da formulação teórica obtida, pois a pureza do material comercial utilizado influencia na composição química elementar do material (Frimaio, 2019).

Os resultados dos ajustes lineares realizados para o coeficiente mássico a partir de imagens de TC mostram que os coeficientes lineares e angular ajustados são compatíveis com zero e com a unidade, respectivamente, o que permite inferir que os coeficientes de atenuação 
mássico calculados são compatíveis aos coeficientes mássicos previstos pela metodologia de Mariano \& Costa. Em relação aos coeficientes mássicos da água obtidos pelo XCOM (Berger et al., 2010), os das amostras AG1, AG2, AG3 e AG5 apresentaram diferenças relativas de 4 a 7\%. A análise do coeficiente mássico a partir de imagens de tomografia computadorizada de dupla energia mostram que os materiais AG1, AG2, AG3 e AG5 possuem diferença relativa média menor que $7 \%$ em relação ao coeficiente mássico da água.

A espectrometria é a metodologia para determinação para dos coeficientes de atenuação linear mais confiável. Nesta análise, observou-se que, para as amostras de materiais radiologicamente equivalentes ao tecido mole e à água no intervalo de energia de 30-100 keV, as diferenças nos valores de coeficiente de atenuação linear determinados e dos valores obtidos pelo XCOM (Berger et al., 2010) dos materiais de referência são menores que 10\%. Os valores de coeficiente de atenuação linear da amostra AG2 é compatível com água no intervalo 40 a $100 \mathrm{keV}$ com $\pm 5 \%$ de diferença como determinado pelo ICRU Report 44. Para a amostra AG6 o intervalo de compatibilidade é entre 40 e $80 \mathrm{keV}$. A amostra MA8 é compatível com o material comercial CIRS BR12 no intervalo 31 a $40 \mathrm{keV}$ com $\pm 5 \%$ de diferença. Já para energias menores que $30 \mathrm{keV}$ e maiores que $100 \mathrm{keV}$ será necessário refinar a metodologia experimental para obter estimativas do coeficiente de atenuação com menor incerteza experimental. Para refinar a metodologia é indicado estender o tempo de aquisição dos espectros experimentais, o que melhora a estatística dos valores de intensidade transmitida. Deve-se também, aprimorar o arranjo experimental e os parâmetros de aquisição dos espectros para obter melhores pontos experimentais nas energias mais baixas $(\mathrm{E}<30 \mathrm{keV})$ e mais altas $(\mathrm{E}>100 \mathrm{keV})$.

A fim de comparar os métodos de análises estudados neste trabalho, foram determinadas as diferenças percentuais entre os valores de coeficiente de atenuação linear obtidos a partir da análise por tomografia computadorizada e espectrometria foram determinadas. Os resultados apresentados nas Tabelas 25 e 26 mostram que os valores de coeficiente de atenuação lineares obtidos para os dois métodos são concordantes. Este resultado verifica que os dois métodos convergem para resultados similares. A vantagem da análise por imagens tomográficas é que pode ser realizada facilmente em um ambiente clínico, mas para caracterização efetiva do material a análise por espectrometria de raios X é mais adequada. A vantagem da espectrometria por raios $\mathrm{X}$ é a possibilidade de aquisição de um número muito maior de pontos experimentais, caracterizando o material em uma ampla gama de energias, além de possibilitar uma melhor análise estatística. 
Tabela 25 - Diferenças percentuais entre os valores de coeficientes de atenuação linear, $\mu(E)$, obtidos para a análise de TC convencional em relação aos coeficientes de atenuação linear obtidos pela análise de espectrometria para as amostras AG1, AG2, AG3 e AG5.

\begin{tabular}{|c|c|c|c|c|}
\hline \multirow[b]{2}{*}{$\begin{array}{c}\text { Energia } \\
(\mathrm{keV})\end{array}$} & \multicolumn{4}{|c|}{$\begin{array}{l}\text { Diferença percentual }(\%) \text { entre } \mu(E) \text { obtidos por } \\
\text { TC convencional e por espectrometria de raios X }\end{array}$} \\
\hline & AG1 & AG2 & AG3 & AG5 \\
\hline 47,6 & $-0,1$ & 3,8 & $-2,4$ & $-0,5$ \\
\hline 53,6 & $-0,1$ & 2,7 & $-0,3$ & $-0,9$ \\
\hline 58,2 & $-0,3$ & 0,8 & 0,1 & $-0,2$ \\
\hline 62,0 & 0,4 & 2,3 & 1,8 & 1,3 \\
\hline
\end{tabular}

Tabela 26 - Diferenças percentuais entre os valores de coeficientes de atenuação linear, $\mu(E)$, obtidos para a análise de TC de dupla energia em relação aos coeficientes de atenuação linear obtidos pela análise de espectrometria para as amostras AG1, AG2, AG3 e AG5.

\begin{tabular}{rrrrr} 
& \multicolumn{4}{c}{ Diferença percentual $(\%)$ entre $\mu(E)$ obtidos por } \\
Energia & \multicolumn{4}{c}{ TC de dupla energia e por espectrometria de raios X } \\
\cline { 2 - 5 }$(\mathrm{keV})$ & AG1 & AG2 & AG3 & AG5 \\
\hline 60 & 1,1 & 1,6 & 1,8 & 2,5 \\
70 & $-0,4$ & $-0,6$ & 1,2 & 1,3 \\
80 & 2,8 & $-0,6$ & 1,0 & 2,6 \\
90 & $-0,1$ & 0,0 & 0,8 & 1,1 \\
100 & 1,1 & $-2,8$ & $-3,3$ & 0,0 \\
110 & 3,2 & 5,8 & 1,4 & $-2,6$ \\
120 & 1,4 & 0,9 & $-0,8$ & $-2,7$ \\
130 & 1,2 & $-1,2$ & 1,7 & 5,9 \\
140 & 8,2 & $-5,2$ & 0,5 & $-6,3$ \\
\hline
\end{tabular}

É importante ressaltar que as comparações feitas para os resultados de tomografia computadorizada convencional, tomografia computadoriza de dupla energia e espectrometria foram realizados a partir de dados experimentais das amostras de materiais produzidos e de dados dos materiais de referência obtidos pelo banco XCOM (Berger et al., 2010). Não foram realizadas análises comparativas experimentais com água ou material biológico. Estas análises são importantes para pesquisas posteriores como forma de validação dos experimentos realizados.

Em dezembro de 2019, a Agência Nacional de Vigilância Sanitária (ANVISA) publicou uma Resolução da Diretoria Colegiada - RDC nº 330 (RDC 330/2019) que tem como objetivo: estabelecer os requisitos sanitários para serviços de radiologia diagnóstica ou intervencionista; e regulamentar o controle de exposições médicas, ocupacionais e do público decorrentes do uso de tecnologias radiológicas diagnósticas ou intervencionistas. A RDC 330/2019 foi publicada em conjunto com seis Instruções Normativas (INs) n ${ }^{\circ}$ 52-57. 
A IN n ${ }^{\circ} 54$ que trata de sistemas de mamografia e a IN n ${ }^{\circ} 55$ que trata de sistemas de tomografia computadorizada médica exigem o uso de objetos simuladores para controle de qualidade de equipamentos e medições de dose.

Recentemente, a RDC $n^{\circ} 440$ (RDC440/2020) e IN $n^{\circ} 58$ foram publicadas pela ANVISA fazendo alterações complementares na RDC n 330.

Mudanças na legislação brasileira sobre o assunto, como as apontadas acima, comprovam a importância que o Estado brasileiro dispensa a respeito da proteção radiológica. Assim, a produção de objetos simuladores se encontra na perspectiva nacional atual em termos de inovação tecnológica e independência de materiais importados. Consequentemente, o desenvolvimento de materiais radiologicamente equivalentes também é de grande importância.

Cerca de quinze novas amostras com formulações com base de polipropileno foram produzidas no final de 2019. Análises com estes materiais foram interrompidas em decorrência da pandemia do COVID-19 e serão retomados em trabalhos futuros. 
Apêndice A - Estimativa do coeficiente de atenuação linear de materiais radiologicamente equivalentes à água

\subsection{Amostra AG1}
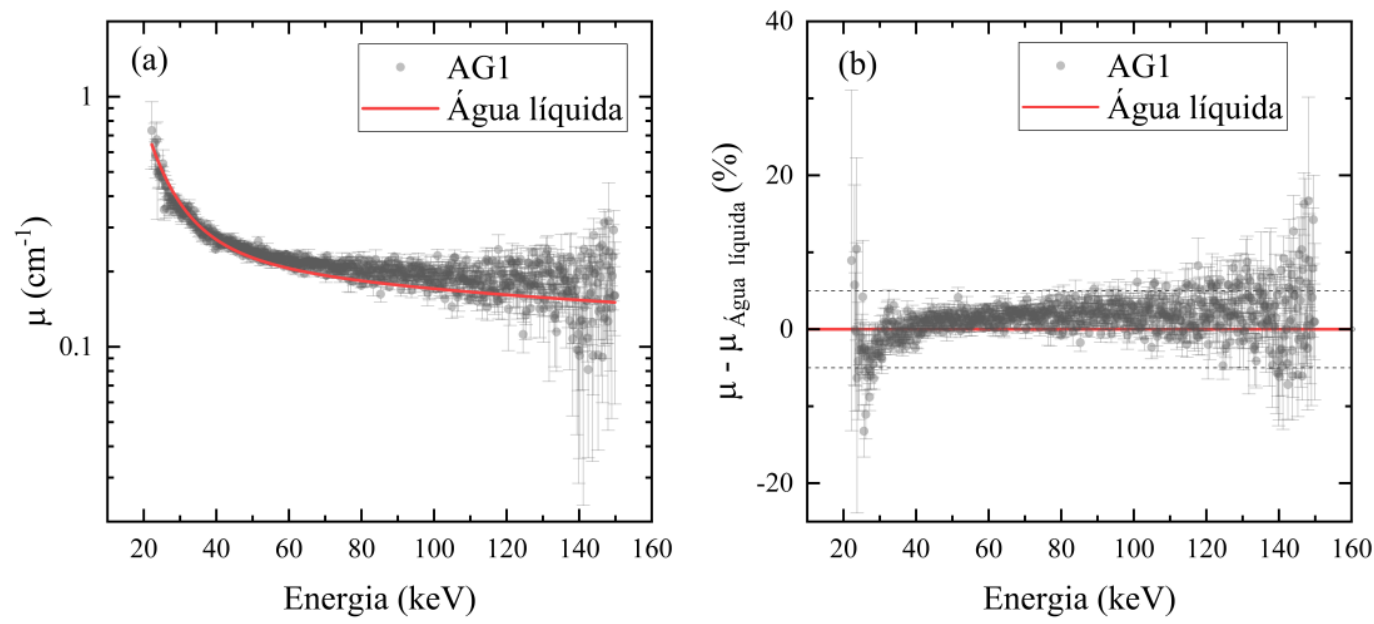

Figura do apêndice 1 - (a) valores de coeficiente de atenuação linear da amostra AG1 e (b) diferença entre estes valores e os valores de coeficiente de atenuação linear da água. As retas pontilhadas demarcam uma diferença de $\pm 5 \%$.

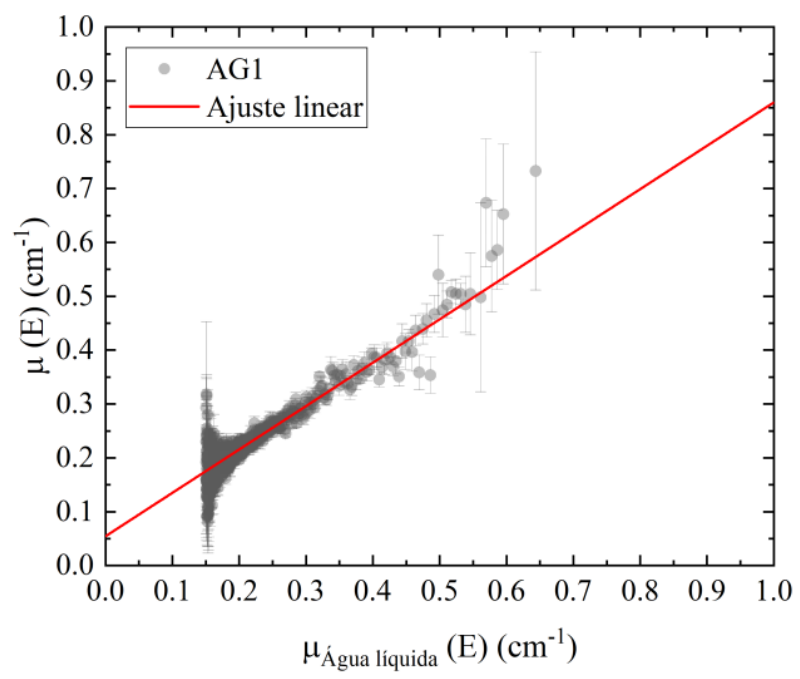

Figura do apêndice 2 - Valores de coeficiente de atenuação linear da amostra AG1 em relação aos valores da água obtidos a partir do banco de dados XCOM (Berger et al., 2010).

Os coeficientes obtidos no ajuste são: $\mathrm{a}_{0}=0,054(2), \mathrm{a}_{1}=0,81(1)$ e $\mathrm{R}^{2}=0,88$. 


\subsection{Amostra AG1*}
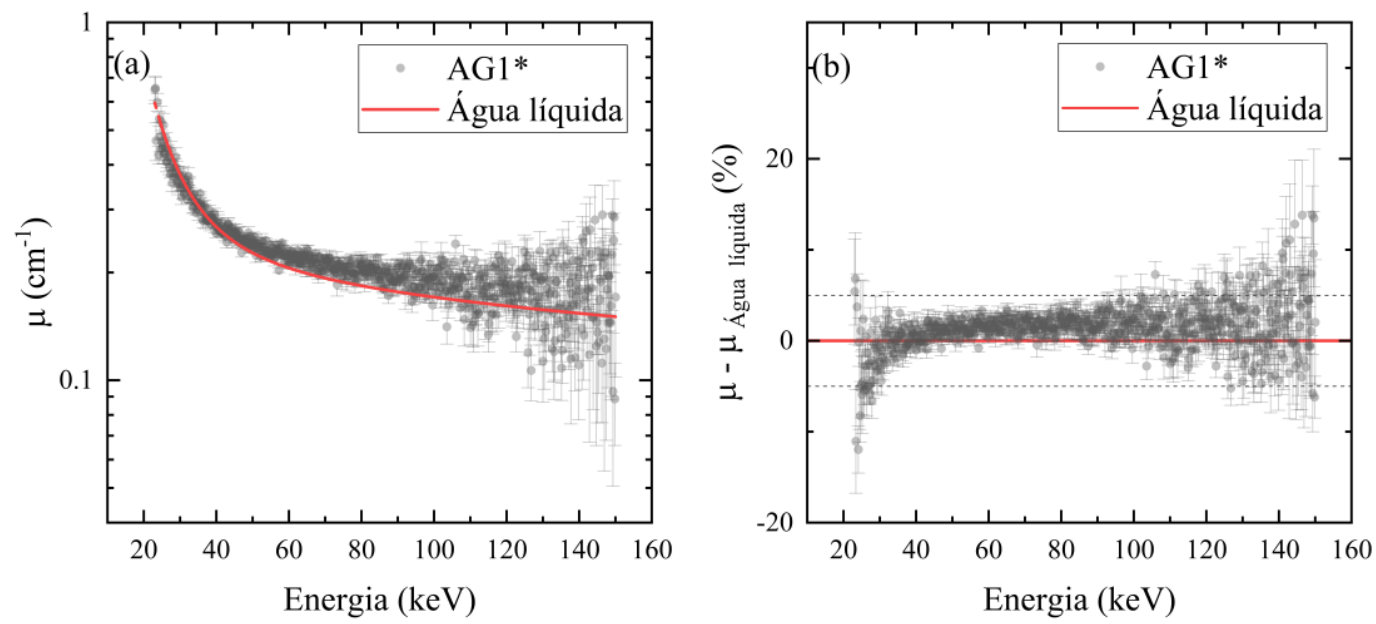

Figura do apêndice 3 - (a) valores de coeficiente de atenuação linear da amostra AG1* e (b) diferença entre estes valores e os valores de coeficiente de atenuação linear da água. As retas pontilhadas demarcam uma diferença de $\pm 5 \%$.

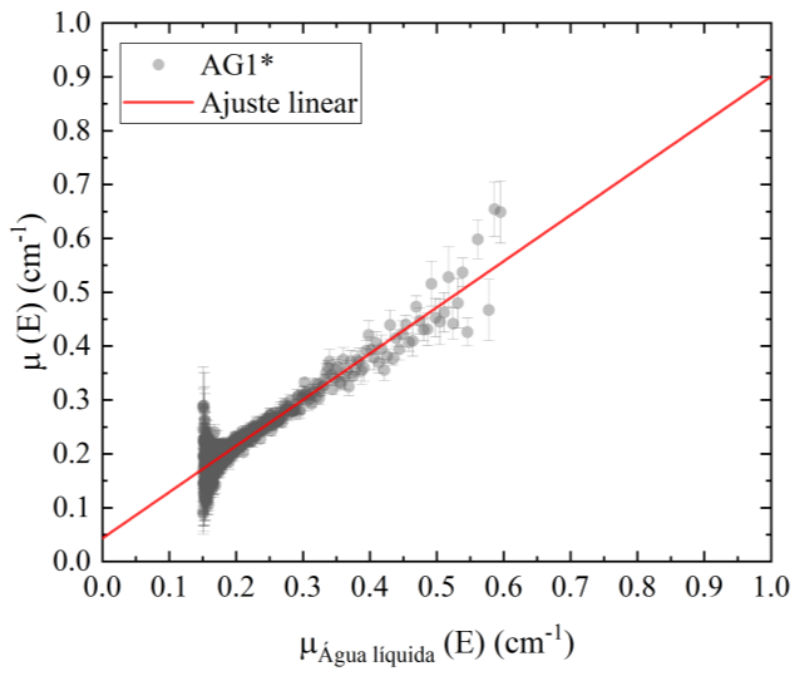

Figura do apêndice 4 - Valores de coeficiente de atenuação linear da amostra AG1* em relação aos valores da água obtidos a partir do banco de dados XCOM (Berger et al., 2010).

Os coeficientes obtidos no ajuste são: $\mathrm{a}_{0}=0,043(2), \mathrm{a}_{1}=0,86(1)$ e $\mathrm{R}^{2}=0,90$. 


\subsection{Amostra AG2*}
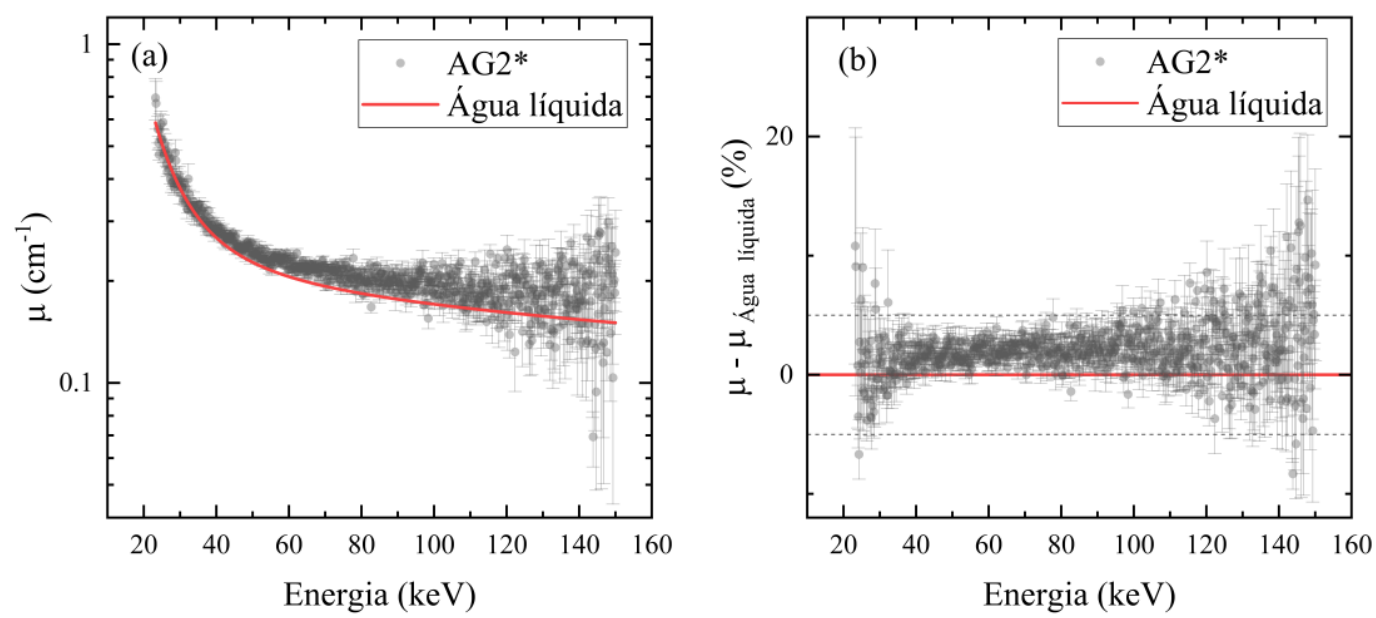

Figura do apêndice 5 - (a) valores de coeficiente de atenuação linear da amostra AG2* e (b) diferença entre estes valores e os valores de coeficiente de atenuação linear da água. As retas pontilhadas demarcam uma diferença de $\pm 5 \%$.

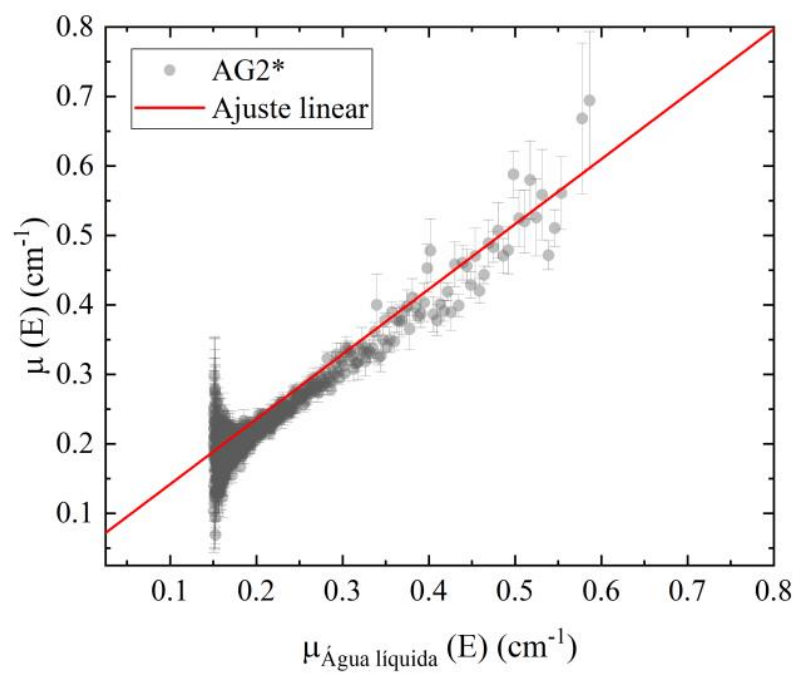

Figura do apêndice 6 - Valores de coeficiente de atenuação linear da amostra AG2* em relação aos valores da água obtidos a partir do banco de dados XCOM (Berger et al., 2010).

Os coeficientes obtidos no ajuste são: $\mathrm{a}_{0}=0,049(3), \mathrm{a}_{1}=0,94(1)$ e $\mathrm{R}^{2}=0,91$. 


\subsection{Amostra AG3}
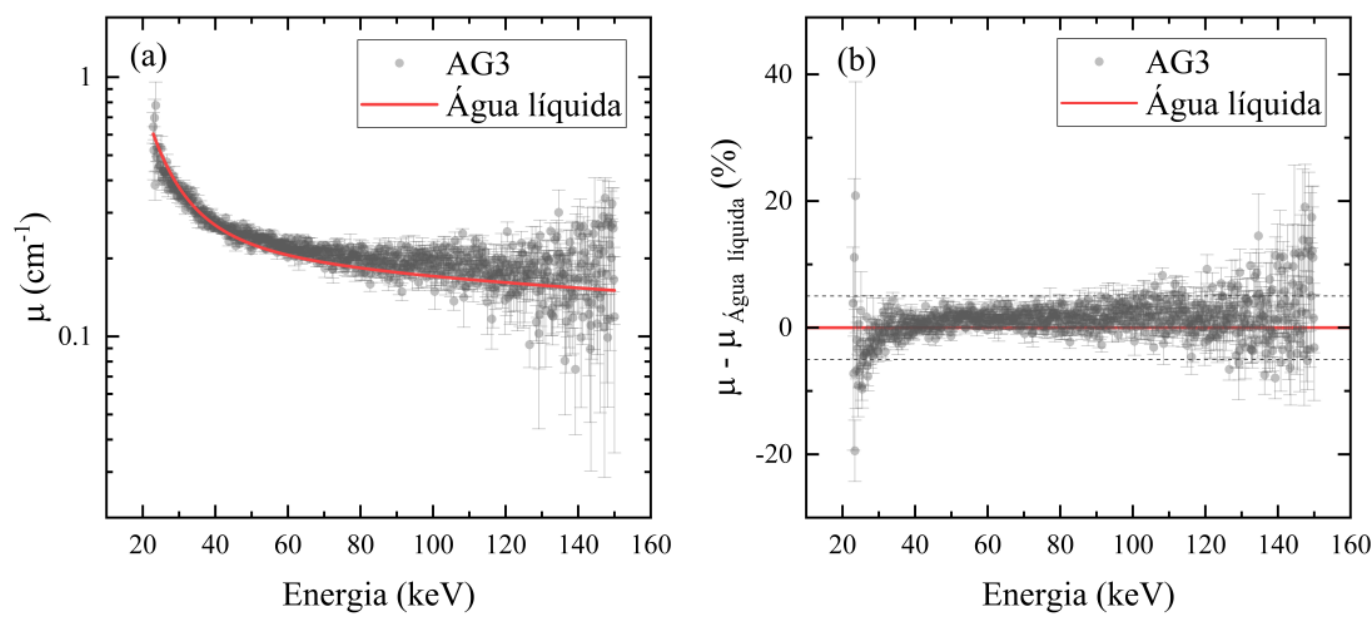

Figura do apêndice 7 - (a) valores de coeficiente de atenuação linear da amostra AG3 e (b) diferença entre estes valores e os valores de coeficiente de atenuação linear da água. As retas pontilhadas demarcam uma diferença de $\pm 5 \%$.

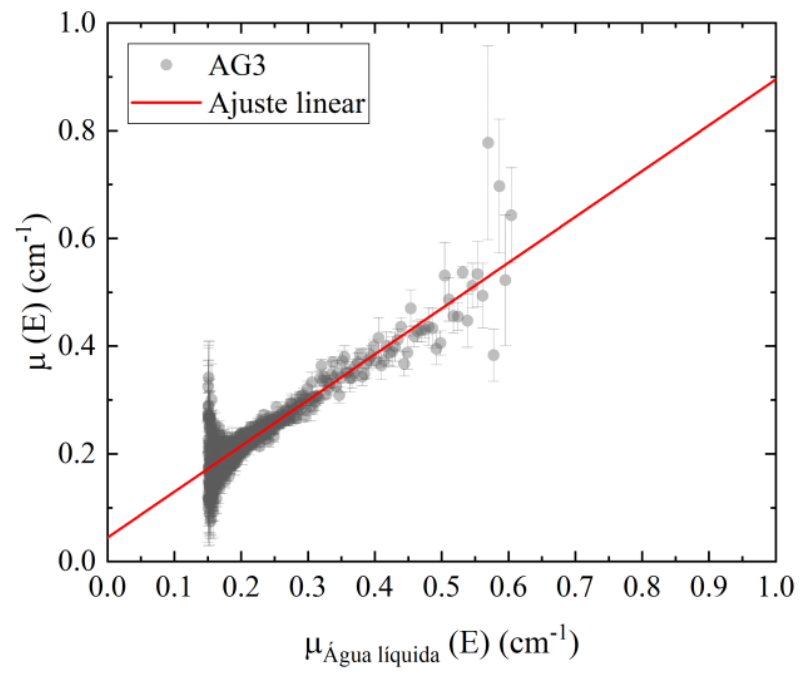

Figura do apêndice 8 - Valores de coeficiente de atenuação linear da amostra AG3 em relação aos valores da água obtidos a partir do banco de dados XCOM (Berger et al., 2010).

Os coeficientes obtidos no ajuste são: $\mathrm{a}_{0}=0,044(3), \mathrm{a}_{1}=0,85(1)$ e $\mathrm{R}^{2}=0,88$. 


\subsection{Amostra AG2}
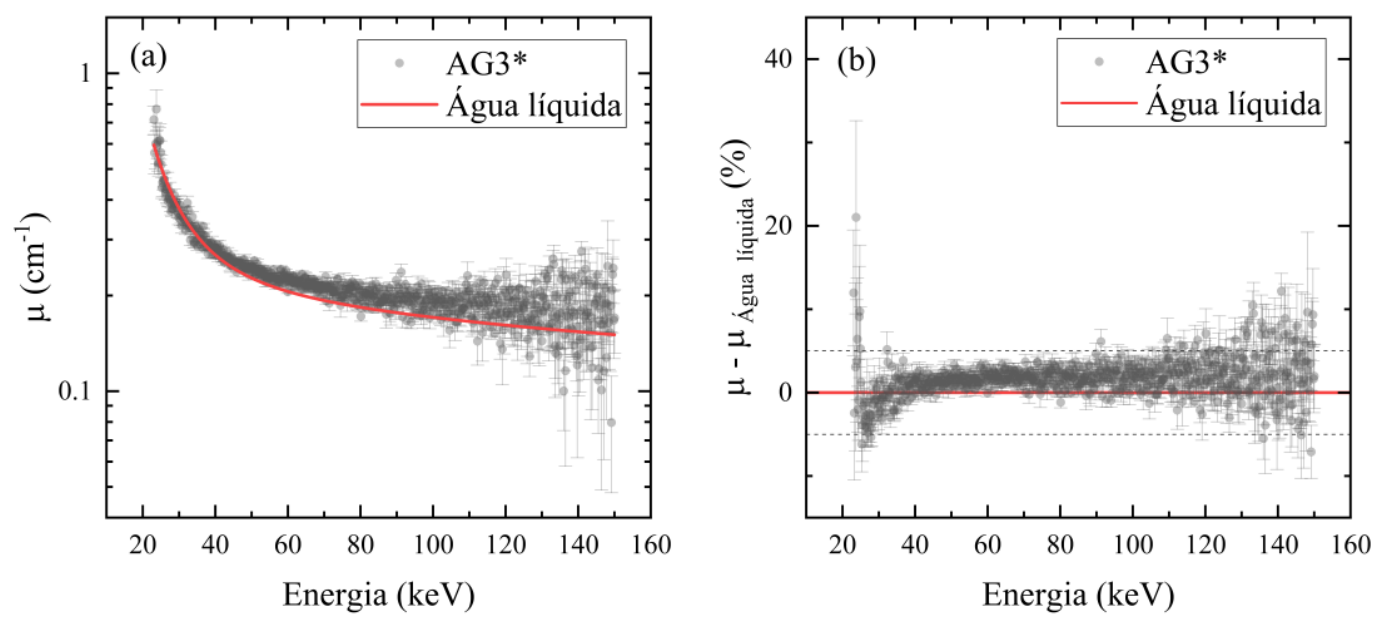

Figura do apêndice 9 - (a) valores de coeficiente de atenuação linear da amostra AG3* e (b) diferença entre estes valores e os valores de coeficiente de atenuação linear da água. As retas pontilhadas demarcam uma diferença de $\pm 5 \%$.

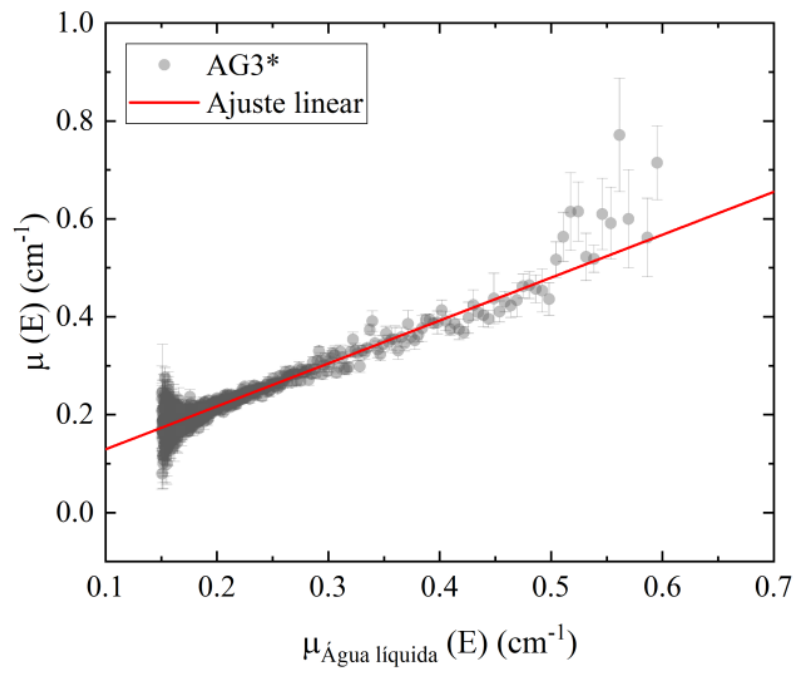

Figura do apêndice 10 - Valores de coeficiente de atenuação linear da amostra AG3* em relação aos valores da água obtidos a partir do banco de dados XCOM (Berger et al., 2010).

Os coeficientes obtidos no ajuste são: $\mathrm{a}_{0}=0,042(2), \mathrm{a}_{1}=0,88(1)$ e $\mathrm{R}^{2}=0,90$. 

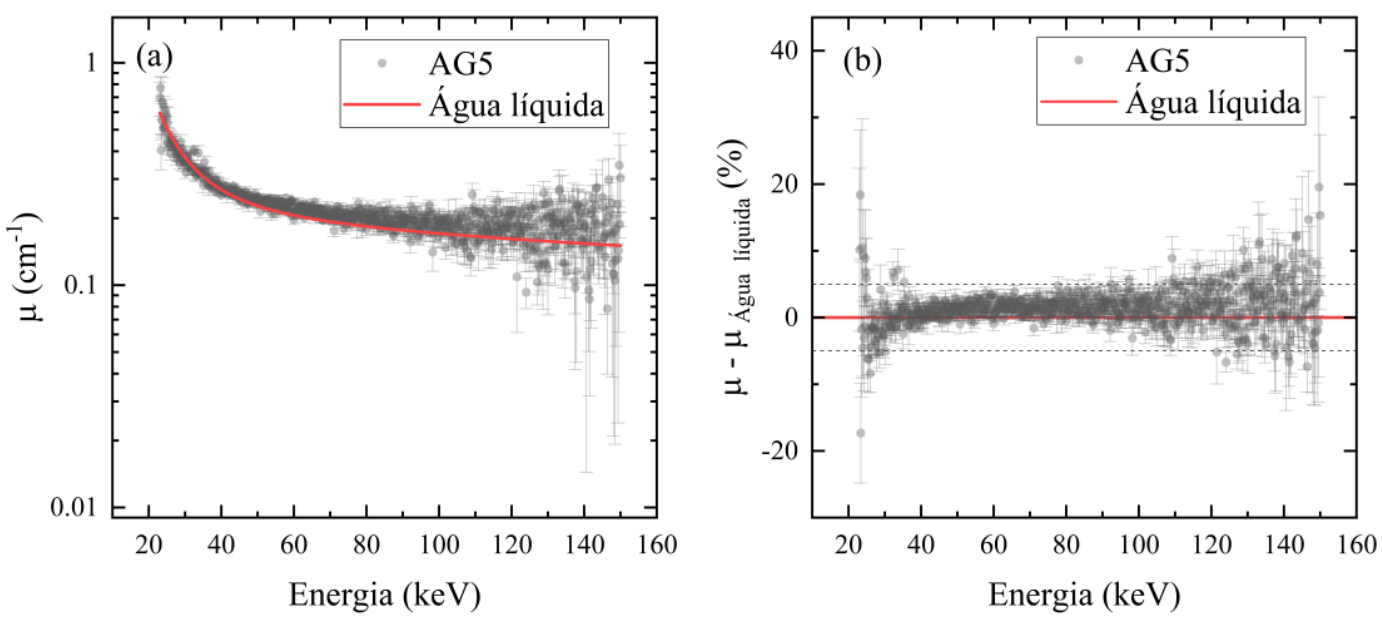

Figura do apêndice 11 - (a) valores de coeficiente de atenuação linear da amostra AG5 e (b) diferença entre estes valores e os valores de coeficiente de atenuação linear da água. As retas pontilhadas demarcam uma diferença de $\pm 5 \%$.

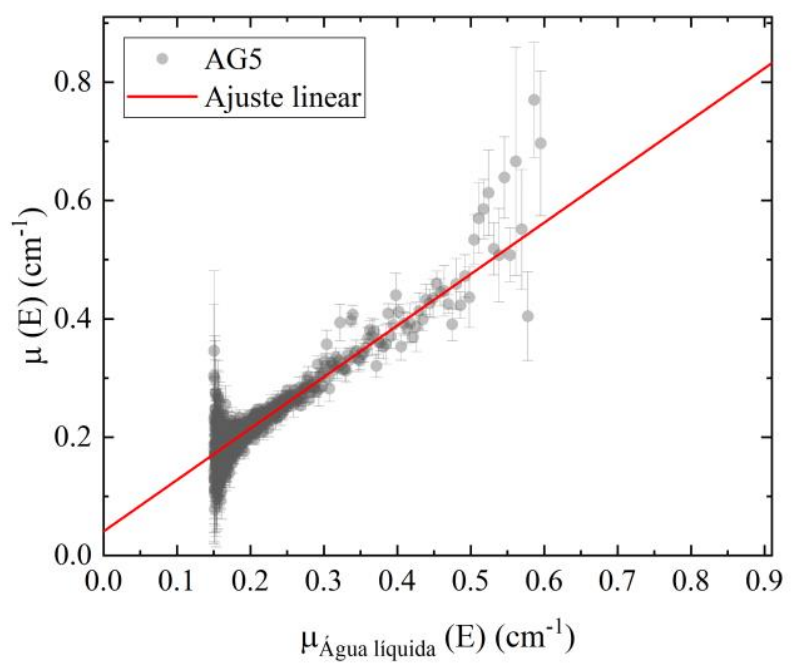

Figura do apêndice 12 - Valores de coeficiente de atenuação linear da amostra AG5 em relação aos valores da água obtidos a partir do banco de dados XCOM (Berger et al., 2010).

Os coeficientes obtidos no ajuste são: $\mathrm{a}_{0}=0,041(3), \mathrm{a}_{1}=0,87(1)$ e $\mathrm{R}^{2}=0,87$. 
Apêndice B - Estimativa do coeficiente de atenuação linear de materiais radiologicamente equivalentes ao tecido mole

\subsection{Amostra TM1}
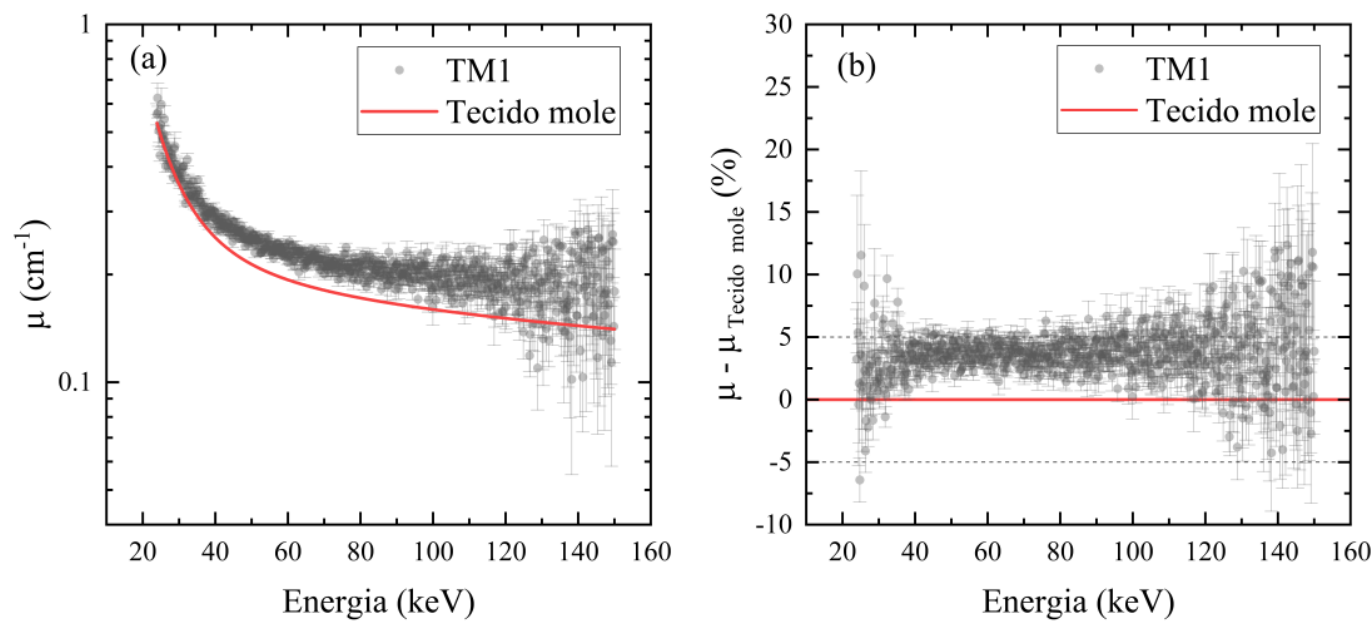

Figura do apêndice 13 - (a) valores de coeficiente de atenuação linear da amostra TM1 e (b) diferença entre estes valores e os valores de coeficiente de atenuação linear do tecido mole. As retas pontilhadas demarcam uma diferença de $\pm 5 \%$.

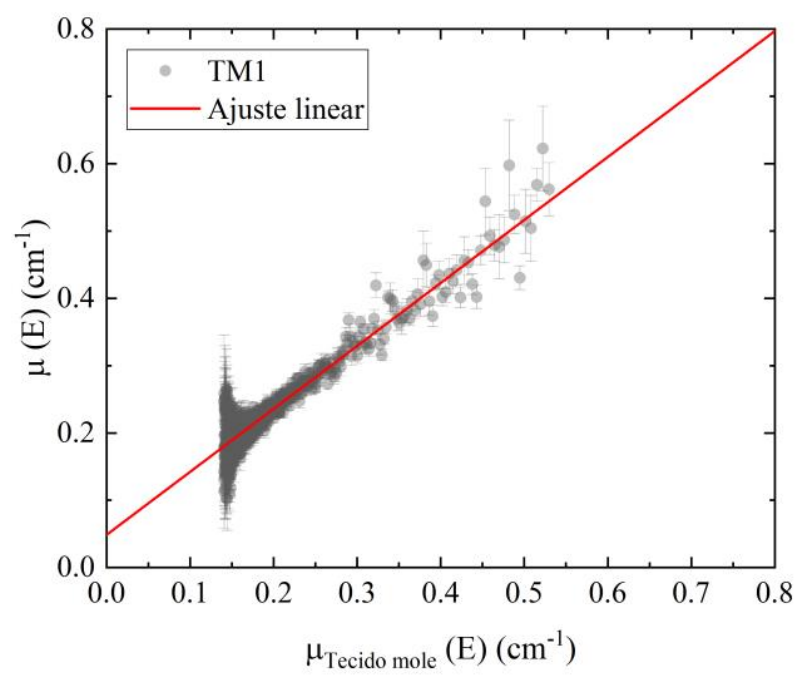

Figura do apêndice 14 - Valores de coeficiente de atenuação linear da amostra TM1 em relação aos valores do tecido mole obtidos a partir do banco de dados XCOM (Berger et al., 2010).

Os coeficientes obtidos no ajuste são: $\mathrm{a}_{0}=0,048(2), \mathrm{a}_{1}=0,94(1)$ e $\mathrm{R}^{2}=0,91$. 


\subsection{Amostra TM3}
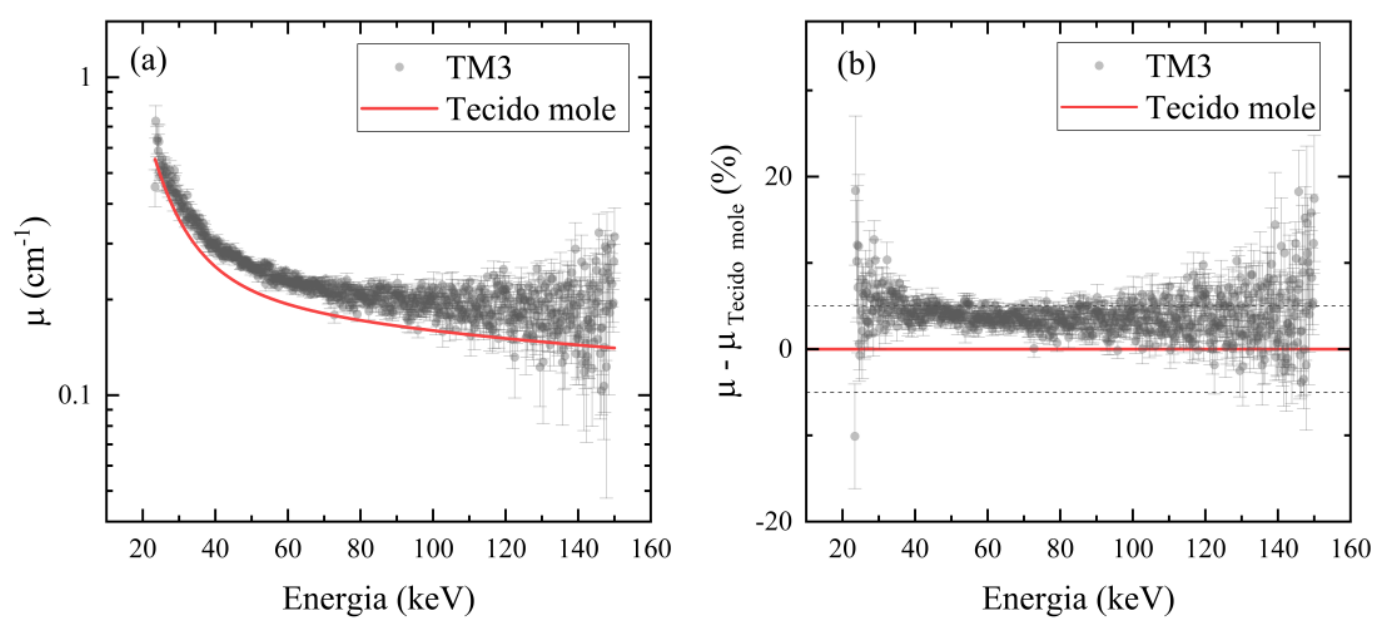

Figura do apêndice 15 - (a) valores de coeficiente de atenuação linear da amostra TM3 e (b) diferença entre estes valores e os valores de coeficiente de atenuação linear do tecido mole. As retas pontilhadas demarcam uma diferença de $\pm 5 \%$.

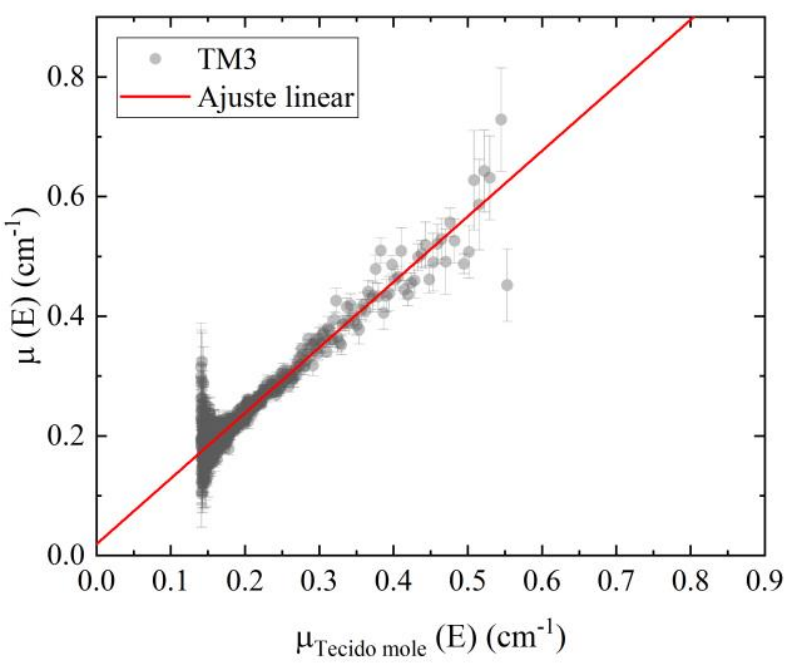

Figura do apêndice 16 - Valores de coeficiente de atenuação linear da amostra TM3 em relação aos valores do tecido mole obtidos a partir do banco de dados XCOM (Berger et al., 2010).

Os coeficientes obtidos no ajuste são: $\mathrm{a}_{0}=0,019(2), \mathrm{a}_{1}=1,10(1)$ e $\mathrm{R}^{2}=0,92$. 


\subsection{Amostra TM6}
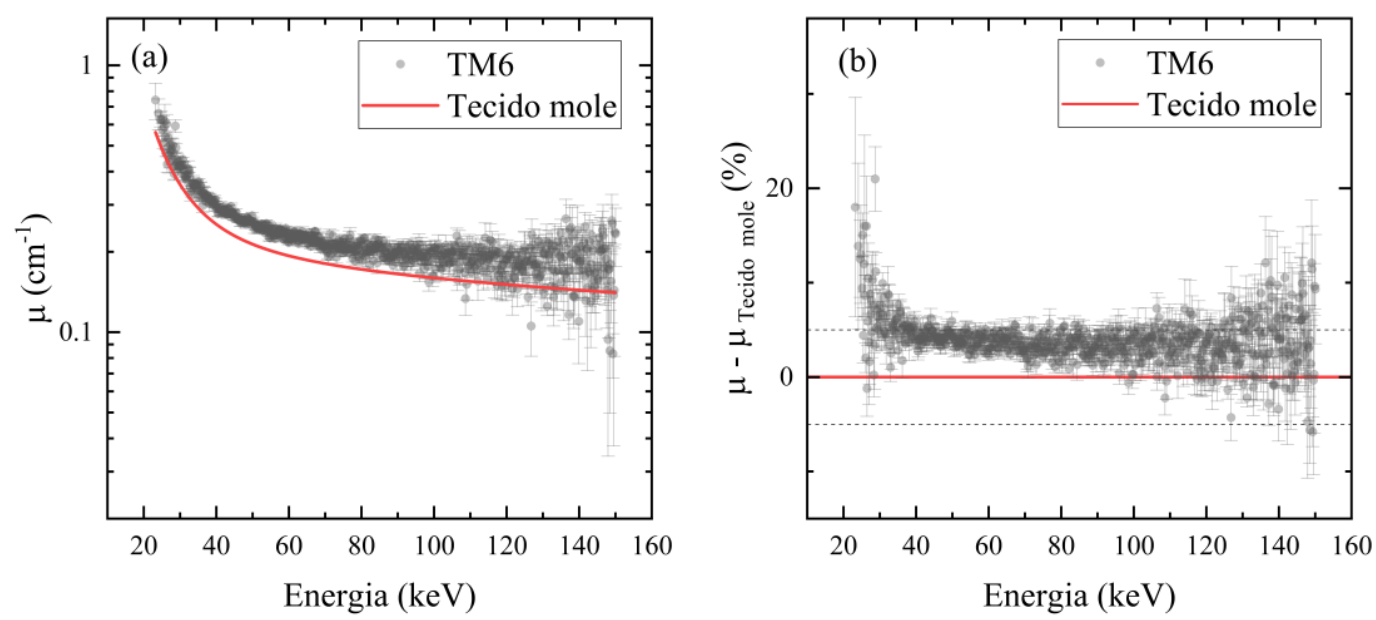

Figura do apêndice 17 - (a) valores de coeficiente de atenuação linear da amostra TM6 e (b) diferença entre estes valores e os valores de coeficiente de atenuação linear do tecido mole. As retas pontilhadas demarcam uma diferença de $\pm 5 \%$.

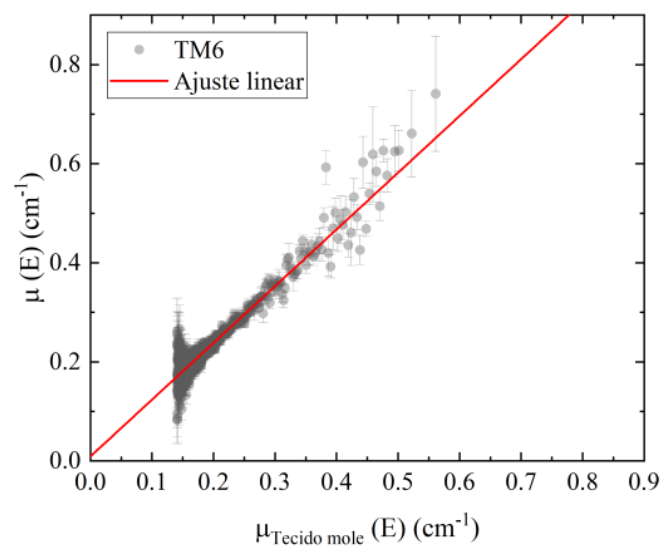

Figura do apêndice 18 - Valores de coeficiente de atenuação linear da amostra TM6 em relação aos valores do tecido mole obtidos a partir do banco de dados XCOM (Berger et al., 2010).

Os coeficientes obtidos no ajuste são: $\mathrm{a}_{0}=0,009(2), \mathrm{a}_{1}=1,15(1)$ e $\mathrm{R}^{2}=0,93$. 
Apêndice C - Estimativa do coeficiente de atenuação linear de materiais radiologicamente equivalentes aos materiais comerciais CIRS BR12 e CIRS 70/30

\subsection{Amostra MA1}
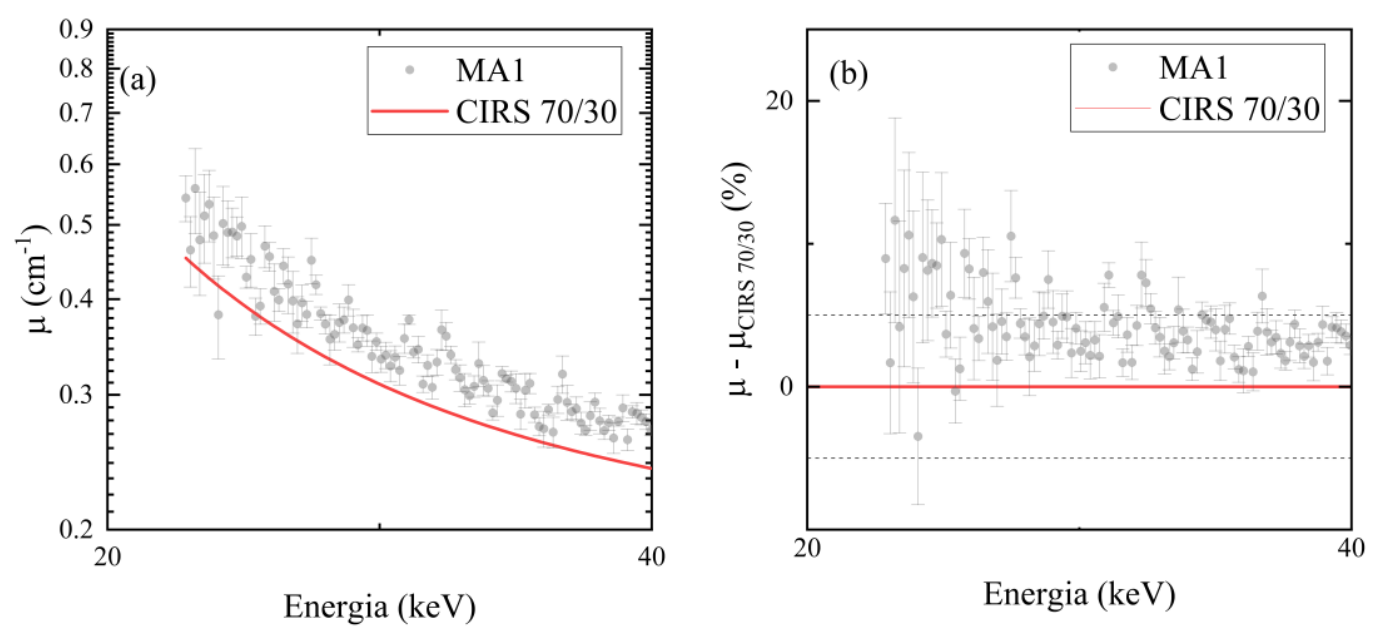

Figura do apêndice 19 - (a) valores de coeficiente de atenuação linear da amostra MA1 e (b) diferença entre estes valores e os valores de coeficiente de atenuação linear do material comercial CIRS 70/30. As retas pontilhadas demarcam uma diferença de $\pm 5 \%$.

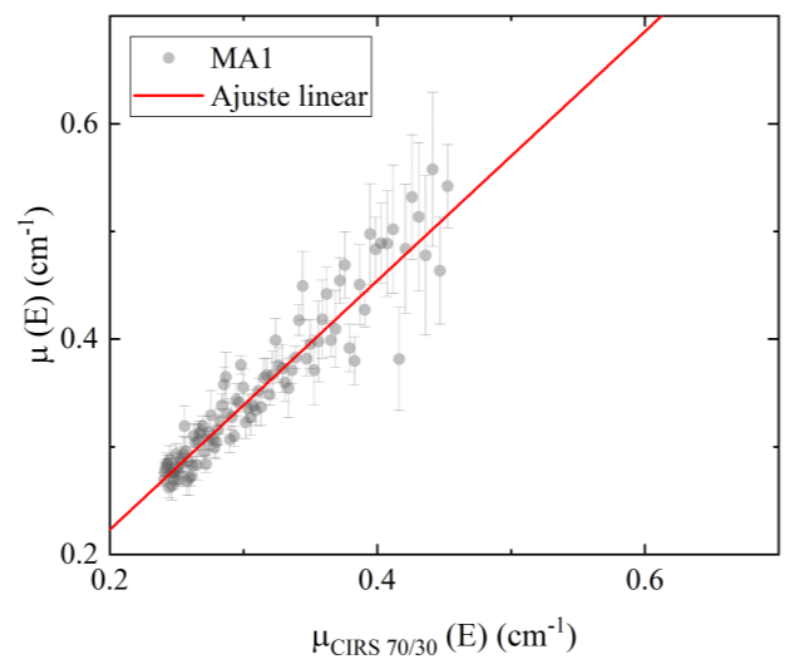

Figura do apêndice 20 - Valores de coeficiente de atenuação linear da amostra MA1 em relação aos valores do material comercial CIRS 70/30 obtidos a partir do banco de dados XCOM (Berger et al., 2010).

Os coeficientes obtidos no ajuste são: $\mathrm{a}_{0}=-0,01(1), \mathrm{a}_{1}=1,16(4)$ e $\mathrm{R}^{2}=0,88$. 


\subsection{Amostra MA7}
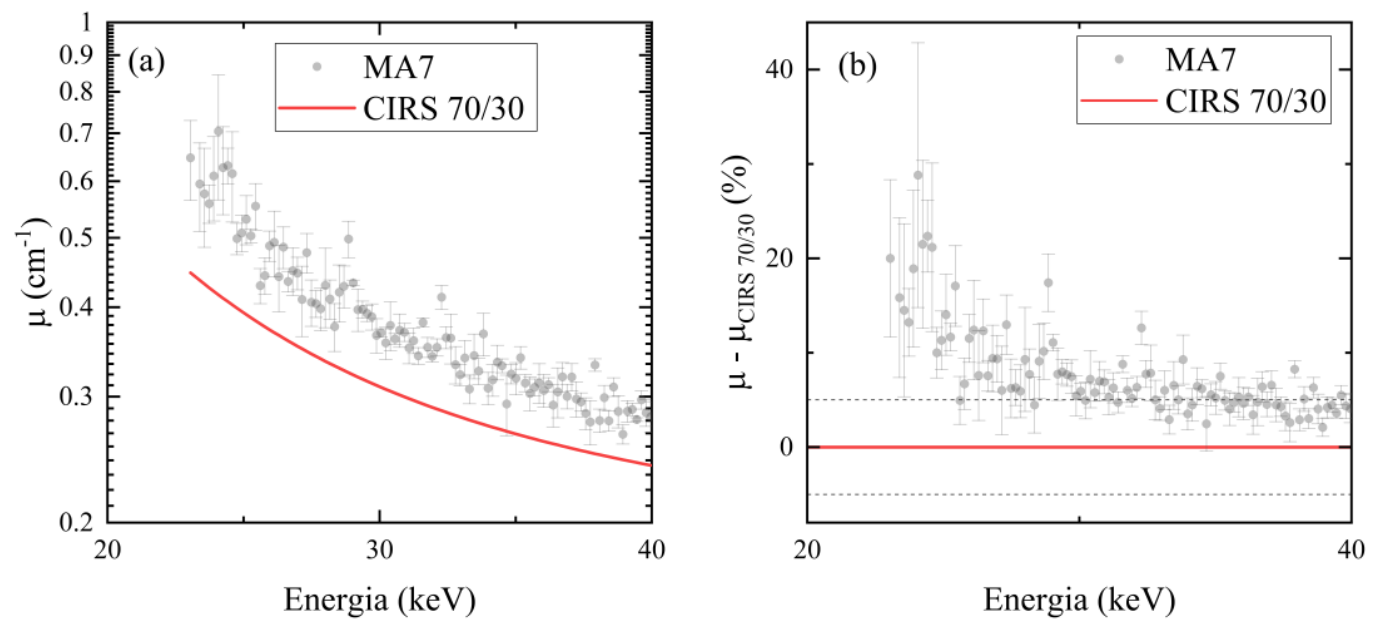

Figura do apêndice 21 - (a) valores de coeficiente de atenuação linear da amostra MA7 e (b) diferença entre estes valores e os valores de coeficiente de atenuação linear do material comercial CIRS 70/30. As retas pontilhadas demarcam uma diferença de $\pm 5 \%$.

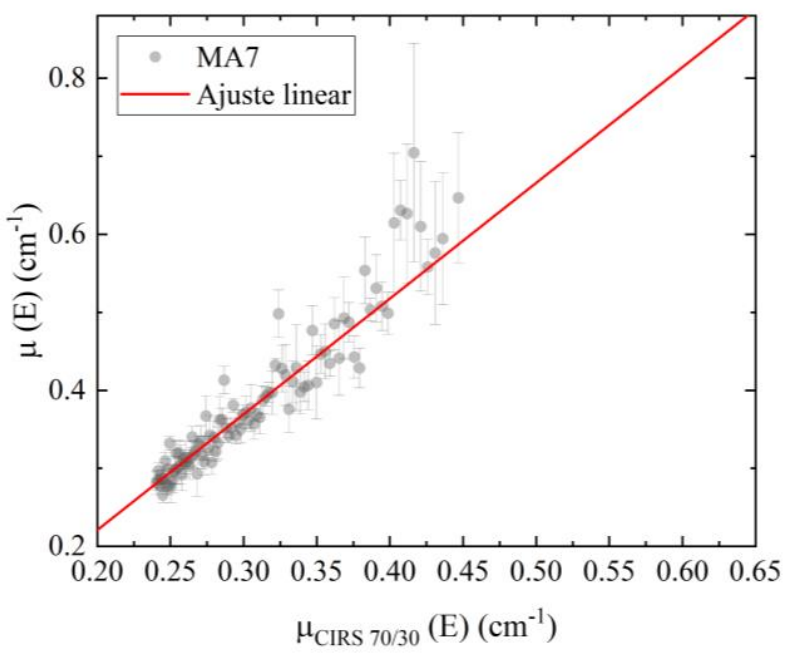

Figura do apêndice 22 - Valores de coeficiente de atenuação linear da amostra MA7 em relação aos valores do material comercial CIRS 70/30 obtidos a partir do banco de dados XCOM (Berger et al., 2010).

Os coeficientes obtidos no ajuste são: $\mathrm{a}_{0}=-0,08(1), \mathrm{a}_{1}=1,48(5)$ e $\mathrm{R}^{2}=0,90$. 


\subsection{Amostra MA9}
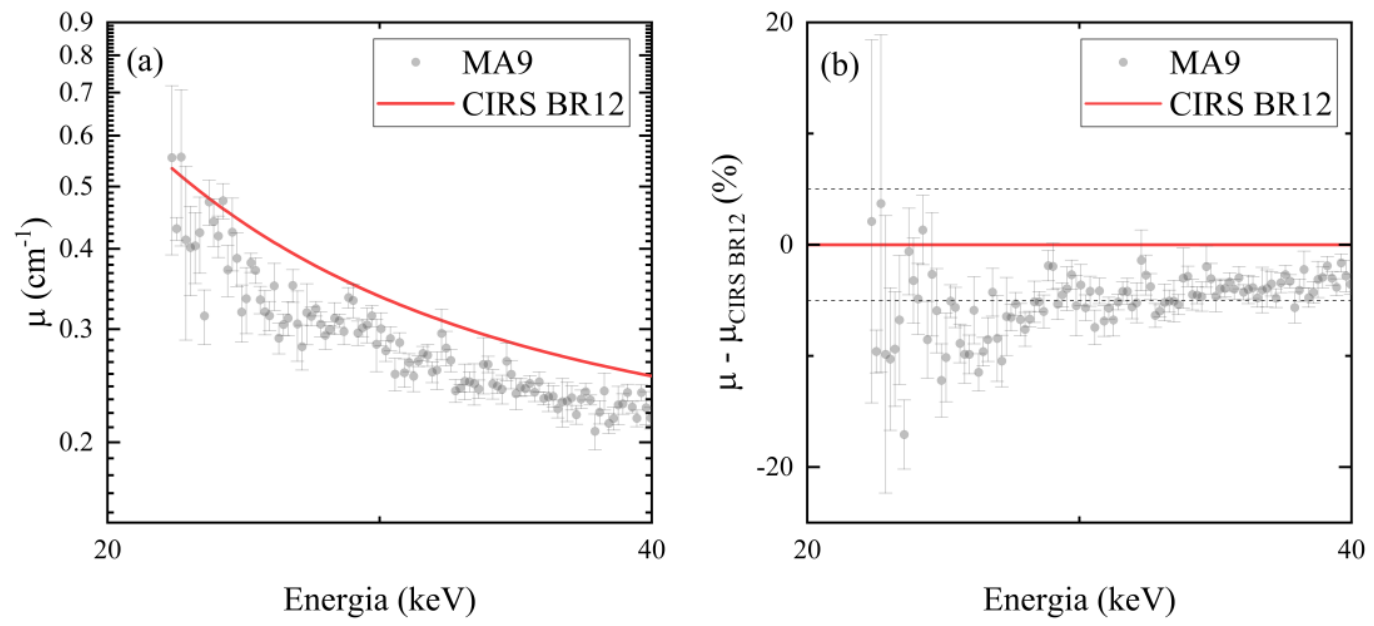

Figura do apêndice 23 - (a) valores de coeficiente de atenuação linear da amostra MA9 e (b) diferença entre estes valores e os valores de coeficiente de atenuação linear do material comercial CIRS BR12. As retas pontilhadas demarcam uma diferença de $\pm 5 \%$.

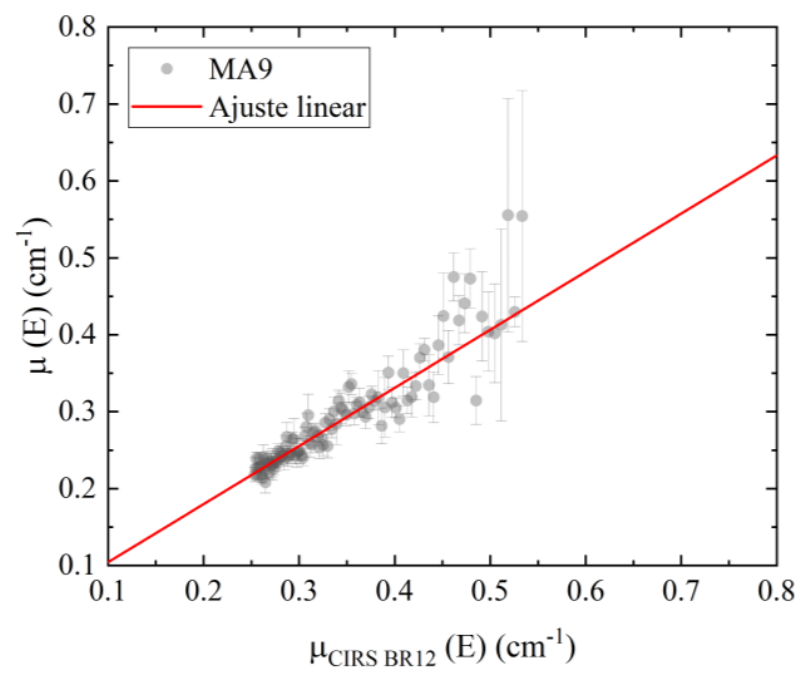

Figura do apêndice 24 - Valores de coeficiente de atenuação linear do amostra MA9 em relação aos valores do material comercial CIRS BR12 obtidos a partir do banco de dados XCOM (Berger et al., 2010).

Os coeficientes obtidos no ajuste são: $\mathrm{a}_{0}=0,03(1), \mathrm{a}_{1}=0,76(3)$ e $\mathrm{R}^{2}=0,81$. 


\section{Referências bibliográficas}

ALMEIDA, C., COUTINHO, C., DANTAS, B., PEIXOTO, J. \& KOCH, H. 2012. A new mammography dosimetric phantom. Radiation Protection Dosimetry, 151, 196-198.

ALSSABBAGH, M., ABDULMANAP, M. \& ZAINON, R. 2017. Evaluation of 3D printing materials for fabrication of a novel multi-functional 3D thyroid phantom for medical dosimetry and image quality. Radiation Physics and Chemistry, 135, 106-112.

ALVAREZ, R. E. \& MACOVSKI, A. 1976. Energy-selective reconstructions in x-ray computerised tomography. Physics in Medicine \& Biology, 21, 733.

ALVES, A. F. F. \& COSTA, P. R. Desenvolvimento de Uma Metodologia de Correção de Espectros de Raios X Medidos Com Detector de Telureto de Cádmio. XV Congresso Brasileiro de Física Médica (Ed.), Anais do XV Congresso Brasileiro de Física Médica, Aracajú, SE, 2010.

ANTONIASSI, M., CONCEIÇÃO, A. \& POLETTI, M. 2011. Study of effective atomic number of breast tissues determined using the elastic to inelastic scattering ratio. Nuclear Instruments and Methods in Physics Research Section A: Accelerators, Spectrometers, Detectors and Associated Equipment, 652, 739-743.

ATTIX, F. H. 2008. Introduction to radiological physics and radiation dosimetry, John Wiley $\&$ Sons.

BADAL, A., CLARK, M. \& GHAMMRAOUI, B. 2018. Reproducing two-dimensional mammograms with three-dimensional printed phantoms. Journal of Medical Imaging, 5, 033501 .

BAUMEISTER, L. \& ROCKY, H. 1923. Roentgen-ray measurements. Acta Radiologica, 2, 418-429.

BERGER, M., HUBBELL, J., SELTZER, S., CHANG, J., COURSEY, J., SUKUMAR, R., ZUCKER, D. \& OLSEN, K. 2010. XCOM: Photon Cross Section Database (version 1.5). National Institute of Standards and Technology, Gaithersburg, MD.

BONNIN, A., DUVAUCHELlE, P., KAFTANDJIAN, V. \& PONARD, P. 2014. Concept of effective atomic number and effective mass density in dual-energy X-ray computed tomography. Nuclear Instruments and Methods in Physics Research Section B: Beam Interactions with Materials and Atoms, 318, 223-231.

BRAGG, W. \& PEIRCE, S. 1914. LXIV. The absorption coefficients of X rays. The London, Edinburgh, and Dublin Philosophical Magazine and Journal of Science, 28, 626-630.

CALLISTER, W. 2000. Ciência E Engenharia de Materiais: Uma Introdução, Grupo GenLTC.

CERQUEIRA, R. A., CONCEIÇÃO, B. M., TEIXEIRA, C. H., MOTA, C. D., RODRIGUES, T. M. \& MAIA, A. F. 2010. Construção de um objeto simulador antropomórfico de tórax para medidas de controle da qualidade da imagem em radiodiagnóstico. Revista brasileira de física médica, 4, 39-42.

CHANDRA, N. \& LANGAN, D. A. 2011. Gemstone detector: dual energy imaging via fast $\mathrm{kVp}$ switching. Dual energy CT in clinical practice. Springer.

COSTA, P. R., NERSISSIAN, D. Y., SALVADOR, F. C., RIO, P. B. \& CALDAS, L. V. 2007. Generation of calibrated tungsten target X-ray spectra: modified TBC model. Health physics, 92, 24-32.

DAHAL, E., BADAL, A., ZIDAN, A., ALAYOUBI, A., HAGIO, T., GLICK, S., BADANO, A. \& GHAMMRAOUI, B. 2018. Stable gelatin-based phantom materials with tunable $\mathrm{x}$-ray attenuation properties and 3D printability for x-ray imaging. Physics in Medicine \& Biology, 63, 09NT01.

DAVISSON, C. M. \& EVANS, R. D. 1952. Gamma-ray absorption coefficients. Reviews of Modern Physics, 24, 79. 
DEL LAMA, L., SOARES, L., ANTONIASSI, M. \& POLETTI, M. 2015. Effective atomic numbers for materials of medical interest at low photon energy using the Rayleigh to Compton scattering ratio. Nuclear Instruments and Methods in Physics Research Section A: Accelerators, Spectrometers, Detectors and Associated Equipment, 784, 597-601.

DEWERD, L. A. \& KISSICK, M. 2014. The phantoms of medical and health physics, Springer.

DI CASTRO, E., PANI, R., PELLEGRINI, R. \& BACCI, C. 1984. The use of cadmium telluride detectors for the qualitative analysis of diagnostic X-ray spectra. Physics in Medicine \& Biology, 29, 1117.

FLOHR, T. G., SCHALLER, S., STIERSTORFER, K., BRUDER, H., OHNESORGE, B. M. \& SCHOEPF, U. J. 2005. Multi-detector row CT systems and image-reconstruction techniques. Radiology, 235, 756-773.

FRIMAIO, A. 2019. Desenvolvimento de compostos termoplásticos ou termofixos radiologicamente equivalentes ao tecido humano. Doutorado, Universidade de São Paulo.

GENANT, H. K. \& BOYD, D. 1977. Quantitative bone mineral analysis using dual energy computed tomography. Investigative radiology, 12, 545-551.

GONZALES, A. L., SANTOS, J., MARIANO, L., TOMAL, A. \& COSTA, P. 2016. Evaluation of mean conversion coefficients from air-kerma to $\mathrm{H}^{*}(10)$ using secondary and transmitted x-ray spectra in the diagnostic radiology energy range. Journal of radiological protection, 36, 842.

HERMANN, K. P., GEWORSKI, L., HATZKY, T., LIETZ, R. \& HARDER, D. 1986. Muscle- and fat-equivalent polyethylene-based phantom materials for X-ray dosimetry at tube voltages below $100 \mathrm{kV}$. Physics in medicine and biology, 31, 1041-6.

HERMANN, K. P., GEWORSKI, L., MUTH, M. \& HARDER, D. 1985. Polyethylene-based water-equivalent phantom material for x-ray dosimetry at tube voltages from 10 to 100 $\mathrm{kV}$. Physics in medicine and biology, 30, 1195-200.

HOMOLKA, P., GAHLEITNER, A., PROKOP, M. \& NOWOTNY, R. 2002. Optimization of the composition of phantom materials for computed tomography. Physics in Medicine \& Biology, 47, 2907.

HUBBELL, J. \& SELTZER, S. 1996. NIST standard reference database 126. Gaithersburg, MD: National Institute of Standards and Technology.

IAEA 2007. Dosimetry in diagnostic radiology: an international code of practice. IAEA Vienna.

ICRU 2011. Fundamental quantities and units for ionizing radiation (revised). ICRU Report 85a. J. ICRU, 11.

IRNSTORFER, N., UNGER, E., HOJREH, A. \& HOMOLKA, P. 2019. An anthropomorphic phantom representing a prematurely born neonate for digital $\mathrm{x}$-ray imaging using $3 \mathrm{D}$ printing: Proof of concept and comparison of image quality from different systems. Scientific reports, 9, 1-12.

JOHNS, H. E. \& CUNNINGHAM, J. R. 1983. The physics of radiology.

JOHNSON, T., FINK, C., SCHÖNBERG, S. O. \& REISER, M. F. 2011. Dual energy CT in clinical practice, Springer Science \& Business Media.

JOSHI, S., AJIKUMAR, P., SIVASUBRAMANIAN, K. \& JAYARAMAN, V. 2020. Synthesis, characterization and low energy photon attenuation studies of bone tissue substitutes. Journal of Polymer Engineering, 40, 99-108.

KALENDER, W., SEISSLER, W. \& VOCK, P. Single-breath-hold spiral volumetric CT by continuous patient translation and scanner rotation. Proceedings of the 75th 
anniversary scientific assembly and annual meeting Radiological Society of North America (Abstracts), 1989.

KNOLL, G. F. 2010. Radiation detection and measurement, John Wiley \& Sons.

KURKOVA, D. \& JUDAS, L. 2016. X-ray tube spectra measurement and correction using a CdTe detector and an analytic response matrix for photon energies up to $160 \mathrm{keV}$. Radiation Measurements, 85, 64-72.

MALLIORI, A., DASKALAKI, A., DERMITZAKIS, A. \& PALLIKARAKIS, N. 2020. Development of Physical Breast Phantoms for X-ray Imaging Employing 3D Printing Techniques. The Open Medical Imaging Journal, 12.

MANOHARA, S., HANAGODIMATH, S., THIND, K. \& GERWARD, L. 2008. On the effective atomic number and electron density: a comprehensive set of formulas for all types of materials and energies above $1 \mathrm{keV}$. Nuclear Instruments and Methods in Physics Research Section B: Beam Interactions with Materials and Atoms, 266, 39063912.

MARIANO, L. 2017. Desenvolvimento de uma metodologia para formulação de materiais radiologicamente equivalentes ao tecido humano. Doutorado, Universidade de São Paulo.

MARIANO, L. \& COSTA, P. 2017. Development of a methodology for formulating radiologically equivalent materials to human tissues. In: IN: RUSSO P, E. (ed.). International Conference on Monte Carlo Techniques for Medical Allications, Napoles: Elsevier.

MARTINEZ, L. C., CALZADO, A., RODRIGUEZ, C., GILARRANZ, R. \& MANZANAS, M. J. 2012. A parametrization of the CT number of a substance and its use for stoichiometric calibration. Physica Medica, 28, 33-42.

MATLAB, M. 2015. R2015a. URL http://www.mathworks.com/products/matlab.

MAYNEORD, W. 1937. The significance of the roentgen. Acta Int Union Against Cancer, 2, 271.

MCCOLLOUGH, C. H., BOEDEKER, K., CODY, D., DUAN, X., FLOHR, T., HALLIBURTON, S., HSIEH, J., LAYMAN, R. \& PELC, N. J. 2020. Principles and Applications of Multi-energy CT Report of AAPM Task Group 291. Medical Physics.

MCCOLLOUGH, C. H., BRUESEWITZ, M. R., MCNITT-GRAY, M. F., BUSH, K., RUCKDESCHEL, T., PAYNE, J. T., BRINK, J. A. \& ZEMAN, R. K. 2004. The phantom portion of the American College of Radiology (ACR) computed tomography (CT) accreditation program: practical tips, artifact examples, and pitfalls to avoid. Medical physics, 31, 2423-2442.

MIDGLEY, S. 2006. Angular width of a narrow beam for X-ray linear attenuation coefficient measurements. Radiation Physics and Chemistry, 75, 945-953.

MILLNER, M. R., MCDAVID, W. D., WAGGENER, R. G., DENNIS, M. J., PAYNE, W. H. \& SANK, V. J. 1979. Extraction of information from CT scans at different energies. Medical physics, 6, 70-71.

MIYAJIMA, S. \& IMAGAWA, K. 2002. CdZnTe detector in mammographic x-ray spectroscopy. Physics in Medicine \& Biology, 47, 3959.

MIYAJIMA, S., IMAGAWA, K. \& MATSUMOTO, M. 2002. CdZnTe detector in diagnostic X-ray spectroscopy. Medical physics, 29, 1421-1429.

MOON, P. 1950. The hard components of scattered gamma-rays. Proceedings of the Physical Society. Section A, 63, 1189.

MORALLES, M., BONIFÁCIO, D., BOTTARO, M. \& PEREIRA, M. 2007. Monte Carlo and least-squares methods applied in unfolding of X-ray spectra measured with cadmium telluride detectors. Nuclear Instruments and Methods in Physics Research 
Section A: Accelerators, Spectrometers, Detectors and Associated Equipment, 580, 270-273.

OKUNO, E. \& YOSHIMURA, E. M. 2016. Física das radiações, Oficina de Textos.

PODGORŠAK, E. B. 2016. Radiation Physics for Medical Physicists, Springer International Publishing.

POLETTI, M., GONÇALVES, D. \& MAZZARO, I. 2002. X-ray scattering from human breast tissues and breast-equivalent materials. Physics in medicine and biology, 47, 47.

PUERTO, L. P. R. 2018. Simulação Monte Carlo do processo de aquisição de imagens de um tomógrafo de dupla energia. Universidade de São Paulo.

RUSSO, P. 2017. Handbook of X-ray imaging: physics and technology, CRC press.

RYBICKI, F. J., OTERO, H. J., STEIGNER, M. L., VOROBIOF, G., NALLAMSHETTY, L., MITSOURAS, D., ERSOY, H., MATHER, R. T., JUDY, P. F. \& CAI, T. 2008. Initial evaluation of coronary images from 320-detector row computed tomography. The international journal of cardiovascular imaging, 24, 535-546.

SAMEI, E., BAKALYAR, D., BOEDEKER, K. L., BRADY, S., FAN, J., LENG, S., MYERS, K. J., POPESCU, L. M., RAMIREZ GIRALDO, J. C. \& RANALLO, F. 2019. Performance evaluation of computed tomography systems: summary of AAPM task group 233. Medical physics, 46, e735-e756.

SAMMARTINI, M., GANDOLA, M., MELE, F., GARAVELLI, B., MACERA, D., POZZI, P. \& BERTUCCIO, G. 2018. A CdTe pixel detector-CMOS preamplifier for room temperature high sensitivity and energy resolution $X$ and $\gamma$ ray spectroscopic imaging. Nuclear Instruments and Methods in Physics Research Section A: Accelerators, Spectrometers, Detectors and Associated Equipment, 910, 168-173.

SANTOS, J. C., TOMAL, A., FURQUIM, T. A., FAUSTO, A. M., NOGUEIRA, M. S. \& COSTA, P. R. 2017. Direct measurement of clinical mammographic x-ray spectra using a CdTe spectrometer. Medical Physics, 44, 3504-3511.

SCHOPPHOVEN, S., CAVAEL, P., BOCK, K., FIEBICH, M. \& MÄDER, U. 2019. Breast phantoms for 2D digital mammography with realistic anatomical structures and attenuation characteristics based on clinical images using 3D printing. Physics in Medicine \& Biology, 64, 215005.

SEELENTAG, W. \& PANZER, W. 1979. Stripping of X-ray bremsstrahlung spectra up to $300 \mathrm{kVp}$ on a desk type computer. Physics in Medicine \& Biology, 24, 767.

SILVA, H., FERREIRA, F., BRASIL, L., LUZ, G. \& CARDOSO, L. Anthropomorphic Phantom of the Pancreas for Scintillation Camera Tests. World Congress on Medical Physics and Biomedical Engineering, June 7-12, 2015, Toronto, Canada, 2015. Springer, 1528-1531.

SINGH, V., BADIGER, N. \& KUCUK, N. 2014a. Assessment of methods for estimation of effective atomic numbers of common human organ and tissue substitutes: waxes, plastics and polymers. Radioprotection, 49, 115-121.

SINGH, V. P., BADIGER, N. \& KUCUK, N. 2014b. Determination of effective atomic numbers using different methods for some low-Z materials. Journal of Nuclear Chemistry, 2014.

SIRICO, A. C. A., FRIMAIO, A. \& COSTA, P. R. 2019. Determinação de números atômicos efetivos de materiais radiologicamente equivalentes ao tecido humano e à água. Revista Brasileira de Física Médica, 13, 15-19.

SOARES, L., GOBO, M. \& POLETTI, M. 2020. Measurement of the linear attenuation coefficient of breast tissues using polienergetic x-ray for energies from 12 to $50 \mathrm{keV}$ and a silicon dispersive detector. Radiation Physics and Chemistry, 167, 108226.

TAYLOR, M., SMITH, R., DOSSING, F. \& FRANICH, R. 2012. Robust calculation of effective atomic numbers: The Auto-Zeff software. Medical physics, 39, 1769-1778. 
TOMAL, A. 2010. Estudo Semianalítico da qualidade de Imagem e Dose em Mamografia. Universidade de São Paulo.

TOMAL, A., SANTOS, J., COSTA, P., GONZALES, A. L. \& POLETTI, M. 2015. Monte Carlo simulation of the response functions of CdTe detectors to be applied in X-ray spectroscopy. Applied Radiation and Isotopes, 100, 32-37.

WHITE, D., BOOZ, J., GRIFFITH, R., SPOKAS, J. \& WILSON, I. 1989. ICRU Report 44: tissue substitutes in radiation dosimetry and measurement. International Commission on Radiation Units and Measurements.

WHITE, D., MARTIN, R. \& DARLISON, R. 1977. Epoxy resin based tissue substitutes. The British journal of radiology, 50, 814-821.

WHITE, D., WOODARD, H. \& HAMMOND, S. 1987. Average soft-tissue and bone models for use in radiation dosimetry. The British journal of radiology, 60, 907-913.

WIESER, M. E., HOLDEN, N., COPLEN, T. B., BÖHLKE, J. K., BERGLUND, M., BRAND, W. A., DE BIÈVRE, P., GRÖNING, M., LOSS, R. D. \& MEIJA, J. 2013. Atomic weights of the elements 2011 (IUPAC Technical Report). Pure and Applied Chemistry, 85, 1047-1078.

WILLIAMSON, J. F., LI, S., DEVIC, S., WHITING, B. R. \& LERMA, F. A. 2006. On twoparameter models of photon cross sections: Application to dual-energy CT imaging. Medical physics, 33, 4115-4129. 